\title{
Rungs on a ladder to empowerment: \\ transforming end-user computing training in Port Vila, Vanuatu
}

\author{
Gayna Vetter \\ A thesis submitted in partial fulfilment of the \\ Master of Development Studies Degree \\ School of Geography, Environment and Earth Sciences \\ Victoria University of Wellington \\ Aotearoa New Zealand
}

February 2009 



\section{Abstract}

End-user training in ICT is a question that currently lurks on the outskirts of development activity. The focus of ICT in development is on implementation of the 'machinery' but lacks specific attention in the building of human capacity to drive and maintain this 'machinery'. The question of training end-users in computing in Port Vila, Vanuatu, was a driving force of this research. In pursuing the question, however, the participatory process, using focus groups to research local industry needs for training, led to the discovery of links between the participation used in researching this question to its use as pedagogy for end-user training. Using participatory action, we are more likely to encourage initiative in pursuing questions and achieving a more localised approach to endeavours such as training, research and development. This participatory approach is also seen as a method more widely applicable in education as well as development. The process lead to empowerment of the individuals involved in the research through raising critical consciousness and providing a form of agency. It raises the question of how to sustain this empowerment in order to lead to transformation. Actual transformation is seen as a quality that takes more than one attempt at empowerment and a temporary taste of agency.

The thesis draws on the analogy of a group of people building a ladder together. They have rough building materials to work with but an abundance of their own ideas and their own ability. The ladder construction is participation, its frame exists but the rungs have yet to be attached. It is the process of interaction, exploration and communication in building the ladder together that becomes important. Transformation is in the process of building of the ladder as well as the finished product. It takes a continual construction effort, building on rungs put in place previously. 


\section{Acknowledgements}

In 1967 there was a springtime blizzard in my hometown of Washburn, North Dakota, USA. It snowed so heavily in the night that the next morning our house was sealed in snow. The front door, four steps up from the earth, was blocked with snow; we could not budge it. We did manage to wedge open a front window and started to dig our way out and around to get to the front door. I was eleven, it was quite an adventure. I was given a spoon and started to dig into the snow, a spoonful at a time. In no time, it became less of an adventure and more of an endless task. And a question started to form between spoonfuls: what do we do once we get to the door? Certainly there would be more digging to get anywhere else, even if we get the front door open. In 2007 I did the research for this thesis and in early 2008 started to write. I was reminded of digging snow in 1967 to get to that front door, a spoonful at a time. In this case I had no idea what it would mean, finishing the research and writing. What then?

As in 1967, when I had my family digging with me, there were people who helped me dig to produce my thesis. Old friends and new acquaintances in Vanuatu extended themselves to work with me in this research. I appreciate their openness and hard work. Very supportive of the research were members of the focus groups along with Ralph Regenvanu, Patrick Shing, Russell Mujee, Joe Tamata, Ravi Kumar staff at USP Emalus, the many interviewees who were willing to share their knowledge and ideas with me, and the owners and staff at the Kaiviti who made my stay more comfortable.

In New Zealand John Overton, my supervisor, kept handing me spoons as I needed them and reminding me that there was a door to dig to. And that I would get to it. My partner, Marko Harris, was always there digging along with me. He has been tireless in his enthusiasm, support and proofreading. I cannot thank you enough. Kabini Sanga was there with suggestions for editing. And finally, the people at Victoria, students and staff, who listened while I talked. They are too numerous to mention. I appreciate having had their ears and sometimes even their attention.

We did make it to the front door in 1967 and when we got there found that city services had been active in clearing roads and sidewalks so we found our path outward easily enough.

And now that I am at the edge of the thesis writing, I appreciate that I was digging a tunnel in similar fashion to those that others have dug, research mixing and making paths. It is a matter of appreciating the small scoops for the bigger end. At this point, I am just seeing the door, so still have a bit of digging to do. But I can see the door, thanks to all those with spoons who were digging in front, alongside and behind me. 


\section{Table of contents}

Rungs on a ladder to empowerment: transforming end-user computing training in

Port Vila, Vanuatu ................................................................................................................................. i

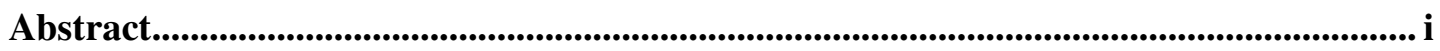

Acknowledgements ........................................................................................................................... ii

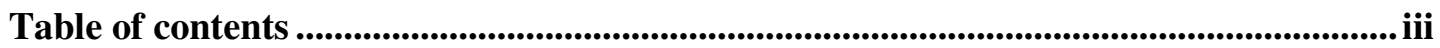

List of Figures...................................................................................................................................... $\mathrm{v}$

List of Tables .................................................................................................................................. v

Acronyms used ......................................................................................................................... vi

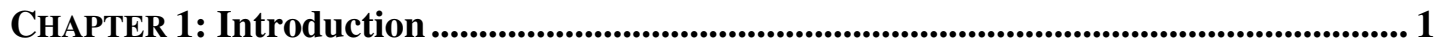

$\begin{array}{ll}\text { The origin of the question } & 1\end{array}$

Research question $\quad 2$

Thesis question 3

Methodology 4

Building a ladder 4

Terminology used in the thesis $\quad 5$

Structure of the thesis $\quad 7$

CHAPTER 2: View through a prism: Ripablik blong Vanuatu / Republic of Vanuatu

/ République de Vanuatu....................................................................................................................9

A worldview askew $\quad 9$

$\begin{array}{lr}\text { Part 1: Background } & 10\end{array}$

Part 2: Foreground 16

$\begin{array}{ll}\text { Conclusion } & 35\end{array}$

CHAPTER 3: Leaning ladders against existing literature ...................................................... 38

$\begin{array}{ll}\text { An alternative perspective } & 38\end{array}$

Stepping up to the new economy 43

Equipped to enter the information age $\quad 45$

Technology: determined or constructed? 49

Preparing future social constructionists for the information age $\quad 50$

$\begin{array}{ll}\text { ICT4D Training } & 54\end{array}$

$\begin{array}{ll}\text { Methodology for the research process } & 59\end{array}$

$\begin{array}{lr}\text { Conclusion } & 59\end{array}$

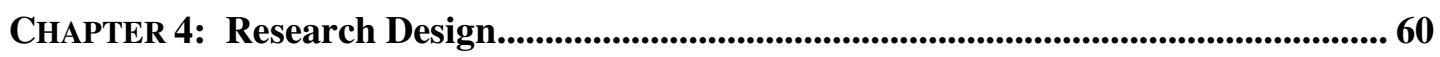

$\begin{array}{lr}\text { Conceptual Framework } & 60\end{array}$

Practical Approach $\quad 63$

The Researcher $\quad 66$

Dealing with data $\quad 71$

$\begin{array}{ll}\text { Reflection on methods } & 76\end{array}$

Conclusion $\quad 83$

CHAPTER 5: Results of focus groups.......................................................................................... 85

Focus on the question $\quad 85$

Analysis of results $\quad 92$

Reflection on Results $\quad 94$

$\begin{array}{lr}\text { Conclusion } & 96\end{array}$ 
CHAPTER 6: Research process......................................................................................................98

$\begin{array}{ll}\text { Introduction } & 98\end{array}$

$\begin{array}{lr}\text { Framing questions } & 99\end{array}$

$\begin{array}{lr}\text { The participants } & 99\end{array}$

$\begin{array}{lr}\text { Framework for sessions } & 100\end{array}$

$\begin{array}{ll}\text { Sessions } & 101\end{array}$

$\begin{array}{ll}\text { Exiting the field and continued contact } & 115\end{array}$

Conclusion 116

CHAPTER 7: Research process discussion ........................................................................118

$\begin{array}{ll}\text { Focus on the process } & 118\end{array}$

\begin{tabular}{ll} 
Reflection on the focus group members & 122 \\
\hline
\end{tabular}

Reflection on the researcher's position $\quad 124$

Reflection on the Process 127

Conclusion $\quad 130$

CHAPTER 8: Conclusions ........................................................................................................... 131

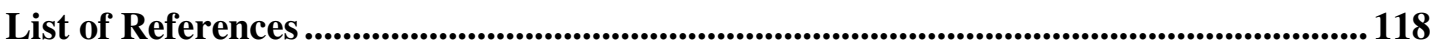

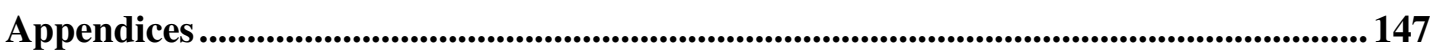

$\begin{array}{ll}\text { Appendix } 4.1 & 147\end{array}$

$\begin{array}{ll}\text { Appendix } 4.2 & 149\end{array}$

$\begin{array}{lr}\text { Appendix } 4.3 & 150\end{array}$

Appendix $4.4 \quad 151$

Appendix $4.5 \quad 152$

Appendix 4.6 a $\quad 155$

Appendix $4.6 \mathrm{~b} \quad 157$

Appendix $4.6 \mathrm{c} \quad 159$

$\begin{array}{ll}\text { Appendix } 4.7 & 161\end{array}$

$\begin{array}{lr}\text { Appendix } 4.8 & 163\end{array}$

$\begin{array}{ll}\text { Appendix } 4.9 & 167\end{array}$

$\begin{array}{lr}\text { Appendix } 4.10 & 168\end{array}$

$\begin{array}{lr}\text { Appendix } 5.1 & 170\end{array}$

$\begin{array}{ll}\text { Appendix } 5.2 & 171\end{array}$

$\begin{array}{ll}\text { Appendix } 6.1 & 174\end{array}$

$\begin{array}{ll}\text { Appendix } 6.2 & 176\end{array}$

$\begin{array}{ll}\text { Appendix } 6.3 & 178\end{array}$

$\begin{array}{lr}\text { Appendix } 6.4 & 179\end{array}$

Appendix $6.5 \quad 180$

Appendix 6.6 182

Appendix $6.7 \quad 183$

$\begin{array}{lr}\text { Appendix } 7.1 & 189\end{array}$ 


\section{List of Figures}

$\begin{array}{lll}\text { Figure 2.1 } & \text { Condocolonial triangulation }\end{array}$

Figure 3.1 Action research showing interpretation of computer 58 learning from a complexity perspective

$\begin{array}{lll}\text { Figure 4.1 Theoretical framework of research } & 60\end{array}$

Figure 4.2 From observation to theory 66

$\begin{array}{lll}\text { Figure 6.1 Session } 1 \text { room layout, Matangi and Y-Grup } & 104\end{array}$

$\begin{array}{lll}\text { Figure 6.2 Session 2 room layout, Matangi and Y-Grup } & 107\end{array}$

$\begin{array}{lll}\text { Figure 6.3 } & \text { Session } 3 \text { room layout, Matangi and Y-grup } & 109\end{array}$

Figure 6.4 Session 4 room layout, Matangi and Y-grup 111

$\begin{array}{lll}\text { Figure 6.5 } & \text { Presentation preparation with workgroups mingling, } & 113\end{array}$ Matangi and Y-Grup

$\begin{array}{lll}\text { Figure 6.6 Researcher and focus group members with their } & 116\end{array}$ certificates after their presentation

\section{List of Tables}

$\begin{array}{lll}\text { Table 2.1 Socio-economic indicators } & 23\end{array}$

Table 2.2 Telephone use changing with introduction of digital service 27

Table 2.3 Vanuatu's telecommunications indicators (urban and rural) 27

Table 2.4 Employment by Industry and age group, 15 - 64, $1999 \quad 30$

$\begin{array}{lll}\text { Table 3.1 } & \text { Issues of ICT for developing countries } & 48\end{array}$

Table 3.2 UNESCO/IFIP Four approaches to ICT Development in 55 Schools 


\section{Acronyms used}

\begin{tabular}{|c|c|}
\hline $\mathrm{ADB}$ & Asian Development Bank \\
\hline AUF & Agence universitaire de la Francophonie \\
\hline CNS & Computer Network Services \\
\hline CRP & Central Reform Programme \\
\hline CS & Computer Science \\
\hline DFL & Distance and Flexible Learning (USP centre at Emalus campus, Port Vila) \\
\hline $\mathrm{ECF}$ & Edward's Computer Foundation \\
\hline EUT & End User Training \\
\hline FG & Reference to Focus Group member when attributing statement's source \\
\hline GDP & Gross Domestic Product \\
\hline HRD & Human Resources Development Unit (formerly Government Training Centre) \\
\hline ICDL & International Computer Driver's License \\
\hline ICT & Information and Communications Technology (a newer version of the acronym IT) \\
\hline INTV & Institut de technologie de Vanuatu (see VIT) \\
\hline IT & Information Technology (see ICT) \\
\hline JICA & Japan's International Cooperation Agency \\
\hline MDG & Millennium Development Goals \\
\hline MIS & Management Information Systems \\
\hline NGO & Non-governmental organisation \\
\hline NZAID & New Zealand's International Aid and Development Agency \\
\hline PAA & Priorities and Action Agenda \\
\hline PFNet & Pipol Fastaem Network (Solomon Islands) \\
\hline TA & Technical Assistant \\
\hline PAR & Participatory Action Research \\
\hline PICISOC & Pacific Islands Chapter of the Internet Society \\
\hline SCOT & Social Construction of Technology \\
\hline TVET & Technical Vocational Education and Training scheme \\
\hline TVL & Telecom Vanuatu Limited \\
\hline $\mathrm{UN}$ & United Nations \\
\hline USP & University of the South Pacific \\
\hline VDP & Vanuatu Development Plan \\
\hline VFIB & Vanuatu Foreign Investment Board \\
\hline VIGNET & Vanuatu Internet Group Network \\
\hline VIT & Vanuatu Institute of Technology (formerly INTV) \\
\hline VITE & Vanuatu Institute of Teacher Education \\
\hline VITUS & Vanuatu Internet Users Society \\
\hline VNSO & Vanuatu National Statistics Office \\
\hline VNTC & Vanuatu National Training Council \\
\hline VRDTCA & Vanuatu Rural Development and Training Centres Association \\
\hline VT & Vatu, the currency of Vanuatu \\
\hline
\end{tabular}




\section{CHAPTER 1: Introduction}

\section{THE ORIGIN OF THE QUESTION}

The origin of this research derives from observation by the researcher during eight years of computer skills training in two different developing countries, Vanuatu and Tanzania. In both locations many trainers, often volunteers, were from Western countries. They attempted to train users with no standards, no coordination between trainers and with foreign course materials because local materials were not available. Often materials were simply downloaded from the internet. If resources were made specifically for the training, it was common for the often temporary trainers to generate them based on a Western standard (i.e. NZ, Australian, US, Japan, etc.) or without thought to standards at all. Trainers appeared not to gather contextual information or take time to consider local training needs. Training was delivered on a Western industry model, which meant it was delivered at a fast pace, in a non-local language, using irrelevant issues or case studies. There was no consideration of localised methodology and often no continuity when a trainer would leave after a year or two, in most cases not soon replaced by another. When they were replaced, standards (or none), materials and teaching styles would likely be re-created.

What is significant about end-user training in developing countries is best appreciated by considering the reality for many individuals in their settings. In Vanuatu, the trainee might enter the computer lab smelling of the morning fire that her breakfast was cooked on. She had eaten this breakfast and perhaps walked some way from a settlement area to catch a bus that would carry her to class. She enters a large, spacious room with ceiling fans that contains fairly new technology. How would she view this after having a breakfast cooked over a fire for which she may have collected the wood?

I feel this individual's desire to be trained to use the computer is a result of the commonly discussed rush to close the digital divide. With the local feeling being the need to learn the technology in order to gain employment, plus the development industry's focus on this, it is a lucrative local business and development 'industry' opportunity. 
I was employed to train in this context and, using my world view, took the problem solving perspective, eg. 'How do I train them to use the internet?'. Perhaps a better question would have been 'What is it they know that I don't?'. My experience led to interest in how computing training in developing countries might be made more suitable to local people. What if locals could create materials and teach using local languages and examples in training? It is my viewpoint that consideration of industry needs, methods, pedagogy, materials and course design for a particular locality is an important consideration for this suitability, or relevance, of training. Application of local knowledge and course design skills could be included in training local teachers and this would be more sustainable than relying on a continued supply of training from the West. In researching this, I have acted on the assumption that knowledge of local needs is best gained from and through local people in their living and work communities. I am aware of biases and assumptions I bring to the study based on these experiences and remain sensitive and flexible to the participants' contributions and the possibilities of an alternative development approach. My research outcome is a description of process rather than specific recommendations, therefore the results are not required to 'fit' my viewpoint, which assists in any temptation to impose external ideas.

\section{RESEARCH QUESTION}

Two focus groups met over a four week period in Port Vila, Vanuatu, between November and December 2007 to question whether there is a universal methodology of training that applies to every context. The key question the focus groups considered was: 'What methods for end-user computer training in developing countries are relevant to their needs?' A secondary issue of this question is the role of trainees and industry in the planning of training programmes.

\section{Research Objectives}

The purpose of this inquiry is to 1) inform future training practice, 2) facilitate more locally sustainable training provision, and 3) assist locals in addressing similar situations using participatory methods. To do this the objectives are to 
initiate a Participatory Action Research (PAR) process by developing at least two focus groups with a cross-section of users who have experienced end-user training in Port Vila, Vanuatu. Methods of end-user training (EUT) of Information and Communications Technology (ICT) are explored by the groups. Training methods investigated include training resources, principles and styles, and methods of training delivery. Local employers are interviewed to investigate industry needs for user training, a range of documents are studied to assess for appropriateness and intended outcome, and training facilities are assessed for suitability to training needs. Documents assessed include course materials, texts, course outlines and software. Following analysis of the information from this investigation, alternatives for training provision are considered and recommendations based on the findings developed. A presentation of results is made to local ICT training stakeholders in the research context.

\section{The process of pursuing the research question}

The research question was the driving force of the research. Focus groups were used to gather information about end-user training (Gupta and Bostrom 2006), validity being tested by having two focus groups meeting separately. What eventuated was a more profound process than anticipated, with the question becoming immaterial to the participatory process.

\section{THESIS QUESTION}

Therefore, the thesis goes beyond the research question by examining the process and considering whether a participatory approach can lead to empowerment. This approach is used in the focus groups' researching the question about end-user training in computing.

\section{Aim}

The aim of the thesis is to show an application of alternative pedagogy and its impact on empowerment of individuals and how this empowerment contributes to transformation. This is done using a participatory research method to pursue a question about end-user computer training in Port Vila, Vanuatu. It was thought that analysis of this training in context would indicate the need for distinct training methods in different settings. 


\section{METHODOLOGY}

During the process, there was co-construction of end-user computing training, using knowledge from individuals in the focus groups based on their experience as receivers of training with the involvement of a former trainer, the researcher. Using a participatory method recognises the power that exists in the knowledge these individuals have (Rahnema 1992). What they lack is both an appropriate method for drawing out what is known and the agency for this to be expressed. The process was a form of pedagogy, having a close relationship with teaching but actually being research. The form of pedagogy used was unlike any the individuals had experienced. During the course of meetings with the groups, the individuals responded positively to the collaboration, the open approach taken and the opportunity to present their work to others. The original question remained at the heart of the process, of interest to both the researcher and the focus group members, but feedback from the focus group members as well as their behaviour in the meetings revealed the value of the actual process.

\section{BUILDING A LADDER}

This thesis is about learning to build a ladder. Robert Chambers (2005) describes a collection of ladders that illustrate different types of participation in development. The ladder is a tool Chambers recommends using to unpack participation for a specific situation ${ }^{1}$.

The analogy is adapted to emphasise that the research this thesis describes is a step on the rung of a ladder that will lead to achieving transformation through empowerment and agency. The research is similar to a construction site, with the ladder's frame being the research question, the participatory process the rungs being attached to the frame and the focus group members being construction workers building the ladder for their use. The blueprint the ladder is built from is very basic; the structure emerges in the process. Rungs that were planned before the construction began are attempts at empowerment, agency, and transformation,

\footnotetext{
1 Adapted from a collection of ladder analogies (Arnstein 1969; Kanji and Greenwood 2001; VeneKlasen with Miller 2002), each use of the ladder analogy is defined in each different participatory situation. The ladder can emphasise levels of autonomy or decision-making, indicate progress or show where in decisionmaking the process has brought participants.
} 
the rest are discovered along the way. The literature section of the thesis is what the ladder leans against.

\section{TERMINOLOGY USED IN THE THESIS}

The use of terms and specific acronyms ${ }^{2}$ in this thesis requires explanation to avoid confusion. This section explains the use of the words construction, constructivism, co-construction, capability and empowerment and describes the acronyms FG, ICT and EUT. Lastly, I will define the end-user, at the heart of the research inquiry.

\section{Terms}

The word construction has several uses in this thesis. As constructivism, it is at the heart of the philosophical stance of the researcher, inspired by Paulo Friere's (1970) 'emancipation' of education. As co-construction, it is seen as a joint endeavour, a collaborative exercise or mutual shaping (Oudshoorn and Pinch 2003 citing Bijker 1995). Construction in terms of the ladder analogy is activity associated with social construction. Social construction is used to mean a constructivist approach to technology (Bijker et al. 1989) and the constructivist approach, which is referred to in educational parlance as well as in sociology, is seen as a philosophy of learner-, or in this case user-, centred knowledge gathering. Simply put, it symbolises a stance that shifts the source of knowledge gathering to those whose voice is normally not heard, in this case users and learners.

The term capability as used in the section on training refers to the studies of competence versus capability. Here the term capability is taken from Phelps et al. (2005, citing Cairns 2000: 1). It is a modern training approach resulting from educational theory based on non-linear approaches to learning. Capability is 'having justified confidence in your ability to take appropriate and effective action to formulate and solve problems in both familiar and unfamiliar and changing settings'. Capable people know how to learn, are creative, have a mature sense of self-worth and the ability to apply competencies in familiar and unfamiliar settings.

\footnotetext{
${ }^{2}$ For generally used acronyms, see the Acronym section in the front section of this thesis.
} 
Capability in this thesis also has an implied meaning relating to human capacity, based on a connection of the terms made by Amartya Sen (1997:1959). Sen describes capability as the ability of individuals to lead lives of value, to have a variety of choices and to be able to enhance these choices. Human capital is used in this thesis as well as human capacity. Human capital is used to denote a value in economic terms (ibid.), as in the worth from a production sense. Capacity is synonymous with capability but is distinguished from the use of capability as it is described above; here capacity is used in the sense of potential.

In order to answer whether empowerment was achieved in this research, how it is determined needs to be established. There being no one established definition of empowerment, it is difficult to measure (Rowland 1997). However, viewpoints from feminist research and from education may give it some meaning in this context. Rowland (1997:129) defines empowerment as a dynamic process, a change based on circumstances and contexts. Kabeer (1999) views empowerment being related to its opposite, disempowerment. Disempowerment is seen as being deprived of choice, empowerment is a change in the ability to make a choice. From an educational point of view, Freire's (1970) view of empowerment includes developing critical consciousness through awareness. Essential in this combined view of empowerment is the existence of agency to complete the act of empowering. Agency is seen as the capacity to action choices (Kabeer 1999). This thesis views empowerment as a process that will expose those who have normally little power in the early stage of a service of which they are at the receiving end, to one that will make them aware of the important place they have at earlier stages of this service.

\section{Acronyms}

FG (focus group) is used to attribute ownership of a statement by a focus group member. Each member has a number and when quoting a particular member, I note this as (FG\#). This is to honour confidentiality of focus group members for ethical reasons.

ICT is used to refer to Information and Communications Technology, which is made up of telecommunications and computing services. At times, when referring 
specifically to end-user training in these technologies I use the acronym EUT but in most cases I'll say end-user training.

To define the end-user I borrow the words of Igbaria and Guthrie (1999:1): ' End users are those people who have trouble fixing tables in word processors. They also program their own applications, manage networks and develop Web sites. End users can be doctors, payroll clerks, financial analysts and scientists. We are entering an age when every business transaction begins and ends with a computer operated, of course, by an end user.'

\section{STRUCTURE OF THE THESIS}

\section{Chapter 2}

The broader context of Vanuatu is described in this chapter. It attempts to illustrate a local's view of Vanuatu, that being somewhat askew due to its unique colonial past. This past has produced influences that have shaped the country to this day, from its divided systems to the diversity of its land and its people and their frequent attempts to establish their own voice in their affairs. Present day issues are looked at, those that underlie relevant education and ICT issues that are significant to the use of a participatory process in this thesis.

\section{Chapter 3}

Chapter three examines literature that the thesis uses as a theoretical foundation. Literature addresses the original research question pursued as well as the participatory approach used in the research process. It includes the reasons for the significance of ICT in developing contexts today and links the social shaping of technology to computer training and education. Methods of end-user computing training methods are considered in light of the research question pursued.

\section{Chapter 4}

This chapter describes the theoretical framework used in the research process and methodology and techniques used to pursue the research question. It includes a description of the research participants and how focus group members were chosen. Details of specific methods applied in the field and after the fieldwork was completed are presented before wrapping up with reflection on the 
methodology and consideration of limitations of the process. A detailed narrative of the process is presented in Chapter six, described in more detail on the next page.

\section{Chapter 5}

Results of the focus groups' pursuit of the research question are summarised, followed by an analysis and reflections on these results.

\section{Chapter 6}

This chapter is a narrative account of the participatory process used to pursue the question by the focus group members. These members focused on the research question while the researcher encouraged a participatory process for the purpose of empowering them. An overview of the framing of questions and how research participants were chosen is included, followed by a chronology of events of the research process. Similar to methodology, the chapter describes methods used but the purpose for it being re-presented in narrative is to re-emphasise its importance. This narrative leads to a discussion and critique of the process in Chapter seven.

\section{Chapter 7}

Chapter seven presents a discussion of the process described in Chapter six. It includes reflection on the role of the focus group members, the researcher's position and the process. It attempts to illustrate the changes observed in the members' orientation to the topic, from receiver of training to awareness of their place in the planning of training programmes.

\section{Chapter 8}

Conclusions drawn from the research are presented in this final chapter. 


\section{CHAPTER 2: View through a prism: Ripablik blong Vanuatu / Republic of Vanuatu / République de Vanuatu}

The context in which this research is situated, Port Vila, Vanuatu, is complex historically and to the present day. Being part of Melanesian Oceania, the archipelago comprises a wide variety of peoples with many languages. This, added to the unique Condominium system during colonial times, makes for an interesting political and social ecology that influences its current development. This chapter has two major parts. The first, Background, details influences that have shaped Vanuatu through historical, geographical, economic and social factors. The second part, Foreground, gives information about Vanuatu's status as a developing country and identifies a place within Vanuatu's education and ICT pursuits that are relevant to this thesis. Together an attempt is made to illustrate the significance of the participatory activity undertaken and the issue explored through the activity, end-user computing training in the context of Vanuatu.

\section{A WORLDVIEW ASKEW}

When I was young, I used to play with a triangular prism in my father's office. Holding the prism across my eyes I saw the room askew. I would wander from one side of the large office to the other, trying not to cheat a peek away from the prism's distorted view of the room; I had to move slowly and carefully to avoid stumbling as I could not see the room clearly. Besides altering reality, the prism created a rainbow which was part of its attraction.

I liken the triangular prism to Miles' (1998:189-192) condocolonial triangulation created by the French and British Condominium in Vanuatu (Figure 2.1, p 12). Imagine the indigenous people having this prism, or 'lens', placed in front of their eyes and being expected to navigate through life with an obscured view of themselves. Independence was an attempt to remove the distorting triangular prism and to see clearly through their own eyes. They desired to no longer be the third side of something but to navigate with undistorted vision in their country. 
However, there is still the attraction of the prism's colours. 'How can we have that and not the other?', they might ask.

\section{PART 1: BACKGROUND Geography's influence}

Vanuatu is a Y-shaped archipelago of just over 80 islands, 68 of which are inhabited, spanning an area of approximately 860,000 sq kms in the South Pacific (VTO n.d.; FCO 2008). It is almost at the centre of a triangle formed by the Solomon Islands, New Caledonia and Fiji. In land area it is approximately the size of Northern Ireland but the islands stretch across an area the size of a large extent of Western Europe (Country watch 2008). This spread of islands makes the transport of goods and communications difficult.

The climate is tropical to sub-tropical. The trade winds from the Southeast provide cooling breezes from March to November but become calm beginning in December, which makes for very hot, humid conditions often until April. When the trades blow during these months they bring torrential rain (Bevan 1990), fierce electrical storms and cyclones. Located on the 'Rim of Fire', ${ }^{3}$, the country averages 2.6 cyclones a year and has recorded more than 40 earthquakes of magnitudes between 4.0 and 7.3 (FCO 2008) with total seismic activity of over 2000 events per year.

\section{Foreign influence}

\section{Shifting land}

The existence of the first known people on the islands is based on the finds of artefacts and human remains (Bedford et al. 2007) estimated to be over 3,000 years old. European contact with the islands began in 1606. Contact turned to conquest in the early and mid 1800s. European settlement was established by the late 1850s, mainly by British from Australia, and later by the French (Rodman 1995:73-75). The archipelago was known as the New Hebrides during colonial times. By the late 1800s the British and French acquired much land in the New

\footnotetext{
${ }^{3}$ The rim extends from New Zealand to the Solomon Islands and then to Papua New Guinea. It is at the boundary of the Indo-Australian and Pacific tectonic plates.
} 
Hebrides but the British sold their land to a French company by 1906 (Rodman 1995: 74). Holding land as a commodity (i.e. land ownership for profit) was an alien concept to the indigenous people; their traditional practice is customary land ownership (Regenvanu 1980:67-69). Conflicts developed over land between French and British claimants and between the settlers and the indigenous people. Regenvanu (1980) explains that the colonisers took possession of the best land, leaving customary landowners with areas that remained untapped for cultivating or development because it was so inaccessible. Since its adoption in 1979, The Constitution of Vanuatu claims all land in Vanuatu can be owned in perpetuity only by Ni-Vanuatu (Regenvanu 1980:69-71). Land is still bought and sold, but on a land lease system which limits non-customary 'ownership' to 75 years (Republic of Vanuatu 1988).

An example of opposing perceptions of land between the indigenous people and the colonisers is of the categories of land written for the Joint Court of the Condominium and those written by a Ni-Vanuatu at Independence. The Condominium defined the three main categories of land as Registered land, Native Reserves and Native land with an additional 4th residual category, land under claim (Rodman 1995:76). From the local perspective, the three categories are Alienated, Customary and Urban land (Regenvanu 1980:73).

\section{Shifting power}

The 1906 Establishment of the Anglo-French Condominium in the New Hebrides was a result of prior measures to protect settlers from attacks by the islanders and conflicts over land (and no doubt culture) between the two colonial powers. This was a unique administrative system, defined as 'a region of joint influence' (Rodman 1995:75 citing Scholefield 1919: 377) that separately gave rights of residence and protection to citizens of Britain and France in the New Hebrides. There was a third system for administering the indigenous people. This was cumbersome and has been aptly dubbed the Pandemonium ${ }^{4}$. It meant that there were dual systems of administration, including school systems, for the British and French and a third system for natives of the islands (Rodman 1995:75), with

\footnotetext{
${ }^{4}$ Bonemaisson $(1994,94)$ has suggested the 'whatsitdominium' adding that it was more of an 'out-of-joint authority than a joint one.
} 
formal schooling for them mainly organised by missionaries. Miles says that because of the lack of political and national unity in the Condominium 'New Hebrideans remained subordinate players in the condocolonial game' (Miles 1998:189) (see Figure 2.1 below). The Condominium lasted until Independence.

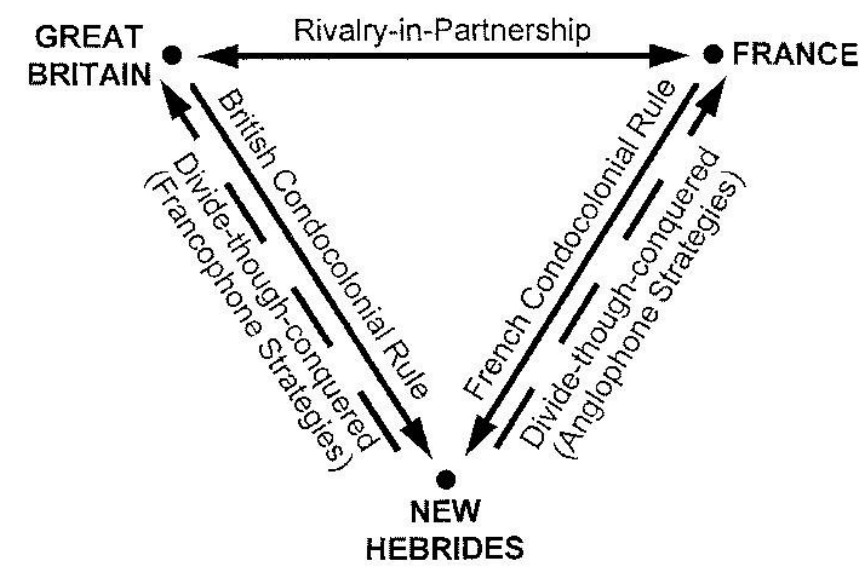

Figure 2.1: Condocolonial triangulation (Miles 1998:192)

With sales of land Bonnemaison observed a shift in character of the main areas settled by both the French and British. He asks '...where was Melanesian society?' (1994:50-51). The settlers behaved as if they were the owners and masters of the archipelago and the balance of power shifted to the 'outsiders' with their collecting of land titles.

\section{Shifting identity}

By the mid 1970s, there was a growing desire by the indigenous people for independence. The two colonising powers finally agreed in 1977 to grant Vanuatu independence by 1980. The first national elections were held in 1979.

On 30 July 1980 the New Hebrides became the Republic of Vanuatu.

\section{Still shifting}

Today there is a renewed shift in land, power and identity happening in Vanuatu. There is a considerable foreign presence in Vanuatu, especially in Port Vila, with a large and growing number of foreigners migrating to Vanuatu for reasons of business, investment and lifestyle. A new Australian High Commission complex, built on the Parliament grounds, is far grander than the High Commission's old offices and attests to the perceived status and increasing number of Australians 
investing and gaining from the tax haven. In fact, its presence is so dominant, it begs the question, 'whose country is this?'.

In the last decade there have been key land development projects with development occurring especially on beachfront properties in the main centres. Many of these projects are results of foreign investment and are based on land lease laws (ref. above p 11). The payoff for locals is one-off cash payments (Niroa 2004:27), however they lose access to beachfront properties for gardens to grow food and homes for local families, not to mention access to the sea. It appears to be a one-generation loss but the land is often 'alienated' for at least two generations, the cost benefit being short term. Long term costs are extremely high.

\section{Social influence}

\section{Identity}

The people of Vanuatu are Melanesian. Melanesia is a sub-group of the greater Oceania; it is not a distinct cultural group but was created along convenient borders (Spriggs 1997).

The word to describe Vanuatu nationals is Ni-Vanuatu, both in singular and plural form. The term Ni-Vanuatu is very general, considering the number of distinct cultural groups.

With few natural resources besides its tropical environment and warm, welcoming people, Vanuatu has long been under the control of others, named and defined by outsiders. Even since Independence almost thirty years ago it is still often 'interpreted' by others. From the Great Cyclades by Luis Vaez de Torres in 1768, to the New Hebrides by Captain Cook in 1774 (Bonnesmaison 1997), as 'Isles of Illusion' byFletcher in 1923 and The Happiest place on earth ${ }^{5}$ (NEF 2006), Vanuatu and its individual islands have been named and renamed by outsiders. In 1980 the people of the New Hebrides took sovereignty over their islands and their identity. They named their country Vanuatu, a blending of the words vanua,

\footnotetext{
${ }^{5}$ Vanuatu ranks first in the Caribbean and Pacific countries with a life satisfaction rate of 7.4 compared to the index's reasonable deal (rd) of 8.2; Life expectancy 68.6 out of an rd of 82; an ecological footprint of 1.1 out of an rd of 1.5; and HPI of 68.2 out of an rd of 83.5.
} 
meaning 'land', a common word in Melanesian languages, and $t u$, which describes the existence of the vanua from time immemorial to the present and future. Vanuatu is 'the islands, the people that existed, still exist and will always exist' (Taurokoto 1980:11) or 'Land Eternal' (Miles 1998:xvii). 'Vanuatu expresses our existence long before we were discovered. We and our islands were here before the European explorers came and claimed that they discovered us' (Taurotoko 1980:11).

\section{Urbanisation}

The total population of Vanuatu is over 220,000 (VNSO 2007 based on projections; UN 2008). There are two main centres: Port Vila, the nation's capital, on Efate, and Luganville, on Espiritu Santo. Port Vila's population is 38,438 , Luganville's is 14,380 . Almost $80 \%$ of the people live in rural areas (EIU country profile 2008).

There is regular electricity supply and piped water only in urban centres (Republic of Vanuatu 2000). Public utilities are provided by monopolies, leading to high costs and poor service as well as a lack of economic motivation to provide rural areas with service. Therefore these rural areas have only basic transport and communications infrastructure.

Development projects have by far been aimed at urban centres. Urban households have five times the income of rural households (NZAID 2006:20). Employment opportunities and modern facilities inside the urban areas attract people to build permanent homes in the centres and their population growth is three times higher than in rural areas, with the two main centres on the islands of Efate and Espiritu Santo, , Port Vila and Luganville, showing the highest growth rates among all islands (EFA 2000).

\section{Culture \& Kastom}

Generally, custom is the habits of culture woven into social life. In Vanuatu, the term kastom is a term used to describe traditional ways of daily as well as ceremonial life. The word kastom is often used interchangeably with custom in common dialogue. However, Rodman (1995:66) refers to kastom as 'conspicuous tradition'. It is seen as a 'created' concept and it is argued that there are identificatory, regulatory and oppositional capacities to kastom. The oppositional 
capacity is to do with having lost and then relocated or reinvented customary practices (Rodman 1995). '[R]ecourse to custom as symbol can allow new ways of doing things to seem old' (Rodman 1995:67) without the new and old ways coming into conflict or contradicting each other.

\section{Language}

Among the characteristics of culture and kastom that are common through Vanuatu and hold great importance are language and leadership. Tied to culture and a factor that influences politics as well as education, Vanuatu boasts the highest per-capita language ratio in the world. It is said there are 106 distinct languages, 81 of these still actively spoken (Lynch and Crowley 2001).

Vanuatu has three official national languages: Bislama (the lingua franca), English and French. All official information must be presented in these three languages. There are separate newspapers favouring one or another of the languages and local radio and TV present news programmes in three languages. Political parties are divided by language affiliation, Anglophone or Francophone.

\section{Hierarchy and power}

Having the opportunity to wield power in Vanuatu comes from distinct features at play in Vanuatu's culture. Prominent is the system of male power. It has influence in social and political arenas in Vanuatu. An expression known as 'Big man' is used to define this male power system. In the 60s, Marshall Sahlins described the idea of 'Big Man' as a person who uses calculated generosities in helping someone in order to gain obligations and who performs ceremonies to enhance his status. Renown is a quality of the 'Big Man' more than position (Lindstrom 1990). The 'Big Man' is based on leadership qualities, bravery and ritual, it cannot be inherited (Brown 1990). It is not bestowed on the basis of physical strength but is granted to magicians and men who receive knowledge by divine inspiration or who have associations to powerful white men. Roles vary depending on what is needed or valued in the immediate situation (ibid.).

There is an argument of the term's origins that begs pause to consider whether the 'Big Man' idea is just a fabrication to make sense of and to categorise a phenomenon by 'outsiders' (Lindstrom 1981; Lindstrom 1990). There is not scope in this study to present this debate. However, it is interesting to note 
Lindstrom's (1990) take on the source of knowledge of the big man in Tannese society, Tanna being a southern island in the archipelago. He (1990:315, citing Foucault 1981) refers to the 'discursive order', that are conditions determining whether a person's talk is worth hearing, interesting or true. Lindstrom calls this a 'conversational regime'. The core idea is whether one's own ideas are as good as ideas from outside sources. In Tannese society, to be authentic and give authority to ideas a person will suggest they are repeating inspired truths from other sources — their fathers, spirits, ancestors — rather than taking credit for them (Lindstrom 1990:316-317). In this context, personal intelligence differs from inspiration systems as the source of knowledge. The Western system of personal intelligence doesn't exist (ibid.), rather sources of inspiration on Tanna include elderly and wise people, travel, books and education, not the individual. Though this view is referring to a very particular Tannese phenomenon, it does explain behaviour in Vila in terms of who has the 'voice' or authority that status gives.

Today there is a power-brokerage system that is firmly straddled by those with status derived from position. This is an issue for changing the opportunities available to empower and give voice to individuals. Change will not only need to be made by those in power for widening opportunities in decision-making, it will also need changes to the attitudes of those without power, often including women and youth, towards the usefulness of their knowledge.

\section{PART 2: FOREGROUND}

Vanuatu's economy is an influence no more or less important than issues presented in the previous section. But it belongs in the foreground of this thesis as it sets up two key factors that have major relevance here, Vanuatu's human capital and its dependence on foreign professional skills. This section outlines relevant aspects of the economy in addition to issues of development, education/ professional development and ICT in Vanuatu.

\section{Vanuatu's economy}

The monetary system has replaced the traditional economy, sustainable agriculture and the local market, where goods were bartered and exchanged (Fischer 2002), and it is now the main economy. Vanuatu has dual economies functioning within its monetary system: informal and formal (Republic of 
Vanuatu 2000:1). The formal economy, mainly urban, includes the services sector earning $60-70 \%$ of GDP and employing about a third of the population (MFAT 2008); and industry, which contributes another 10\% to GDP (Republic of Vanuatu 2000). The informal economy resides mainly in agriculture and some domestic service.

Foreign investment, services, tourism and land development are areas showing growth in Vanuatu's economy. Lacking economically valuable natural resources, Vanuatu joins other Pacific island countries that look to services such as offshore banking, being a tax haven and hosting online gambling sites (Fischer 2002:273) for its income generation and growth. Its tax base is derived from import duties and consumer goods and services, there is no income tax for the government to draw on so foreign investment is avidly promoted. The government intends on keeping its tax haven status and offshore financial centre to attract foreign investors (Republic of Vanuatu 2000).

The dependence on foreign investment is a reality for economic development and, in order to attract this investment, the logistics of establishing and maintaining businesses in Vanuatu have been addressed, resulting in the formation of the Vanuatu Foreign Investment Board (VFIB). Their main task has been to address the bureaucracy of getting a business license (Republic of Vanuatu 2000; ADB 2008) but also to focus on constraints such as the poor infrastructure and high costs of utilities. At the end of 2007, the government passed legislation to end the telecommunications monopoly (Daily Post 2008; VIGNET 2008). This is a step in the direction of improving telecommunications' infrastructure, therefore increasing accessibility and decreasing costs through competition. While attracting foreign investment, a spin off of this is to make ICT more accessible to Ni-Vanuatu for communications and business. After this legislation passed and other suppliers started to move into the country TVL, the former single telecom provider, announced a price reduction due to start in September 2008. The price for home users changed from VT16,800 (NZD279.58 ${ }^{6}$ ) to VT5,950 (98.88) per month (Moon 2008). This is still high by international standards but a considerable change for Vanuatu.

\footnotetext{
${ }^{6}$ Exchange rate of 60vt to 1NZD on 29 January 2009.
} 


\section{Local Iabour}

Attracting more business into Vanuatu's economy should improve the job market. Vanuatu claims a labour force of 76,370 with an overall unemployment rate of $6.6 \%$ urban and $0.6 \%$ rural (VNSO 2007, based on the 1999 census). A 2000 estimate of occupations in general was agriculture $65 \%$, industry $5 \%$ and services 30\% (CIA World Factbook 2007). The census also sheds light on the current median age, 18.8, which is estimated to increase slightly based on the VNSO's projections. The working age group, 15-64 in 1999 made up 54.5\% of the population and was projected to increase to $55.7 \%$ by 2004 and to reach $57.1 \%$ in 2009.

Today the makeup of Vanuatu is about 94\% Melanesian, 4\% European and $2 \%$ Asian. Most non-Melanesians live in one of the two main centres (Country watch 2008), Port Vila and Luganville. The relationship between emigration and immigration is that few Ni-Vanuatu permanently emigrate from Vanuatu. As a share of population, Melanesia's emigration rates are the lowest in the Pacific, with $1.18 \%$ of the total population migrating in 2005 . This had decreased from $1.27 \%$ in 2000 (IOM 2008). Their lack of emigration is partly justified by there not being established communities of $\mathrm{Ni}$-Vanuatu living in neighbouring Australia and New Zealand, and partly caused by Vanuatu's laws threatening loss of citizenship (Shing, pers. comm. 2007b). Therefore there is little likelihood of NiVanuatu leaving to live overseas. The World Bank projects an excess of labour supply by 2015 in Melanesia, with the working age population increasing from 95,000 in 2004 to 129,000 in 2015. They project the increase in employment will not increase enough to meet this need (ibid.). The likelihood of skilled labour being preferred in the centres is strong.

With the growing number of young $\mathrm{Ni}-\mathrm{V}$ anuatu coming into the workforce, there is a growing disparity between indigenous people and expatriates. A 1985 'Family Income and Expenditure Survey' showed that expatriates' income is 7.5 times that of Ni-Vanuatu (Republic of Vanuatu 2000:14, Kilman 2006). Increasing business is one thing but increasing opportunities for local rather than imported employment is an important factor. And this involves increasing skill levels at an early age to meet the sort of business possibilities technology offers. At the moment, many foreign firms taking advantage of the tax haven status hire 
foreign consultants to do their ICT business as they assume locals do not have the skills they require. This is true for technical ICT to a greater degree as local endusers are more readily hired. However, those who are working in local industry have limited scope for professional growth with this reliance on foreign labour.

\section{Development}

Vanuatu is a developing country. At independence, it lacked leaders with the education and experience to support economic and social growth (Republic of Vanuatu 2000:27). It has been on a development path since. Having created national development plans in the past, the government is now developing reform strategies in compliance with the Central Reform Programme (CRP), which started in 1997 with a loan from the Asian Development Bank (ADB). \$21.2 million was released to Vanuatu between 1998-2001 (DFAT 2007).

Reform was deemed necessary on the basis of economic stagnation, an inefficient and weak public service and unstable government known for abuses of power (Republic of Vanuatu 2000) so its purpose has been to address economic, social and political aspects of Vanuatu. CRP was accepted at a National Summit held at its inception, with participation from a wide section of the country's public and private organisations. CRP is, in essence, an overall development platform, with donors' projects integrating with the reform (Republic of Vanuatu 2000).

Since the reform, the economy has shown growth but not in keeping with population growth and the economic needs of the society. Officially Vanuatu is still considered a least developed country (LDC) and is highly reliant on foreign aid. Its political leaders have continued to reaffirm the LDC status despite indicators that human and economic growth have improved enough to allow for Vanuatu's removal from LDC status. These improved indicators might indicate that CRP is effective but the local argument for continuing to be considered an LDC has been inaccuracies in measurement of Gross National Income (GNI) per capita (Kilman 2006). Kilman argues that the GNI does not take into consideration the inequality between urban and rural incomes as well as the pay disparity between expatriates and $\mathrm{Ni}-$ Vanuatu living in the centres. 


\section{Recent development initiatives: national and regional}

National initiatives include a Priorities and Action Agenda (PAA) set up in 2003 to give Vanuatu a strategy for self-reliance in prioritising activities in CRP. Regionally, recent activities include the Suva Declaration on Sustainable Human Development in the Pacific, endorsed in 1994 to promote sustainable human development by promoting relevance of education, formal and non-formal, and to finance human development by using participatory, community-based development (Republic of Vanuatu 2000:33).

The Pacific Plan, begun in 2005 provides an implementation framework for 10 years (PIFS 2005a:3) and is active in promoting regionalism to confront problems and strengthen cooperation and integration by resource sharing and policy alignment. It supports national capacities and encourages separate nations to develop specifics to meet their needs while offering the strength of a unified region. Through this there is the opportunity also of a greater link of Pacific island countries with Asian countries, especially in the areas of trade, investment, infrastructure and ICT.

\section{Aid and Assistance}

Vanuatu owes much of its financial support to outside assistance, relying on foreign aid to finance its government and its development. The aid includes bilateral and multilateral deals with cash grants, aid in-kind, technical assistance (TA) and loans (Republic of Vanuatu 2000:35-36). According to the 2000 development plan, aid accounted for $21 \%$ of total receivables, $59.7 \%$ of government revenue and $56.8 \%$ of government expenditure (Republic of Vanuatu 2000:36). The main three sectors receiving aid and assistance from 1998 - 2002 were infrastructure, human resources, education and macroeconomic stability with transport, roads and telecommunications infrastructure receiving nearly half of all aid (Republic of Vanuatu 2000, adapted from Figure 1: Value of ODA by sector 1998-2002).

Regionally Vanuatu's developed neighbours, Australia and New Zealand, are the biggest donors to Vanuatu. Australia, Vanuatu's largest donor, is estimated to have given assistance up to AUS $\$ 44.5$ million in 2007/08. Australia's assistance is focused on needs identified through Vanuatu's PAA (DFAT 2007). It is New 
Zealand's third largest aid recipient. In 2007/08 Vanuatu received NZ\$15 million and is expected to rise to NZ\$20million in 2009 (MFAT 2008). Aid from New Zealand is also arranged through multilateral and regional programmes Through NZAID, New Zealand oversees projects in the area of governance strengthening, education, and building sustainable economic growth in rural areas. In 2006 Vanuatu was selected as one of five Pacific island countries for participation in a kick-start of the Recognised Seasonal Employer (RSE) scheme. The scheme offers temporary employment for unskilled and semi-skilled labourers in horticulture and viticulture, mainly in Central Otago and Hawkes Bay. This is expected to aid Vanuatu through remittances (MFAT 2008).

Other donors to Vanuatu include France, European Union (EU), Japan, United Kingdom (UK), China, ADB, World Bank/International Development Association, International Monetary Fund (IMF), Canada and UN agencies (Republic of Vanuatu 2000:13).

\section{Problems with development}

Constraints on economic development include a dependence on its few export products, a need for skilled local human capital and high infrastructure costs, i.e. public utilities and transport (Republic of Vanuatu 2000:6). The geographical makeup and dispersion of islands and population create negative factors making development and maintenance of infrastructure expensive and difficult (Republic of Vanuatu 2000:24; ADB 2008). Almost all business ventures depend on importing goods and there are high costs in obtaining and transporting the materials (Fischer 2002:272).

Development aid furthers Vanuatu's vulnerability as it cannot be counted on and is not, in itself, a sustainable development method. (Republic of Vanuatu 2000:18). Ni-Vanuatu see another problem with aid and assistance being that donor procedures can undermine government's role, especially when they fund civil societies and the private sector. In addition, loans often have conditions that are not Vanuatu-initiated yet implementation of these plans must be done by $\mathrm{Ni}$ Vanuatu who then bear the cost of the loans (Republic of Vanuatu 2000:12). Vanuatu's own national development plans have not included community participation in the planning process which means the beneficiaries of aid have no 
ownership of the plans and therefore lack the will to implement them (Republic of Vanuatu 2000). CRP is meant to specifically address this issue.

\section{Education and Professional Development}

\section{Human capacity}

With a focus on improving social performance and economic growth, the most recent development plan encouraged investment in human capital, ending the continuing dependence on expatriate labour and investments (Republic of Vanuatu 2000). The need for increased human capital and decreased foreign dependence are related problems and key issues in this research.

Writing in 1980, Mildred Sope, a local teacher and poet, foresaw a problem with the need to carefully decide what population the country could support and to start limiting the numbers of expatriates granted residency in order to replace their labour with Ni-Vanuatu (Sope 1980). She felt 1980 was the time to start and saw education of Ni-Vanuatu as a key. Instead of that happening, the current reform programme has flooded the country with foreign Technical Assistants. One programme alone had up to 42 foreign consultants advising it (Republic of Vanuatu 2000:24). Technical assistance programmes, which amount to about $46 \%$ of external aid funds, are meant to transfer skills and help raise the local capacity, especially in the areas of management, technical fields and entrepreneurship (Republic of Vanuatu 2000:27) but it is found that expatriates are not transferring skills to locals.

Therefore we return to Sope's 1980 recommendation about using education to improve local capability and diminish the need for foreign labour.

\section{Education/Literacy}

In the development plan for 2001-2010, addressing the shortage of skilled, educated, literate and numerate labour across sectors was considered a high priority. Education in Vanuatu has been receiving over a quarter share of the National budget since 1999 (VNSO 2007). Most people attend at least primary school. They have a reasonable record for further education, seen by the percentage of combined primary, secondary and tertiary enrolments in Table 2.1 
below. However, enrolment alone does not indicate completion or, more importantly, quality of education (Desjardins 2008:31).

\begin{tabular}{|ll|}
\hline Primary school enrolment (net) & $93.9 \%$ \\
Primary school students continuing to secondary school & $25.6 \%$ total \\
& $(24 \%$ male \\
& $26.5 \%$ female $)$ \\
Literacy rates & $50.1 \%$ males \\
& $49.9 \%$ females \\
Combined primary, secondary and tertiary gross enrolment ratio & $63.4 \%$ \\
\hline Table 2.1: Socio-economic indicators & Source: VNSO, ADB 2007
\end{tabular}

\section{From traditional to imported}

$\mathrm{Ni}-$ Vanuatu believe in education but also still greatly value traditional knowledge (Rodman 1995). Traditional education is based on an oral tradition, storytelling and personal memory (Niroa 2007; Tamashiro 2007).

Historically, western education stems from European arrival, especially the work of missionaries in the early and mid 1800s. Exposure to books and different types of knowing expanded the Ni-Vanuatu horizon (Rodman 1995). The new knowledge appealed to the indigenous people; they linked knowledge to religion and felt this knowledge would help them gain political, economic and moral equality with the Europeans (Rodman 1995). In Ni-Vanuatu writing in 1980 and 1981, Western-style education and training is expressed as being an important link to success in leadership (Sope 1980, Macdonald-Milne and Thomas 1981).

\section{Dual Systems}

During the years of the Condominium, there were dual systems of formal education and these have persisted to this day. There are separate English and French schools, depending on the island, and Port Vila has both. Based on 2002 figures, there were 156 Francophone and 254 Anglophone primary schools and 21 Francophone and 38 Anglophone secondary schools (Bibi 2004). A recent government policy, written in 1998 and put in place in 1999, provided for vernacular education in primary schools with either French or English starting in high schools (Nako 2004). 
For such a small population, the dual systems give some choice of schooling but it also aggravates the language divide. There has been discussion about having one system, either French or English, chosen as the post-primary education system followed by the other language for upper secondary but the difficulty is which system will, in effect, 'back down, ${ }^{7}$ ? What is interesting to note is the lack of formal academic training in Bislama at any level, though it is a national language that has established grammar rules, set spelling standards and a dictionary.

\section{Higher learning}

Post-secondary education is available in Vanuatu but few can afford to attain this level. The University of the South Pacific (USP) Emalus Campus in Port Vila hosts the School of Law of USP. USP Emalus also has an extension centre, including the Distance and Flexible Learning centre (DFL), which runs programmes from the main centre, Suva, through audio and satellite technology ${ }^{8}$. There is growing interest in and attainment of online courses through USP's various regional programmes.

The Institut de technologie de Vanuatu (INTV) was a French vocational institute that has now become Vanuatu Institute of Technology (VIT), run through the Australian funded Technical Vocational Education and Training (TVET) scheme with Australian technical assistance ${ }^{9}$. VIT offers a wide range of vocational courses.

Agence universitaire de la Francophonie (AUF), a branch of the University of France, offers university level courses online in French. They have a one-building complex in Port Vila that provides administration, computer facilities and a library.

There are various smaller post-secondary training opportunities offered in the private sector but I will not describe these here. Computer skills-related institutions are described in the ICT training information later in this chapter.

\footnotetext{
${ }^{7}$ See Nirua's (2004) argument to introduce French as the standard post-primary teaching language.

${ }^{8}$ USPNet, donated and installed with Japanese funding and technical assistance in 2001 with financial assistance from Australia and New Zealand.

${ }^{9}$ The buildings of the complex have gone from being painted the blue, white and red of France to the green and gold of Australia.
} 


\section{Re-thinking Vanuatu's education}

In 2001 and 2002 leading educators gathered to discuss Vanuatu's education. This led to Ni-Vanuatu educators proclaiming a desire to develop their skills in order to be able to take a more active role in educational decision making in Vanuatu (Sanga and Niroa 2004). This is part of the regional Re-Thinking Pacific Education Initiative, which has been active since 2001 (Sanga and van Peer 2008). Sanga and Niroa (2004:14) explain that the desire to have more input and make education more sustainable and less project-based came from the educators' view of the educational scene in Vanuatu since Independence. They feel the knowledge basis of their education has become more foreign-based and that local input in planning needs to be made in order to make a more relevant education system fed by indigenous voices and with more locally articulated visions for their own educational development. To do this, they set out to improve their own research and analysis skills to be able to reflect on their educational policies and practices (Sanga and Niroa 2004). They have produced a book of their combined research and ideas, Re-Thinking Vanuatu Education Together (2004).

This resembles a similar event in the late 1970s when research training was organised to produce the book Yumi Stanap (1981). The Conference of Churches and New Hebrides Christian Council established a Pacific Churches Research Centre to research and write a book about leaders' roles, how they could cooperate better and why there were divisions in the community and the church's role in assisting this (Macdonald-Milne and Thomas 1981). Fourteen local researchers were chosen among a list of potential candidates and they received training in research skills in a series of workshops starting in February 1980. After training, the researchers returned to their islands, researched and wrote articles about their prominent leaders for the book.

These initiatives show the desire for local involvement and leadership in their education system as well as the desire to improve local research skills.

The last issue in this section deals with the growing use of ICT in Vanuatu and the region, highlighting benefits, problems faced, its application in business, education and training and how it is being provided to increase capacity, to use and construct the local and regional ICT culture. 


\section{Information and Communications Technology}

\section{Communications in Vanuatu}

In writings from Vanuatu near the time of Independence, the term communications is often used when referring to the roads and the sea (Taurokoto 1980; Tamata 1980). In Vanuatu's context, this is an important point, for when either of these methods of transport is cut off, it can also cut off communications. In 1980, Martin Tamata (1980:87) said 'sea communications have perhaps been the most important single factor in the development of our society, economy and culture.'. These sea communications gave access not only to other islands in the archipelago, but also to more far-reaching islands and continents; the sea extends across the globe.

The phrase 'Should we be bringing this technology to them?' is all too commonly heard among expatriates working in ICT in developing countries. Perhaps part of the problem is that the expatriates' viewpoint of ICT in developing countries is envisaged in its worst light: in homogenisation, excesses and access to 'things they shouldn't see'. A very protective outlook. But why not see ICT similar to the sea, a channel of communications and a transport system, the transport of ideas, knowledge and culture. And see it as a two-way process. It need not be all incoming traffic.

Besides that, expatriates are not 'bringing' anything, it is here. And it is not up to expatriates to decide whether 'they' need it, it is the Ni-Vanuatu choice to implement what they find useful and decide how they want to use it, a process that has been in practice since the discovery of fire and the invention of the wheel (i.e. other technologies).

It is evident ICT is here by looking at the numbers. Teledensity is the number of telephone lines per 100 people and can also be used to indicate the level of telecommunications infrastructure. In 2002 the analogue cellular telephony network was replaced with a digital system that resulted in more than three times growth in mobile subscriptions (EIU 2007). Interesting to note is the change in the number of landlines as mobile technology is introduced into Vanuatu (see Table 2.2, next page). 


\begin{tabular}{|lllllll|}
\hline & 2001 & 2002 & 2003 & 2004 & 2005 & 2006 \\
Fixed phones (/1000) & 0.561 & 0.788 & 1.05 & 1.002 & 0.969 & 0.916 \\
Mobile phones (/1000) & 0 & 3.372 & 4.44 & 5.087 & 6.213 & 8.996 \\
\hline
\end{tabular}

Table 2.2: Telephone use changing with introduction of digital service

Table 2.3 below shows increasing internet use. The costs for accessing the internet are high in the small island countries yet the figures show the technology is being adopted, despite the high cost of use (ref. internet charges, p 17).

\begin{tabular}{|lll|}
\hline \% of total by year \\
\hline Internet users, estimated (/1000) & 2000 & 2005 \\
\end{tabular}

Table 2.3: Vanuatu's telecommunications indicators (urban and rural)

Source: UN Statistics division 2008

Several sources indicate the number of PCs per 100 people in Vanuatu to be 3.5 as late as $2006^{10}$ (UNESCAP 2006; World Bank 2006). By far, the majority of users would be located in the main centres but there are increasing numbers of computers being sent to smaller provincial centres. At the moment, only $6.9 \%$ of rural areas have electricity provided as compared to $60.6 \%$ in urban areas (UN Statistics 2008), which will certainly influence the use of electronic equipment. Still largely an urban phenomenon, if and when access and usage costs decrease and infrastructure reaches remote areas, use may increase even more. Increasing mobile (wireless) technology that requires less infrastructure will likely have a significant ongoing impact in developing countries to overcome the high costs of infrastructure development and in establishing connectivity technology with the outside world.

\footnotetext{
${ }^{10}$ New Zealand's figure at this same time was in the early 50s: 50.2 (World Bank 2006) - 51.6 (UNESCAP 2006 http://devdata.worldbank.org/ict/nzl_ict.pdf and www.unescap.org/stat/data/apif/2006/New-Zealandapif2006.pdf).
} 


\section{Implementing ICTs in the Pacific}

ICT technical issues: infrastructure

Many Pacific island countries have fallen behind in the infrastructure that makes ICT more feasible and available to many. In early 1970 the first satellite earth station was established in the South Pacific by New Zealand. A number of Pacific Island countries were able to establish their own after this and they benefited by having high quality international communications. However, since that time New Zealand and Australia have continued to develop telecommunications capability using high capacity undersea cables and once set up, increased competition helped lower prices for services to the point that New Zealand enjoyed $1 / 10^{\text {th }}$ the cost of other Pacific Island countries by 2001 (Zwimpfer 2003). These cables do not connect many small Pacific island countries to this day.

International connectivity, low bandwidth, choice of network infrastructure; challenges in establishing and maintaining infrastructure; and costs of services are among the problems for the smaller Pacific Island states. In Vanuatu their telecommunications company, Telecom Vanuatu Limited (TVL) has held a monopoly position since its inception, which has been blamed for limited services and high prices (EIU 2007). A study by Mbarika et al. (2002) found that LDCs have the highest average 'operator profitability' in the world. With the telecommunications act in draft form (Republic of Vanuatu 2009), some of these problems are starting to be addressed (ref. telecommunications monopoly, $\mathrm{p}$ 17).

\section{Additional issues}

Other obstacles common to Pacific countries' implementation of ICTs include inadequate human resources, emigration of trained personnel and outdated curricula to help establish minimum skill level, equipment and facilities (Whelan, 2007b).

In addition to the above, factors in the development of ICTs in Vanuatu are the limited network availability and use, lack of human resources as opposed to neighbouring Fiji, little institutional capacity and lack of commitment from the national government. In the 2000 development plan, a short paragraph mentions technology in general and states there is not the required specialised human resources and 'the industrialization (sic) and technological capability' to support 
venturing into a strategy for technology development and suggests this will not change for some time (Republic of Vanuatu 2000:35). A lot has changed since 2000, yet there has been no move toward an ICT policy until only recently. At the time of writing (January 2009) it has not been confirmed if the policy has gone beyond draft stage, the stage it was in March 2008.

There is limited knowledge of using ICTs in the general public and the constraints due to the lack of human resources and institutional capacity plus the cost of technical support limit the introduction of ICTs into education as well as the workplace (WSIS 2004). Although there has been a growth in the number of technically qualified Ni-Vanuatu, the lack of trust and thus opportunity for skilled locals limits their progress.

Part of the problem with passing down these technical skills to locals is indicated in the 1999 Employment by industry and age group chart (Table 2.4, next page). This breaks down by category the number of people employed by sector and age group. The computer sector, which will consist of technical employment, shows that of the 40 employed in this sector, the greatest number employed are in the age group 25-29, the least in the 15-19 age group and no one in the age groups 50-64. This last age group is significant, illustrating the lack of embodied local skill (Denning and Dunham 2001) and, therefore a lack of mentors of an age group with experience in ICT. This means there will be a dependence on foreign skills and mentoring until there is a generation of locals to become mentors, teachers and trainers for younger Ni-Vanuatu. This carries with it the continued possibility of non-localisation of the industry. While this occupational breakdown is at the technical level, technical decisions do impact on the end-users. I argue that this also creates a likelihood of there being no incentive or natural tendency toward local social construction of the sector, so reducing local adoption and ownership of this technology, thereby extending the reliance on expatriates. 


\begin{tabular}{|c|c|c|c|c|c|c|c|c|c|c|c|}
\hline ISIC summary & $15-19$ & $20-24$ & $25-29$ & $30-34$ & $35-39$ & $40-44$ & $45-49$ & $50-54$ & $55-59$ & $60-64$ & Total \\
\hline Agriculture & 37 & 86 & 117 & 124 & 83 & 49 & 61 & 28 & 32 & 9 & 626 \\
\hline Building and Construction & 97 & 221 & 240 & 252 & 217 & 144 & 134 & 99 & 63 & 27 & 1,494 \\
\hline Community Social Services & 25 & 114 & 118 & 99 & 90 & 57 & 45 & 26 & 12 & 11 & 597 \\
\hline Computer Services & 1 & 5 & 9 & 8 & 6 & 6 & 5 & & & & 40 \\
\hline Education & 64 & 355 & 451 & 374 & 294 & 210 & 128 & 85 & 30 & 9 & 2,000 \\
\hline Electricity, Gas \& Water & 3 & 19 & 21 & 15 & 9 & 18 & 13 & 5 & 4 & & 107 \\
\hline Financial Services & 7 & 53 & 87 & 64 & 54 & 55 & 22 & 15 & 7 & 3 & 367 \\
\hline Fishing & 5 & 24 & 13 & 9 & 14 & 3 & 4 & 2 & 2 & & 76 \\
\hline Forestry \& Logging & 13 & 50 & 50 & 49 & 43 & 29 & 16 & 6 & 7 & & 263 \\
\hline Government - policy, regulation etc. & 43 & 215 & 428 & 504 & 541 & 365 & 229 & 109 & 58 & 21 & 2,513 \\
\hline Health & 5 & 74 & 96 & 88 & 94 & 92 & 79 & 56 & 20 & 7 & 611 \\
\hline Hotels \& Restaurants & 70 & 277 & 309 & 234 & 169 & 106 & 65 & 43 & 18 & 9 & 1,300 \\
\hline Manufacturing - Food Products and Beverages & 20 & 76 & 92 & 71 & 58 & 37 & 31 & 16 & 11 & 5 & 417 \\
\hline Manufacturing - Textiles and Clothing & 2 & 7 & 10 & 16 & 16 & 16 & 7 & 10 & 3 & & 87 \\
\hline Manufacturing - Wood and Wood Products & 6 & 30 & 28 & 20 & 20 & 11 & 12 & 3 & & 1 & 131 \\
\hline Manufacturing -Basic Metals and Fabricated metal products & & 1 & 2 & 1 & & & & & & & 4 \\
\hline $\begin{array}{l}\text { Manufacturing -Chemicals and Chemical products (rubber, plastic, } \\
\text { glass) }\end{array}$ & 1 & 1 & 6 & 5 & 8 & 2 & 4 & & 1 & & 28 \\
\hline Manufacturing -other & 11 & 25 & 21 & 16 & 13 & 13 & 6 & 4 & 2 & 4 & 115 \\
\hline Mining & & 1 & & 1 & 1 & & & & & & 3 \\
\hline Other Business services & 6 & 37 & 69 & 67 & 44 & 33 & 14 & 10 & 6 & & 286 \\
\hline Private households with Employed Persons & 193 & 300 & 329 & 285 & 285 & 196 & 161 & 76 & 66 & 18 & 1,909 \\
\hline Publishing and Printing & 2 & 7 & 4 & 5 & 3 & 2 & 2 & & & & 25 \\
\hline Real Estate & & 6 & 3 & 4 & 1 & 5 & & 1 & 3 & 3 & 26 \\
\hline Renting of Machinery and Equipment & 1 & 6 & 1 & 3 & 4 & 3 & & & & 1 & 19 \\
\hline Transport and Communication & 38 & 196 & 265 & 270 & 266 & 212 & 169 & 94 & 45 & 16 & 1,571 \\
\hline Wholesale \& Retail & 220 & 562 & 503 & 458 & 365 & 240 & 197 & 111 & 75 & 39 & 2,770 \\
\hline Not stated & 8,822 & 9,125 & 8,344 & 7,145 & 6,142 & 4,884 & 4,400 & 3,633 & 3,014 & 2,216 & 57,725 \\
\hline Total employment & & & & & & & & & & & 75,110 \\
\hline
\end{tabular}

Table 2.4: Employment by Industry and age group, 15 - 64, 1999 
Development of ICT: Regional and National

Robert Whelan (2007a) of the Pacific Learning Observatory at USP, Laucala campus recommends that regional plans for development of ICTS need to include ICT training, development of local expertise, and increased community involvement in establishing ICT in schools. Regionally, Whelan (2007a) says, there should be development of local content that builds on authentic values, customs and local culture.

Pacific Island countries have been very active since the early 2000s in meeting to set priorities and strategies for technical infrastructure of ICTs in the region, though this is largely overseen by Australia and New Zealand. Among the factors considered important are establishing infrastructure, improved access, developing government policy, developing local human resources and making local communities aware of the importance of ICT development and how they can benefit from it, in other words, working to develop a culture of ICT. (Harris pers. comm. 2008). Regional countries benefit from this approach by sharing ideas and resources and will likely help them to reduce costs by introducing more and better infrastructure. However, in practice, this does nothing for local labour as it brings expertise from developed neighbours.

Initiative 2.2 of the Pacific Plan to implement a digital strategy for the region is an attempt to bridge the divide in ICT availability and use in the Pacific between island countries and the rest of the world as well as local urban and rural areas (PIFS 2005a). The Pacific Plan Digital Strategy was approved by the Pacific Islands forum Leaders in October 2005 (PIFS 2005b). This strategy is guided by the Plan of Action of the World Summit on the Information Society (WSIS). Vanuatu's first ICT policy is in draft stage and only recently a draft of a new Telecommunications and Radio Communications Act has been circulated for comment (VIGNET 2008). Local ICT groups are actively involving themselves in the process (VIGNET 2009). An e-Government policy is also presently being developed (Shing, pers. comm. 2008), in line with the Pacific Plan's Digital Strategy (PIFS 2005b), to implement e-government in the region. Government involvement in setting a strategic framework for ICT has been considered a necessity for ensuring more sustainable development. Whelan's (2007b)Vanuatu- 
specific investigation for development of ICTS recommends more training provision and ICT skill development opportunities for Ni-Vanuatu specifically. The government's strategic framework will assist in obtaining technical assistance required to build technical capacities; to develop, accredit and monitor staff training and development to build institutional capacity; and to begin to provide an ICTinclusive curriculum in education (WSIS 2004).

Meanwhile, Vanuatu's civil society organisations are focussing on outreach of ICTs into remote areas of the islands. One example is the Vanuatu Rural Development and Training Centres Association (VRDTCA), awaiting funding from UNDP to implement wireless access similar to the Solomon Islands-inspired Pipol Fastaem (PFNet) wireless project. Once access is available, several centres throughout the provinces will be set up with internet access points run by trained support people (Nako 2007).

Local and regional ICT culture

To support a regional and local ICT culture (ref. Ch 3, p 48), several groups have been set up by local ICT professionals and interested parties. The Pacific Islands Chapter of the Internet Society ${ }^{1}$ (PICISOC: www.picisoc.org) covers 22 Pacific Island countries with a membership of more than 300 throughout the region. PICISOC holds a yearly meeting called PacINET. PICISOC's brief is to focus on local issues and developments for the countries involved and to advise governments of relevant issues.

Vanuatu's VIGNET forum, an online discussion group, originated from the Vanuatu Internet Users Society (VITUS) which has been active since the early 2000s. A group of an estimated 150 ICT technical people who work or are involved in the industry are involved in this (Shing 2007a; Nirua 2007; Mujee 2007).

\section{ICT in Vanuatu's public domain}

ICT services have already successfully been implemented in public and private areas in the main centres in Vanuatu. Applications of Management Information Systems (MIS) for health, customs and education have been implemented with donor funding (Oxfam 2006). 


\section{ICT in Vanuatu's workforce}

According to a 2004 presentation $^{11}$, by sector workforce statistics give some indication of the application of ICTs so far in Vanuatu. 30\% of employees are in the public sector (4000 government employees) and $70 \%$ are in the private sector (11,000 non-government employees). Estimates of ICT users show that $18 \%$ of government employees have access to email, 3\% have internet access and 5\% of non-governmental employees have email and internet (WSIS 2004).

\section{ICT in Education}

A February 2005 workshop at USP in Suva met for the purpose of reviewing the regional situation of ICT in education. They discussed approaches of implementing and enhancing ICT in schools and how to get regional Education Ministries to introduce compulsory Computing Science (CS) and Information Technology (IT) courses in schools (USP 2005). Note that these are technical subjects with no holistic end-user focus. Regardless, only three out of the twelve member countries had by this time implemented ICT courses; the others viewed the first priority to be English literacy; the three are Cook Islands, Niue and Tonga (ibid.).

Vanuatu has made modest progress in educational ICT; progress made is attributed to motivated individuals and schools. Out of Vanuatu's 77 secondary schools, very few offer computer training (Whelan, 2007a). Many secondary schools use computers for administration but not for teaching. Among the issues concerning the lack of implementation of ICTs in schools are those discussed previously concerning Pacific-wide implementation (ref. p 28-29).

Lack of ICT expertise and training in schools presents significant challenges to opportunities for Ni-Vanuatu ${ }^{12}$. Whelan notes there are no formal programmes in place for schools and limited development of ICT in education. Most teachers are trained at Vanuatu Institute of Teacher Education (VITE), which has not developed its own ICT training facilities, instead they use the Human Resources Development Unit (HRD) for training its teachers-in-training (details about HRD are presented in

\footnotetext{
${ }^{11}$ presentation at the WSIS preparation for the 2nd phase of the sub-regional symposium on ICT for development in Pacific island developing countries in Suva, 6-9 December 2004

${ }^{12}$ ref. Ni-Vanuatu, p 13
} 
the next section). They are taught to use computers for their course preparation and administration. Using computers to teach is an untapped area.

At government policy levels, the 1999 Education Master Plan specified that there would be a new 'holistic' ICT in education program developed rather than simply technical courses. With no national ICT policy or budget available yet, this is awaiting further development (Whelan, 2007a).

\section{ICT Training / Professional development}

Major institutions in Port Vila offering regular end-user computing training are USP's Emalus campus, VIT and Edward's Computer Foundation (ECF) run through Computer Network Services (CNS), a Ni-Vanuatu-owned private business. The government training service, HRD, established under the Public Services Commission, addresses human resources issues through a Human Resource Development Plan (Republic of Vanuatu 2000) and this includes end-user computer training. It is available mainly for government departments but also serves civil society.

USP's DFL runs general MS Office training courses. In the past filling the trainer role has been a problem; the present instructor is a volunteer from Japan's International Cooperation Agency (JICA). VIT has used technical assistance (TA) from Australia, the TA having trained local end-user trainers using the International Computer Driver's License (ICDL) materials and standards of measure. Besides short courses, they also offer diploma and degree courses in technical ICT. In its business studies area VIT boasts a new wing which started offering ICT technical and end-user training in early 2008 (Moon 2007). ECF runs short courses in computer software, diploma and degree courses in software and hardware. They use expatriate and local trainers, the present expatriate trainer being the training manager. HRD have a local trainer who is being further trained with assistance from Japan. They have had Japanese volunteers undertaking on-site end-user training up until recently.

Now that ICT has become a priority in the region, training regulation has become a necessity. The Vanuatu National Training Council (VNTC) was established 18 October 1999 by Act of Parliament, Act 13 (Republic of Vanuatu 1999). Its purpose is to promote and co-ordinate effective vocational education and training, 
to accredit and monitor training programmes, register course providers and to ensure relevance and inclusion in training. Part of their plan is to determine market needs for training through research, striving to include local industry in information gathering (Lambukly 2007).

A Vanuatu Qualifications Framework (VQF) exists for defining nationally recognised qualifications for technical and vocational education and training and a Vanuatu Quality Training Standard (VQTS) defines criteria and standards for training organisations and for accrediting courses in vocational education and training (Republic of Vanuatu 1999).

\section{Conclusion}

It is possible to see the effects today of many aspects of Vanuatu's historical experience as a colony of dual, conflicting powers in an artificially amalgamated region called Melanesia. The puzzle created by this unique situation is exemplified in the kaleidoscope of cultural life in Vanuatu, in the vast collection of languages used in villages around the archipelago and the three languages used in education and national expression. Ripablik, Republic or République: which is the true local worldview? Sometimes it is not easy to identify.

In nearly three decades since Independence and with a continued dependence on foreign aid, will the next two decades offer any greater advance toward true independence? Will the increasing reliance on ICT only create more dependence? In the time since Independence many more local people have attained higher levels of education and have increased their capability and the desire to make decisions and influence systems formerly handled by foreigners. One stumbling block today is not local capabilities as much as the lingering influence of foreign power. Often with foreign aid comes the justification of aid compliance and avoidance of recognising and respecting the ideas and ways of doing things in developing country contexts. An attitude of 'ownership' still pervades, with foreigners living in Vanuatu overriding local endeavour with foreign-planned projects and systems.

The colonial fallout of having had a unique dual-system administration imposed on them for 74 years, after three hundred years of contact and forms of conquest from these colonial powers, means there is still the tug-of-war over languages and administrative systems. Vanuatu's political parties are even today based on an 
Anglophone/ Francophone divide, while their own common language is often neglected although it is a strong unifying factor, as language can be. With this tugof-war as well as other issues, breaking open opportunities for locally-influenced decisions is vital to Ni-Vanuatu. Their desire to be involved in research that supports local voices for local choices is an ongoing theme as it has been an ongoing theme in $\mathrm{Ni}-\mathrm{Vanuatu}$ history if the the colonial prism is removed.

$\mathrm{Ni}-$ Vanuatu spirit shows strength of purpose and adherence to local ideals, as when they fought for and gained independence from the joint Condominium. This spirit today is confirmed by their celebration of kastom and relationships and by their willingness and ability to consider and adopt technologies and practices that help support their economic and social independence. The local people's desire for involvement in research is evident in publications that were the fruit their activities as well as in the country's research policy (ref. policy, p 63). It is this local spirit: the desire, willingness and ability that this thesis attempts to reflect on and to advocate; to illuminate the view from the third perspective of the prism.

Focussing on a question of end-user computing training through a participatory process, contextual factors that are relevant to this research include the issues of differing perceptions and questions of identity that have effected a quiet acceptance of others' ways. Imposed systems of language and education are still in practice but there are ever-increasing efforts toward more localised systems. The imposed and existing systems of power in both the administrative and social systems are challenged in this research activity through awareness raising and action of trainees regarding their computing training. Issues such as the often harsh geography and climate influence present day choices and plans for implementation and expansion of the technology they wish to be trained in. Desire for this technology exists in this setting by the local people, both for its communications possibilities and educational opportunities.

A paradox of the triangular prism: on the one hand, Ni-Vanuatu have had an obscured vision of their country but on the other, there is the allure of the rainbow, of possibilities that come from the same thing that can obscure the vision. There is the need for attracting foreign investment to boost economic growth and broaden employment opportunities, the rainbow. But often foreigners come with their own vision of what status they should assume in Vanuatu, the obscured vision. Foreign 
aid assists in developing programmes in health and education but often the aid is limited by or tied to the donors and, therefore, systems are put in place that do not fulfil what the locals want for themselves. How can there be one without the other? Participation in planning and decision making might be part of a new rainbow and is a question posed in this thesis.

In the next chapter, a base of literature that has relevance to this thesis is presented. It is grounded in development research relating to the place of ICT in developing countries, education and training. The importance of ICT is established as justification for this interest. 


\section{CHAPTER 3: Leaning ladders against existing literature}

Literature examined in this chapter emphasises both the research question pursued and the approach taken within development studies. It includes reasoning behind the significance of ICT in developing contexts, that being the shift in the economic base of society. The social shaping of technology is linked to training, which is at the core of this research. Training is seen as a form of education and training methods of end-user computing training are considered. Methodology used to explore the research question is introduced, leading to Chapter four which gives more detail about the theoretical perspective and methodological approach taken to pursue the question.

\section{AN ALTERnATIVE PERSPECTIVE}

This research is situated within development studies, with an emphasis on practical development supported by theory. The term development carries connotations of growth, progress, and change from a state of 'undeveloped'. With over 50 years of practical and academic development pursuits, it could be said to have not achieved much of value for developing countries because of its slant toward economic growth and modernisation (Hettne 1990). Recent academic incarnations of development paradigms challenge the apparent development stalemate. These are post-development, a rejection of development in its present form (Sachs 1992), and alternative development, which believes in but attempts to redefine, development (Pieterse 2000:181). They share a critical view of development (Kothari and Minogue 2002) and a focus on privileging unprivileged people (Pieterse 2000:181; Escobar 1992).

When we think of the impacts of development on individuals in developing countries rather than on the countries themselves, it can be said that '[d]evelopment can be imagined as a blast of wind that blows people off their feet, out of their familiar space, and places them on an artificial platform, a new structure of living' (Illich 1992:96). One goal of this research is to focus on individuals in a developing context, to expose them to a different place in a 
process of development that affects them now and will more so in the future, to keep them from being blown off their feet.

To indicate where this research is situated in the development debate it is important to define what development means in this application. Development is seen as an ongoing process that includes people that the methods and outcomes affect the most. It is the actual process, and not an end result, of this activity and it touches individuals personally. Through this, social development is the hopedfor, ongoing outcome. The outcomes are defined and facilitated by ordinary people as participants of the process.

This research is located in the alternative development paradigm. Alternative development recognises a need for human, non-material growth as opposed to earlier models' economic growth focus (Brohman 1996:201). It is a deliberate effort to make an improvement to individuals for their social growth and wellbeing. Nurturing development from within, from the bottom up, is believed to produce more sustainable processes. Inspired by Paulo Freire (Rahman 1993:5), whose work in education focussed on the rise of critical consciousness in marginalised people (Freire 1970), alternative development aims to improve the lives of those who participate in the research and thereby to transform societal structures and relationships (Maguire 1987:3).

The alternative theory of development is not an alternative to development (Pieterse 2000) as put forth in post-development discourse but instead seeks alternatives to the ways development has been practiced. Rather than development by plans and projects, tick lists and impacts that are generated externally (Escobar 1992), the alternative is to listen rather than tell, to follow rather than lead (Chambers 1997), to be people-oriented rather than task-oriented. Most importantly it seeks participation of those affected by changes triggered by 'development' and to locate an alternative way of involving people who are not normally included in development activities.

\section{Participation}

The specific approach taken within alternative development is participatory, also known as the 'popular' (Brohman 1996) or 'people-centred' (Kothari and Minogue 2002) approach. It attempts to assist in influencing more natural 
equitable change through participation. It is clear to see participation's place within the alternative paradigm in that they both view processes and people as central concerns.

Participation involves a development practitioner or researcher becoming a member of, and contributor to, a group that allows the group to determine what ends may be achieved. Using this approach an outside catalyst attempts to initiate awareness-raising, questioning and analysing previously unquestioned issues (Maiava 2001:17-18). Local individuals come to recognise the value of their knowledge and, through acts of increasing agency (described below), gain a central place in their own development. At first there may remain an imbalance in power in the participatory process but this can be altered if power is truly shared and passed on (Chambers 2005). In this way, instead of seeing development as an economic pursuit, it is seen as social development, extending power to people to make choices for themselves and create locally-driven change that may or may not be economic.

Brohman (1996:252-253) notes the distinction between participation that is a means to an end (outcomes) or that is a means to improving the quality and relevance of projects (processes). He suggests that for there to be 'authentic' participation that leads to empowerment there needs to be participation at the outset of decision-making. Participation like this is new to most of the people involved. The development industry is filled with people who are used to 'doing' and not 'working with', and people in developing countries used to having things done for them and not being invited to contribute during any, or all, stages of the process but who are expected to support the changes in the long term. In 'pseudo' participation a development objective is sought with participation only at implementation and maintenance levels (Brohman 1996). This is a form of coopting, when development practitioners or researchers in the participatory process have an agenda and use participation as a token activity only to achieve their desired end (Kothari and Minogue 2002; Hickey and Mohan 2004).

A model for participation is Freire's (1970) concept of the changing of a teacherstudent relationship from a giver-receiver role to one of shared cognition, or joint reflection. This participation is a model for education and also for development (Chambers 1997:106). 
The research that supports this thesis attempted authentic participation by not only including participation at the planning level, but also by including stakeholders who are normally not considered for participation, the young receivers of training programmes. Focus group members acted the part of fellow researchers in a collaborative process. Activity led to reflection by the participants about that activity. This was where the local knowledge was to be found.

\section{Empowerment, agency, and transformation}

Three key elements in a participatory approach in alternative development are agency, empowerment and transformation. If transformation is the goal, both empowerment and agency need to be established and sustained for transformation to occur.

Empowerment is still very much 'on the table' in development debate, from Chambers questioning whether there is meaning left in the word (Chambers 2006) to Rahnema (1992:122-123) who discusses 'the notion of empowerment' in the past tense, as if it has 'passed on' from development practice. Rowland suggests that empowerment is a process whose core is 'self-confidence and self-esteem, a sense of agency, of 'self' and of dignidad', or being worthy of and having a right to respect from others (1997:130). Freire (1970:27) suggests empowering by developing critical consciousness, or 'conscientization' in people who are normally at the receiving end of decisions. He explains that a state of awareness where participants see that their situation is limited, not failed, leads to an altered perception of the reality of a situation and if this is achieved, participants can become objective about it and are more likely to see the possibility of transforming the situation (1970:66).

The form of empowerment attempted in this research was to stir consciousness of the impact training services that are designed for trainees have on their lives and to raise their awareness of the different part they could play in defining these services. An early choice made was in considering the participants to be fellow researchers, to encourage realisation that researching is not just something elites do. By analysing training options, materials, facilities and methodologies, there was a possibility of heightened awareness of the planning and the choices that are 
behind these services. And from this the desire was nurtured for them to have input into the planning processes and to be an integral part of the whole process. Agency is the ability of people to act and inform social change that is desired to assist in a growth toward equity in social, economic and political life (Thomas and Allen 2000:189; Chambers 2005). It is often seen in the sense of political agency (Hickey and Mohan 2004). Critics of participation have pinpointed that there has been little focus on power relationships and on working toward a more political level of influence where actual empowerment and transformation are more likely to occur (Hickey and Mohan 2004; Brohman 1996:218-19).

In this research agency is treated as a quality that gives people who are normally at the receiving end of development the capability to have input into social or market level factors that affect them (Kothari and Minogue 2002; Friedmann 1992; Alsop et al. 2006). While the political level is not an intended outcome in this research Friedmann (1992:32) suggests that often there is a sequence of empowerments that leads to political empowerment, so this could be an unintended consequence. For this to happen it is likely there would need to be repeated attempts and gradual increases of empowerment and agency for it to be sustainable.

Transformation is a higher-level outcome of agency and empowerment. Kabeer (2005) focuses on the importance of what sort of agency is gained in order for true transformation to occur. These different forms of agency are related to the inequalities institutions can perpetuate. These are effective, where the outcome desired is greater efficiency in carrying out roles; or transformative, where there is a change in the actual roles performed by people (Kabeer 2005:15) ${ }^{13}$. ransformative agency would have the greatest impact in getting more local input into development and therefore support sustainability.

In this research, rather than simply increasing the young trainees' competency, which likely will make them more efficient, their role in training programmes

\footnotetext{
${ }^{13}$ An example of effective or transformative agency is the new quota for women in Parliament in Afghanistan's 2004 Constitution. At least a quarter of elected posts are set aside for women. While they have the legal right to vie for these seats and be more effective in local politics, which is effective agency, the cultural institution is such that men feel they cannot be ruled by women so will not grant these women in Parliament any power or voice. If there was cultural acceptance the new quotas would be a transformation of agency (Baker 2005; Dahlerup and Nordlund 2004).
} 
should be transformed by offering them a greater part in defining and planning training. This would extend their capabilities and could make training programmes more locally relevant.

\section{Opportunity structure}

Formal and informal institutions act as either a support or constraint to transformative agency and influence the behaviour of people in their living and working environments (Chambers 1997:221; Alsop et al. 2006). Alsop terms these opportunity structures. There is a formal structure that may appear to grant agency but an informal structure (eg. cultural factors) that may be so powerful that agency is effectively blocked (Alsop et al. 2006:15). 'Institutional transformation requires movement along a number of fronts: from individual to collective agency, from private negotiations to public actions, and from the informal sphere to the formal arenas of struggle where power is legitimately exercised' (Kabeer 2005:16).

In Vanuatu the research was aimed at the individual, private and informal levels, considering the process to be similar to constructing and climbing a ladder. This analogy is inspired by Chambers' (2005:105) ladders of citizen participation. The ladder is built of local materials and is rough hewn. The rung spacing is measured by the local people's step, not the researcher's. It is thought that a gradual building of the ladder and then stepping up the rungs at their chosen speed may lead to a realisation of collective power through working in groups. These young people may be more likely to continue from private to public action in more formal arenas as they gain experience in the process and increase their personal confidence. This is more likely to be a result of repeated, gradual successes where they become more self-mobilised (Chambers 2005:105). What is important is a continued focus on the 'ladder building' as a collective construction done at a speed of their choosing.

\section{STEPPING UP TO THE NEW ECONOMY}

In the past, development has carried an intention to assist less developed countries to shift from an agrarian economy toward industrialisation. Now, it is said, there is a new shift in economic base, from secondary industry to information as the basis of wealth. It is generally accepted that this shift has occurred, at least in 
some places, and that we have entered a new knowledge-centred economy. Different ways of referring to this new age essentially have the same end result: the base economy has changed from being purely industrial to one based on information and knowledge (Martin 1988:36-44).

Information is considered the main method of wealth creation, service rather than production as the main staple of the economy and intellectual creativity is a driving force rather than material consumption (Lyon 1998:6). Daniel Bell (1973) sees the primary resource of this age to be human capital.

Castells (1996:204) proposes that this new age, rather than being based on knowledge production as the new economic structure, is more affected by 'the revolution in information technologies and its diffusion in all spheres of social and economic activity, providing the infrastructure for the formation of a global economy'. However it is also felt that the technology has not determined the change but that it has been determined by a mixture of social and technical changes (ref. SCOT ${ }^{14}$ vs. Schumacher p 49).

\section{Information, knowledge and poverty}

The new economy introduces a new form of poverty into the development mix; that is information poverty, or an imbalance due to lack of information or inadequate information systems (Sein and Harindranathy 2003). Flor (2001) concludes that since the start of the concept of an information society, the relationship of access to information and poverty has been recognised. This new poverty is a central concern of the digital divide debate and is seen to be solved by introducing information technology and communications systems into developing countries so that this new, valuable information can be accessed. Access means resources and opportunities; lack of access means lack of resources, opportunities and, therefore, poverty (Flor 2001).

Yet this introduces the assumption that without ICT developing countries are lean on, or without, information and that only new information is valuable. According to Wilson (2003) this devalues local information and knowledge, which is vital within context rather than outside it (so locally there is no poverty). This also

\footnotetext{
${ }^{14}$ Social construction of technology (ref. p 49-50).
} 
shifts the argument to a form of poverty that it seems can be dealt with, lack of information technologies (ibid.). So, rather than dealing with forms of poverty based on basic needs like food, shelter and education, we now have a form of information-aid that brings in the 'valuable' information from 'out there' (ibid.).

\section{EQUIPPED TO ENTER THE INFORMATION AGE}

ICT is said to be the 'first technology of the third wave', discussing the shift to the information economy (Denning and Dunham 2001:23), the third wave being the information society, as discussed by Alvin Toffler in the book The Third Wave (1980). It is clear that we have become dependent on ICT for our work but it is also both a tool and a channel for communications and a vehicle for our leisure. ICT is becoming the new transport mechanism in the world as a result of increasing oil prices and costs of traditional forms of travel. Electronic 'roadways' are often the affordable alternative to meetings of people in different countries, transporting documents, communicating news, finding a mate, etc. It is so pervasive that it can now be thought of as infrastructure, as 'necessary' to us as electric lighting ${ }^{15}$.

Nicholas Carr (2003) asks the question Does $I T^{16}$ matter?. His argument focuses on ICT as a business strategy. He questions the sort of technology IT is, proprietary or infrastructural, arguing that infrastructural technologies are those whose value increases when they are shared. He claims that if access is restricted from use by others, it can be an advantage to the owner of the technology.

Advantage can also be gained by insights into particular uses of a technology that are not shared. The advantage of private ownership (proprietary technology) dwindles as a new technology becomes more affordable and more widely used and is commoditised and then becomes part of an infrastructure, and that not having the technology becomes a disadvantage. He argues that ICT is an infrastructure technology now, that in transporting digital information it is like any other transport technology and this role makes it much more valuable shared than not. He also explains that as it comes into the infrastructure, many of the practices of its use become standardised and best practices are established.

\footnotetext{
15 this supports Illich's (2005) argument about our changing needs.

${ }^{16}$ IT $=$ ICT
} 
Martin (1988:39) suggests that an important consideration for development of information societies will be a knowledge base. Among Dordick's (1978: 279, cited in Martin 1988) continuum of stages a society must go through towards becoming an information society is the development of a sound information processing environment. This will require human capital, not just equipment. And with innovation as a factor in this information age (Vila 2000:5), it is not the technology that is required to be innovative, but its developers and its users. Technology alone is meaningless without application of it by individuals and societies.

How local training contributes to building the local knowledge base is a reason why ICT is an important discussion point in developing countries ${ }^{17}$. If it is true we have entered the new economy, ICT is a useful tool; if it is not true, the world is behaving as if it is so it is still a useful tool.

\section{ICT's role in development}

ICT is a hot topic in developing contexts, commonly seen as the new technology that will make 'the difference'. This transformation has happened in just over a decade, noted by the ever-increasing number of hits obtained by an online search of the acronym ICT4D (Information and Communications Technology for Development). But ICT is only one variable in development and it is not an independent variable. It relies on many different factors to be truly capable of making any difference. As Raiti (2007:1) says, quite rightly, ICT is not the solution for development but just part of the puzzle.

Development organisations' reports hail ICT as an urgent matter for developing countries, for them to make the 'leap' to adopt ICT or to be 'left behind'. Wilson (2003:1) identifies, in the ICT4D discourse of seven main international organisations, the prevalent attitude being a need for the 'information poor' to 'catch up' to the technology, saying this underlies a 'binary opposition' of developed and underdeveloped and it reeks of modernisation. She also stresses the limitations of having access if people are not able to use the technology or understand the information it delivers.

\footnotetext{
${ }^{17}$ ICT stands out because, as Lyon (1998:2) says, it is the first technology with so much impact that it requires a strategy.
} 
Academic literature tends to be critical of this 'rush' mentality and promotes analysis of specific situations, of recognising relationships between multidisciplinary fields and ICT and it seeks to ensure that there is a sound theoretical basis in future literature (Heeks 2007; Raiti 2007; Chacko 2005). A problem with playing 'catch-up' is that the external target keeps moving, and it moves fast. It seems wiser to do a specific context analysis, as academic literature suggests, and to set targets specific to local context rather than to that of an external moving target. An important additional question is, who does the analysis? It would be wise if this was done by local initiative and local input rather than external forces. Local people know their puzzle pieces better than outsiders.

\section{Issues of ICT in development}

Economic and social subjects of ICT literature include various issues, five of which are shown in Table 3.1 (next page). In this thesis the main concern is for the successful adoption of ICT in Vanuatu and the question of whether technologies should be leapfrogged ${ }^{18}$. However, all ICT issues have implications for this research as appropriate training can influence and be influenced by all. The digital divide is a backdrop to the activity in developing countries for implementing and training in ICT. It seems this is the reason why implementation has gone ahead to the degree it has without proper study to assess needs. Diffusion of ICT is not directly relevant to this thesis, however teledensity statistics are given in Chpt 2 (ref. p 26-27) to get an idea of how ICT is growing in Vanuatu. The issue of adoption supports the need for education and experience, which is said to be at the heart of the successful adoption of ICT (Wozniak 1987). ICT culture is thought to be a requirement for sustainable adoption of ICT. The issue of leapfrogging is not only about leapfrogging from one level to state of the art technology but also about leapfrogging stages of development from agrarian economies to information (Adeya 2002). Leapfrogging will leave gaps in the ICT knowledge base and without resources such as textbooks and appropriate training

\footnotetext{
${ }^{18}$ which works as modernisation
} 
the gap of locals lacking historical knowledge of systems will remain

(Steinmueller 2001).

\section{Digital divide}

Defined: uneven diffusion of ICT between and through countries

Factors: seen as a gap in ICT between developed and developing countries, this gap creating inequalities

Related issues: The mentality that the gap is a deficit makes countries and individuals feel they have to rush into implementing ICT and thus they may make hasty decisions based on established use of the technology elsewhere. The established use may not be what is needed in the new location.

\section{Diffusion}

Defined: The spread of ICT between and through countries

Factors: Teledensity is used to measure this, with mobile phone technology as a standard.

There is uneven diffusion between centres and the periphery in developed as well as developing countries.

Related issues: Measuring mobile phones for spread can be misleading as many features of the technology are not used by the average user. Even in developed countries, most use mobile technology for telephony only, not as PDA (personal digital assistant) or for remote computer connections

\section{Adoption}

Defined: 'implementation of an innovation during the earliest stages of diffusion' (Wozniak 1987:102).

Factors: The appeal for adoption of technology happens at an individual level so that the individual must see why it is useful. He/she must see increased social benefits - how it will improve their quality of life.

Availability and an attitude towards its ability to meet needs and user-friendliness speed its adoption. Perhaps it can be seen as coming to depend on the technology but primarily it is seen as accepting its use.

New technology once adopted can often replace an older technology (e.g. mobile telephony replacing analogue, computers replacing televisions, forks replacing fingers)

Related issues: It requires a level of education and experience to use the technology for successful adoption.

There is often a confusion of adopting or adapting confusing adaptation with having to adapt to the technology rather than innovatively adapting the technology to the needs.

\section{ICT culture}

Defined: ICT culture can form when there is the acceptance of the need for the technology. In organisations, once the use of ICT technology becomes so counted on that losing it would be disruptive, there can be said to be a culture of ICT. The culture will form around a growing need as it becomes part of the infrastructure.

Whether an individual has joined the ICT culture or not is understood to be how they deal with the technology, whether their attitude is one of acceptance of it in their life and work or not.

Factors: ICT culture is related to the maturity level of ICT in an organisation or country. The culture can form once there is good diffusion and adoption of technology. The existence of government support, through a national policy and budget is important as then a strategy is able to be implemented.

Related issues: Culture may form in the people before the country is ready, therefore a lack of infrastructure and policy frustrates locals who have accepted ICT as something they want and need.

The emergence of an ICT culture is closely related to adoption of technology but has more to do with mindset. Factors that support an emerging ICT culture include the capability and opportunity to use ICT, also known as usability and utility. With this culture there is the problem of a new class forming, that of the 'technocrat' and those with technical knowhow controlling the technology. This has changed the status systems in these countries so that their traditional ways of achieving status are now compared to those with education and found lacking.(the 'technocrat' in Vanuatu is still largely an expatriate).

\section{Leapfrogging}

Defined: Implementing the very latest technology in developing countries rather than a gradual phasing in and phasing up to state of the art technologies.

Factors: Uses an imitative process, like that of modernisation, to apply ICTs to developing countries. Steinmueller (2001) writes of a need for absorptive capacity in leapfrogging, suggesting there must be the existence of background information such as texts to fill the knowledge base gap that leapfrogging involves

Related issues: Leapfrogging implies there is one solution. In the leapfrogging process the qualities of ICT use in developed countries are simply transferred to developing countries, regardless of contextual differences.

Raiti (2006) notes a problem with leapfrogging being that it is a large move all at once and the steps that are missed from letting a technology emerge are ones that actually assist local adoption.

Some things, such as the less 'negotiable' high-level technical and standard configurations, can be leapfrogged but when you get to user level, leapfrogging assumes an understanding of the foundation of the technology that may not exist if it is missed in leapfrogging.

Table 3.1: Issues of ICT for developing countries 2000; Wijkman and Afifi 2002; Steinmueller 2001; Adam and Urquhart 2007; Raiti 2007; Pierson 2004; Heres 2004 


\section{TECHNOLOGY: DETERMINED OR CONSTRUCTED?}

ICT is a technology and technologies are often introduced to developing countries after they have been used in developed countries for some time. It has long been assumed that when any new technology is introduced it has the power to change our lives. This is known as technical determinism (Oudshoorn and Pinch 2003; Lyon 1998). Technology is seen as having impact on culture and society and perhaps this is more so in developing countries. That impact is usually seen as negative, inhuman change. An opposing view is that technology is a tool of culture and society and is socially constructed to fit our needs. This social construction of technology (SCOT) (Bijker et al. 1989) underlies the importance of considering computer skills training in such depth because if we are aware of the choices we have and are knowledgeable about the technology, we are more likely to be able to alter whatever course the technology may be said to be taking.

\section{SCOT vs. Schumacher}

Technical determinism has a related concept, that of technology's inevitable trajectory (MacKenzie and Wajcman 1985). Determinism claims technology is constructed outside of and has the power to effect change on societies; trajectory is seen as an inevitable path that a technology will follow (MacKenzie and Wajcman 1985, based on 1920s writings of Ogburn and Thomas). Inevitable trajectory has been refuted. MacKenzie and Wajcman 1985, citing Dosi 1982) described two separate applications of a base technology that was thought to have only one purpose. The actual applications were different from each other as well as from the base technology. Although inevitable trajectory has been refuted, I feel it can still be seen in our mental models of technology.

Determinism is supported by Ernst Schumacher (1973:138) who argues that technology has its own laws and principles and that these are different from the laws of human nature. He claims that human beings and the natural world have self-limiting, self regulating, self-cleansing qualities that make it impossible to destroy what is natural. Schumacher asserts that technology is the cause of the world's sickness; that 'human nature knows where and when to stop'.

The Social Construction of Technology (SCOT) grew out of a meeting in the early 1980s of scholars from the sociologies of science and technology and the history of 
technology (Bijker et al. 1989). SCOT involves people working within 'technological frames', the frame being an attribute that gives different meanings to the technology than that for which it was originally designed. Consider 'technological frames' as scope; there can be a broader or narrower scope for use of a certain technology at different times and in different places. As an example of this, Gottschalk and Khandelwal (2002) have compared levels of ICT growth, or ICT maturity, in various developed countries and found significant differences to their local and international managerial needs. They find differing facets of ICT between countries.

Technology is made and mastered by humans. If we focus on how we choose and use our technology we must have knowledge of ourselves and our technologies in order to know how we influence them rather than simply accepting its inevitable trajectory. We must be capable of using it to the point of challenging its use. It is not only that we accept that it is possible to socially construct technologies, but also how important it is that we actively do so, especially in the context of development. 'As it is more difficult to change [the person], the fastest way to stimulate adoption is to adapt the product' (Heres et al. 2004:44).

\section{The construction crew}

It is not just designers and technicians, but also to a great extent the end-users of technology who affect its potential. Literature reflects the increasing focus on user input in designing, constructing, giving technology a meaning and in changing or expanding a technology's intended use A clear example of this user focus is Oudshoorn and Pinch's How Users Matter (2003) which looks at the adoption or rejection of technologies by users and non-users, advocates who define and represent users and the different stages where users are defined in developing a technology.

\section{PREPARING FUTURE SOCIAL CONSTRUCTIONISTS FOR THE INFORMATION AGE}

This thesis has considered the possibility of having entered a new economic age. There has been an introduction to ICT and a view from a wider perspective of it being a technology that may not have the power to harm us. The development stance has been identified and tied in with the participatory approach that was used. 
Now the role of education and training is considered from the perspective of shifting the power of technology into the hands of people who have normally been at the receiving end of development, technology and education.

If the basis, or 'first profession', of the information age is ICT (Denning and Dunham 2001) it seems clear that having quality training in ICT is now more desirable than ever in order to gain the ability to use and adapt the technologies to what is needed. The rapid growth of ICT requires and provides an adjustment to the delivery of training and with this, a need for different kinds of skills and mindsets. It involves different processes and outcomes to be developed for education and training. It is also more important than ever to consider learning as a lifelong process rather than something that we do for a limited time.

\section{What is education?}

The process of education is thought to enhance our lives socially and economically. In its pure state, it is considered a medium for transmitting attitudes, values and beliefs along with knowledge and skills (Schumacher 1973; Desjardins 2008). It is considered a human right (UN 1948) and so important that the goal is to make its delivery universal, at least at basic levels (Bowden 2002).

\section{Education in development: economic or social?}

Education in the context of the Millennium Development Goals (MDGs) focuses entirely on primary education, its intent to improve literacy rates in developing countries. The benefits of education in general are reasons why it is considered so important to people in developing countries throughout the world.

There is evidence to show that a primary education increases production and therefore economic growth (Bowden 2002; Vila 2005:3; Psacharopoulos 1988) and it is also said to increase employment and decrease the instances of unemployment (Vila 2005:3). It is known to be a factor that influences better health, sanitation, birth rates and infant mortality and is thought to increase the likelihood of participation in community work, which is considered to contribute to better governance (Bowden 2002:405; Psacharopoulos 1988). Economists believe it is linked to economic growth through innovation and productivity, providing comparative advantage and that this increased productivity increases income which 
enhances people's well-being (Vila 2000:22). Benefits are seen to be the growth of human capacity, for the most part reflected in literacy and economic productivity rates (Psacharopoulos 1988). It is suggested that human capital promotes growth opportunities and that it does this better in countries already using technologies, or already 'inside the technological frontier' (Lange and Topel 2006:466-467).

The debate between education's economic or social benefits brings up well-being and tries to define it. The question is, does well-being only exist as a result of an improved economic position? This is not a debate that can be presented here in full, however, this research attempts to prompt focus group members to reflect on their reasons for training, which may indicate preferences toward social or economic benefits. This could be a fruitful exercise for aiming training at the benefits most desired in this situation or at least prompting more research into the question.

\section{Imported education}

In developing countries education and training have largely been based on a Western comparative model, derived from set common standards all students are expected to achieve. Applied in this context, knowledge, skills and achievements are defined outside of the context in which the education is delivered (Crossley and Tikly 2004). This degrades the value of local knowledge and emphasises skill sets that may not be as applicable in these different contexts.

Paulo Freire's (1970) work guides approaches to education in development. His ideas on education and literacy introduced 'conscientization' (ref. p 41) through participation and constructivism, inspiring both education and research methods. The educational philosophy constructivism, simply stated, is an active, learnercentred method of constructing knowledge in the learner's context based on prior knowledge and experience (Duffy and Cunningham 1996; Lau 2006). Freire criticised the education system that he termed 'the banking system', or teachers 'filling the empty vessels' of the students with facts and meaningless information, and he set the scene for individuals collaborating in groups to construct knowledge based on their experiences. It is interesting to compare this with Niroa's (2004:27) description of the style of education in Vanuatu as a 'zoo experience'. Students are 'fed' and lose the ability to hunt. Once the student is finished with schooling and 
returns to the village or enters the workforce, 'the domesticated animal needs retraining' to be able to feed him/herself.

\section{Adult education}

Emphasising primary education in the MDGs excludes the benefits of a longer duration of schooling (Vila 2005:3), the contribution of increased education for adults toward poverty reduction (van der Veen and Preece 2005), and raises the question of who it is that teaches the children in developing countries and who their role models are.

Literacy alone is not enough in this global world to make a difference to a country's development. The need for higher level training is needed for the innovation that is said to be a factor for economic growth in the information society (Vila 2005:6). The best way to fight the continued dependence on expatriate labour is to build a strong adult population with human capacity in both academic abilities and practical skills. It will be local adults who can teach local children in a way that is more relevant to their lives and environments.

Looking at developing countries that have benefited from the information age and the opening of markets under globalisation, the things that set them apart from those countries that have not benefited are markets, capital, adapting technology and those that have a system of human resource development (Stewart 1996). The countries that have good human resources, good economic policies and high savings attract foreign investment and technology and ICT helps development (Stewart 1996:327).

\section{Training}

Training is defined as 'systematic instruction and exercise in some art, profession, or occupation, with a view to proficiency in it' (Oxford University Press 1989b:no page). The definition for education is ' $[t]$ he systematic instruction, schooling or training given to the young in preparation for the work of life; by extension, similar instruction or training obtained in adult age' (Oxford University Press 1989a:no page). Training's similarity to education is clear, their difference is the intended outcome, breadth of content and to some extent, delivery methods. For this study, 
we will consider training ${ }^{19}$ a subset of education, based on the same broad theories. It will assume that there could be more application of educational philosophies and practices to training in order to expand its usefulness in the information age, especially regarding pedagogy and methodology.

\section{Vocational education}

Nowadays there is a greater focus on building workplace skills in secondary education rather than leaving that only to training, professional development or vocational education (Desjardins 2008:24). While there is debate whether education should contain more vocational components, especially at the secondary level (UNESCO 2003), it is not as evident in the literature that the reverse is true: that training should, or could, contain a more educational component. I hope to challenge that oversight. Rather than focus on 'just in time' or 'just in case' training, it could be broadened in developing countries to offer opportunities for receiving benefits of a more continuous nature rather than narrow, skills-based vocation. This is especially true where access to higher education is limited.

\section{ICT4D TRAINING}

At the core of this research is the challenge of end-user computing training. What is evident in literature is that continual training has become critical due to the technology's ever-changing nature. Most focus remains on technical training with end-user training assumed to be a simple matter of how to perform functions (Sein et al. 1999).

\section{Learning ICT vs. using ICT to learn}

End-user training can be accomplished to some level in primary and secondary education as it has been done around the world for some time. It is used as a tool of education as well as being taught as a technical discipline. UNESCO/IFIP ${ }^{20}$ have identified four stages as common in ICT development in secondary education. These stages are described in Table 3.2 on the next page. They are supportive of ICT as a tool for wide use, not just a technology to learn and be used by technically-oriented people.

\footnotetext{
${ }^{19}$ also professional development and vocational training 20 International Federation for Information Processing (IFIP)
} 
One of the main faults when ICT is discussed as being included in curriculum is that it is perceived only from the viewpoint of learning about the computers and how they work, i.e. Computer Science and Information Technology. These are technical skills only. The number and variety of industries that employ workers with end-user computer skills points to a greater need for ICT training at user level. ICT technical 'represents a relatively small cohort of the overall workforce' (Trend, 2001). A larger proportion of workers will fit into the retail, health care, sales, transportation and education occupations. Being a user does not require a depth of understanding of how the computer functions. Therefore early exposure to computers should not only be through technical courses.

\begin{tabular}{|ll|}
\hline Emerging & $\begin{array}{l}\text { An exploration of possibilities and consequences, adding ICT in the } \\
\text { curriculum and also in school administration (which normally has been } \\
\text { implemented and helps identify user-training needs for future staffing). }\end{array}$ \\
Applying & $\begin{array}{l}\text { The starting point for increased basic skills and awareness of the uses of ICT } \\
\text { for learning. Teachers use presentation software and prepare electronically } \\
\text { produced handouts. Students access computers through classrooms and } \\
\text { computer labs to prepare assignments. }\end{array}$ \\
Integrating & $\begin{array}{l}\text { There is a change in the practice and productivity of school staff and relevant } \\
\text { materials are accessible on a network. Students access materials and relevant } \\
\text { applications that reflect real activities and they are able to demonstrate their } \\
\text { knowledge in different subject areas with the use of ICT tools, and have a } \\
\text { wider range of tools to choose from. } \\
\text { ICT is used to rethink learning and the organisation. At this point a more } \\
\text { learner-centred focus is at play; collaborative experiences are enhancing } \\
\text { leadership and 'community' skills with group research and production } \\
\text { projects that relate to actual community needs. It is important to have } \\
\text { involvement from the community in this learning environment and this could } \\
\text { be achieved by student-run computing skills lessons to parents and } \\
\text { community members. Funding possibilities are carried out with community } \\
\text { training programmes and linking to actual community projects. }\end{array}$
\end{tabular}

Table 3.2: Four approaches to ICT Development in Schools UNESCO/IFIP n.d.

If computing is introduced at basic educational levels, its best use is across the curriculum, learning to use the technology as a tool to find, process and produce information. The students who are drawn to the more technical levels will emerge from this sort of experience and can pursue the more technical levels once they have been identified, either in higher level electives or post-secondary and vocational training. 


\section{Research about End-user computing (EUC) and end-user training (EUT)}

There is a growing amount of literature on end user computing (EUC) (Sein et al. 1999; Bostrom et al. 1990; Gattiker 1989) at a professional development level in the contexts of small and large organisations but mainly for developed contexts. There is a noticeable lack of information that directly deals with training of any kind in a developing context. Perhaps it is assumed training will be universal and easily transferred. Much literature about ICT4D has to do with implementing ICT in developing countries, how ICT can help alleviate poverty and enhance educational opportunities by delivering courses online from universities in the developed world. This does not touch on the appropriateness or relevance or delivery methods of ICT training to developing countries. This situation of neglect in studying training relevance in developing countries is similar to the methods of education from colonial times having been transplanted in these countries without considering their relevance in the local context.

Established methods of training fail to define appropriate knowledge (Sein et al. 1999). Studies challenge the common directive systems used and promote the need to address changing skill sets and mental modes needed by people to be able to make full use of the technology. Many of the materials used in computer training worldwide are standardised. They are mostly delivered in a prescribed, step-bystep 'how-to' and skills-based way (Sein et al. 1999), using a competence-based approach (Phelps et al. 2005) to teach standard functions of the technology. A broader range of skill sets would be useful, for instance troubleshooting and study skills for the continuous learning that is necessary in the fast-changing environment of ICT (Sein et al. 1999; Denning and Dunham 2001).

Other research sees experience using ICT as contributing toward learning. Some skills and understanding come after doing something enough; Denning and Dunham (2001) call this embodied skill. This builds a knowledge base through experience over time. On a more educational level there are technical studies that identify knowledge-level needs (Sein et al. 1999) and instructional designers consider individual learning styles (Bostrom et al. 1990) for producing alternative 
training materials. While the results of these studies may not be useful applied directly to developing contexts they can be useful to guide future research.

\section{Competence or capability?}

The question of competence or capability has interesting literature attached to it. Criticism of the standard competency method for measuring training draws flak. In computer training it is recognised that there is a need for some competence and understanding in order to be able to communicate with the computer and to draw on the knowledge that is stored in online help systems and throughout the internet. Yet once you have a little competence, a very effective method for increasing your skill is to explore, to play with the machine and the software and to just 'muddle' your way through various problems, which is akin to a capability approach (Davis 1999).

Capability is explained as the confidence of having the ability to apply competencies and take action in familiar, unfamiliar and changing situations (Phelps et al. 2005:68 from Cairns 2000). While competencies are measurable skills, based on agreed standards, capabilities include competencies as well as personal qualities, knowledge and experience in responding to situations with creativity and confidence. 'Adaptability to change and an emphasis on lifelong learning are thus central to capability but are usually conspicuously absent in competency-based initiatives' (Phelps et al. 2005:69).

Training for capability rather than competence alone is illustrated in a 3-year action research by Phelps et al. (2005), which compares competency and capability in computer skills training through a complexity model (Figure 3.1, next page). The illustration shows much broader learning using a capability method. 
Legend

Indicates individual's background and 'initial conditions', including, for example attitudes, values, beliefs and motivation

Indicates external input. External input on the capability continuum involves two-way stimulus

$\longrightarrow$ Indicates potentia/pathways of learning

Indicates potential bifurcation points which increase self-efficacy

Indicates potential bifurcation points which decrease self-efficacy

Reference is made to these particular positions A-J in the text

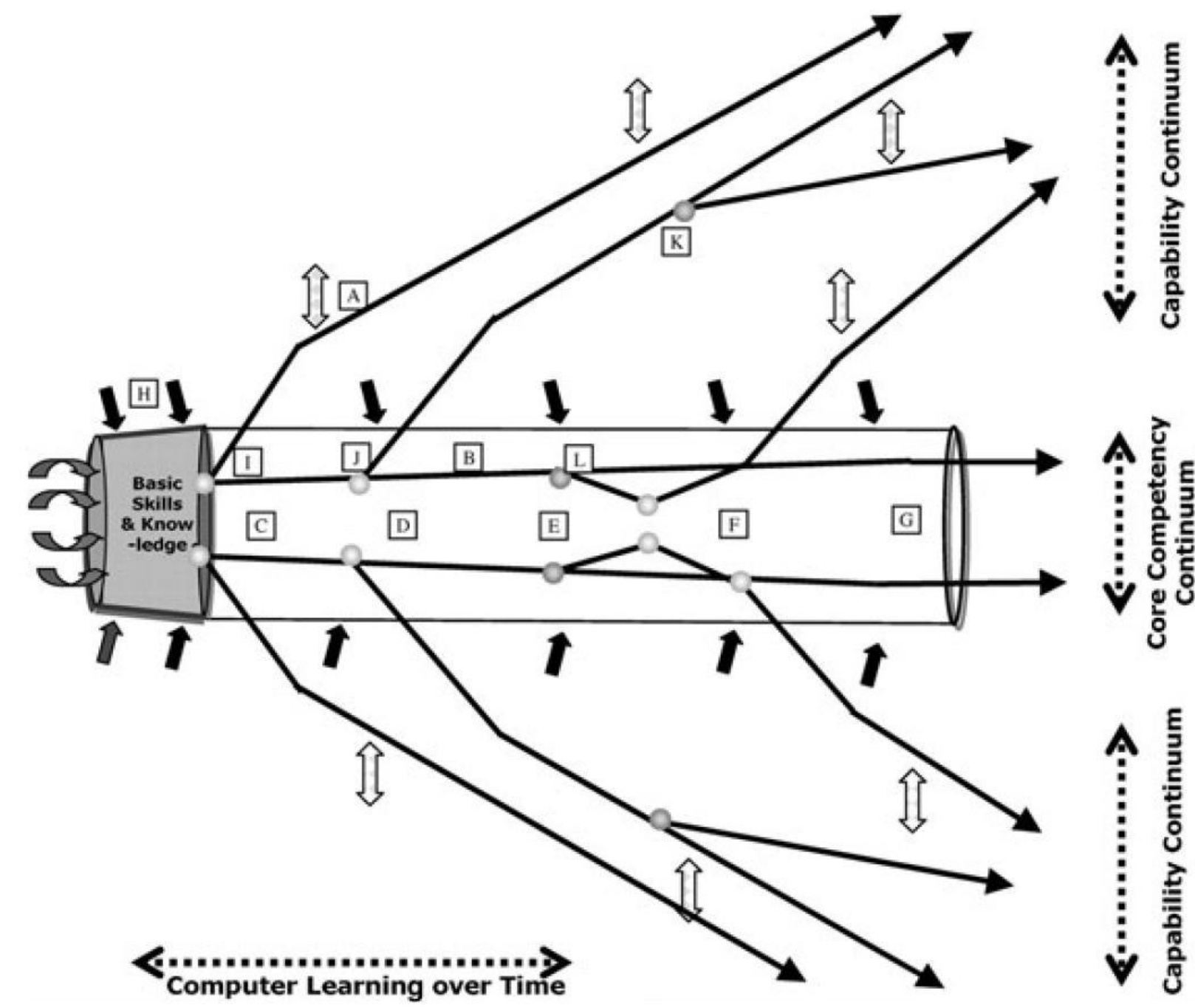




\section{METHOdOLOGY FOR THE RESEARCH PROCESS}

Using the alternative theory of development via participation relates well to the Participatory Action Research (PAR) methodology which will be discussed in more detail in the next chapter. Tapping indigenous knowledge for their wants and needs and raising awareness (Friere 1970) means the research will have twoway benefits between researcher and participants.

PAR could also be useful in building skills of the focus group members by their collaboration with established local researchers and up-and-coming young researchers 'to conduct such analyses, rather than relegating the task to parachute consultants' (Psacharopoulos 1988 6). The purpose of this is to give voice to those on the margins who are direct recipients of decision making for available training; not just those with jobs to fill, but those who seek those jobs (van der Veen and Preece 2005:388-389).

\section{Conclusion}

This research takes a broad view of issues relating to the relevance and appropriateness of computer end-user training in a developing context, made important as a result of a shift in the world's economic base toward information and knowledge. A participatory process was employed to address the research question which generated observations about education and methods of pursuing knowledge. The participatory process is similar to constructivist education, where focus group members actively explore and construct meanings based on their experience and existing knowledge. While this has implications for education and for socially constructing computer training, it also has implications for methods used with participatory processes in development research. Where a transformation is being sought in a developing context there needs to be sustained empowerment and agency capable of sustaining that transformation. 


\section{CHAPTER 4: Research Design}

This chapter includes a description of the theoretical framework used in this research, including rationale for choices made. The methodology and techniques used to pursue the research questions and generate the recommendations are detailed along with ethical issues. Details of methods applied in the field, data collection, recording and analysis and reflection on the methods used are presented.

\section{CONCEPTUAL FramewOrK}

\section{Epistemology}

Epistemology represents the knowledge claims that research practice is based on.

The philosophy underpinning research design has been described as part of a bridge between the conceptual and the logistical elements of research (Murray and Overton 2003:19). A model by Michael Crotty (1998:4) illustrates the sequence from conceptual to logistical levels of research and is the framework on which this research design is based (see Fig. 4.1, below.

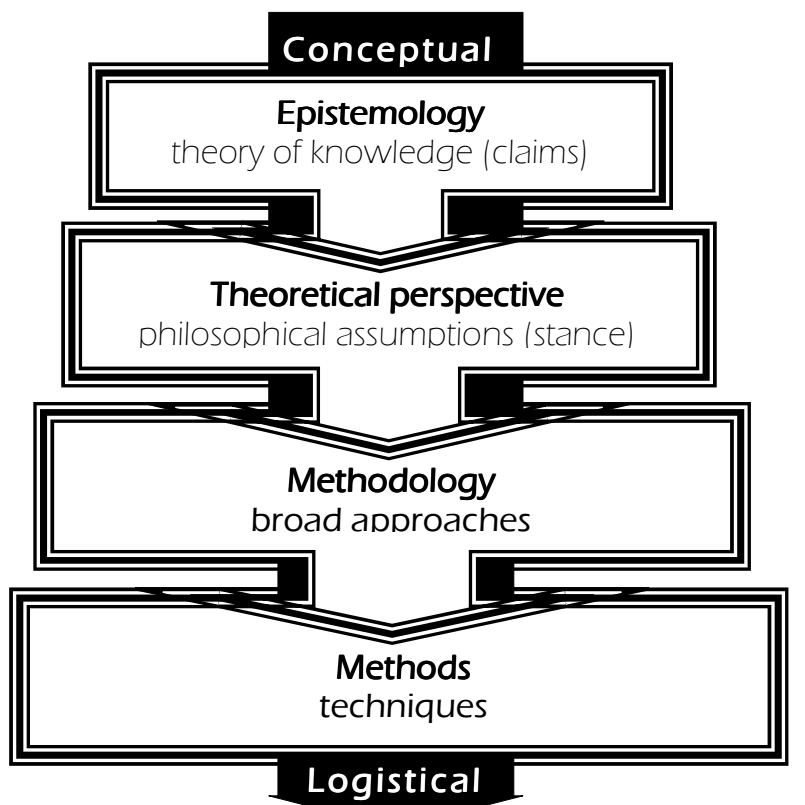

Figure 4.1: Theoretical framework of research Adapted from Crotty, 1998:4; Murray \& Overton 2003:19 
The specific epistemological choice used is based on Creswell's four categories of knowledge claims, the one best describing this research being the Advocacy/Participatory claim to knowledge (Creswell 2003:6). The Advocacy/Participatory claims fit well with social research in development, addressing social justice issues with methods promoting participation and collaboration for change. It is important that rather than a focus on theory generation there is a focus on action and empowerment, meaning the activity is for participants' benefit not the benefit of the research (Creswell and Clark 2007:24-25).

\section{Theoretical perspective}

Murray and Overton (2003:20, based on Habermas 1978) describe a continuum of perspectives, termed 'types of science': empirical-analytical, hermeneutic and critical. The empirical-analytical type is a positivism/post-positivism perspective, hermeneutic is perception-based and the critical perspective includes a moral dimension (Murray \& Overton 2003:20). The perspective most suited to this research is critical inquiry in that it seeks to achieve an outcome of empowerment. It is important that interpretation is done in a critical manner in order to promote change; critical inquiry's main intention is to challenge and change.

Critical inquiry has come through issues of power and oppression from Karl Marx (1818-1883) through Paulo Freire (1921-1997) (Crotty 1998). It has arrived to be what Crotty (1998:157) says is the critical inquiry of today: more about the power of ideas than about revolution by the oppressed. This type of inquiry is useful for encouraging people to see themselves in a new way in social situations, giving rise to self-determined emancipation (Maguire 1987:14).

An appropriate methodology to complement this perspective is one that promotes a cycle of self-reflection and action, and this is a type of qualitative methodology known as Participatory Action Research (PAR) (Marshall and Rossman 2006:7).

\section{Methodology}

\section{Qualitative Research}

Traditional research takes a power position that makes participants passive subjects of research and 'objects of inquiry' (Marshall and Rossman 2006:4 citing 
Denzin/Lincoln 2005). Postcolonial research that followed traditional philosophies led critics toward strategies that use more democratic means for empowering people (Marshall and Rossman 2006:4). The commitment to local contexts and a more democratic process means there is less distinction between researcher and researched (Marshall and Rossman 2006:6) and participants are brought into the process to establish direction, plan, write questions and set goals. Done collaboratively results are more meaningful in the local context and collaboration assists in decentralising power (Marshall and Rossman 2006:7), both in the research and in the participating society. In social research's paradigm shift from statistics to social reality, qualitative methods have moved to reflect more accurately the lives people experience in their natural settings (Marshall and Rossman 2006:4).

Linda Mayoux (2006) lists participatory methods as being a separate division from quantitative and qualitative methodologies based on underlying approaches, tools and techniques. Here that distinction between qualitative and participatory is not stressed, the participatory approach being viewed as a partner to qualitative methodology based on the general nature of the outcome being descriptive rather than numeric. The qualities Mayoux uses to define participatory methodologies, however, are useful in this application and reflect the criteria used for choosing a participatory approach as the distinct type of a qualitative methodology. The criteria that gives this fit are its appropriateness to developing contexts, its focus on grassroots' views using discussion in focus groups to explore participants' realities, and the skills of the facilitator to ensure the local view is expressed.

\section{Participatory Action Research (PAR)}

PAR, a methodology with roots in Alternative Development's theoretical framework has, as Maguire says, the 'explicit intention of collectively investigating reality in order to transform it' (1987:3, citing Gillette and Tandon 1982 and Fals Borda 1977).

The participatory approach has been criticised for the appearance of a gap between practice and theory (Brohman 1996:220), or the difference between 'authentic' and 'pseudo' participation (Brohman 1996:252 citing Midgley 1986). Pseudo participation is when participation is only included at implementation and 
maintenance levels and is used in order to achieve a development objective. Authentic participation leads to empowerment and improving the quality and relevance of projects and for this there needs to be participation at the outset of the decision-making (Brohman 1996:252-3).

\section{Practical Approach}

\section{Scope of study: Process}

In keeping with the Vanuatu Cultural Research Policy's (VNCRC 2004:2) statement, 'priority will be given to projects which involve active collaboration with counterpart $N i$-Vanuatu researchers', this research was conducted by forming focus groups that worked in a collaborative process using PAR. Members of the focus groups engaged in all parts of the process from posing questions and gathering data to interpretation, identifying findings, preparing and reporting recommendations. Another part of their research process included interviews.

The researcher held semi-structured interviews with local stakeholders to gain a base of current information and opinion in the context. Each focus group participant interviewed an employer from a local business, training institution, government department or non-governmental organisation (NGO) to gain an understanding of local ICT end-user skill needs in Port Vila. These, again, were semi-structured, each group using the same base list of questions but allowing a degree of divergence, depending on the situation.

Documents relating to end-user computing training were analysed. These included pamphlets advertising training courses and course materials used at training centres. End-user training facilities in Port Vila were analysed for suitability, some by sight, while others that that groups did not have access to were analysed based on photos and room design descriptions, obtained through interviews by the researcher.

\section{Scope of study: Research participants}

There were three distinct types of stakeholders involved in this research. To differentiate between the types, I call those interviewed for information and opinion the local stakeholders; those whose activities were central to this study are 
focus group members; and those who were interviewed by the focus groups members to ascertain end-user training needs are known as employer interviewees. Although the focus group members are in fact stakeholders, it is not apparent that this is seen to be so by other, more elite, stakeholders. Part of the point of the research is to establish the members' relevance in the local mindset as being actively included in the larger stakeholder group.

The choice of local stakeholder interviewees included as wide a selection as possible from local industry and government. Some of these were planned in advance, others found through snowball sampling. Snowball sampling is a nonprobability survey technique where contacted interviewees suggest other potentially interested interviewees and they suggest others (Fink 1995:34). Twenty-five people were interviewed. These included people in training institutions, public and private; training related government ministries and bodies; civil society organisations; and local people who have an interest in training, whether as receivers or employers. Much of the information gained in these interviews informed questions for other interviews and themes for the focus groups to address.

The choice of focus group members was based on their currently receiving, or having received, end-user training at any level from any institution, formal or informal, in Vanuatu. It was hoped to include teacher trainers who have had enduser training but, due to the timing of their studies, this was not possible. A mixture of island of origin and ethnic groups representative of local population was also sought to gain a realistic cultural mix. However this mix was not possible, given the people who were available to participate in the research. The groups were a mix of island-of-origin and also primary or preferred language of study (French or English). Because their part in the process is the main focus of this thesis, the choice of focus group members is detailed in the following subsection.

The choice of employer interviewees was made by each focus group participant. The requirement for their participation was the use of ICT and the employment of computer users in their workplace. 


\section{Scope of study: Choosing focus group members}

Five out of six main local training organisations were considered when looking for members for the focus groups: USP's DFL, ECF, VIT and the HRD. AUF offered a different type of computer skills training than was considered in this research, that is online tuition with less emphasis on end-user skills, so were not included in the scope of identifying participants. There was an attempt to get at least two teacher-trainers in each group from the teacher training college, VITE. Several businesses and NGOs were approached about offering participants.

No commitment for participants was available from VIT and VITE and, because the HRD trains people who work full time in Ministries and NGOs, it was not possible to get a commitment of time from them. It was also not possible to get participants from local businesses.

ECF and USP provided names and information about training background for 41 and 20 (respectively) possible participants and two more potential candidates from the NGOs Vanuatu Family Health Association (VFHA) and Wan Smol Bag showed interest. The trainees from USP had received varying levels of computer skills training between 2004 - 2007. The trainees from ECF were currently receiving training, some in their second year, some their first. One NGO candidate had received training from USP and was now delivering training at a youth centre; the other NGO candidate had attended training at the HRD.

Participants were phoned or visited when there were contact details available, and a liaison at ECF passed on information to possible participants there. Eleven people were contacted from the USP list, the others lacked a form of contact. Several of those without contact details were students or staff at USP so a small poster was placed around the campus, written in Bislama and English, to attract interest.

The research budget allowed for a maximum of 20 focus group members. To choose 20 from the 63 possible members, a questionnaire was used (Appendix 4.1). The questions were presented in three sections, written in English and Bislama. They included details such as name and island of origin, what sort of computer training they had received and, if they were in paid employment, whether their computer skills were helpful in this employment. Along with the 
questionnaire, a copy of what might be called an appeal for their participation was used (Appendix 4.2). Written in plain English this appealed to their participation and included my local contact details.

The questionnaire helped in selecting participants based on three variables: a sample of island of origin; a difference in type, breadth and location of end-user, in-the-classroom training experience; and a reasonable gender balance.

From the eleven USP contacts three questionnaires were obtained. The ECF liaison gathered 39 questionnaires from the list of 41 and one questionnaire was obtained from a person at this organisation as a result of a chance meeting.

\section{THE ResearcheR}

\section{Positionality}

Marshall and Rossman (2006:31) explain how personal observation can lead to tacit theory (personal understanding) and when this is added to formal theory it brings questions, or phenomena, into focus, and into a position to be generalised (see Fig. 4.2 below).

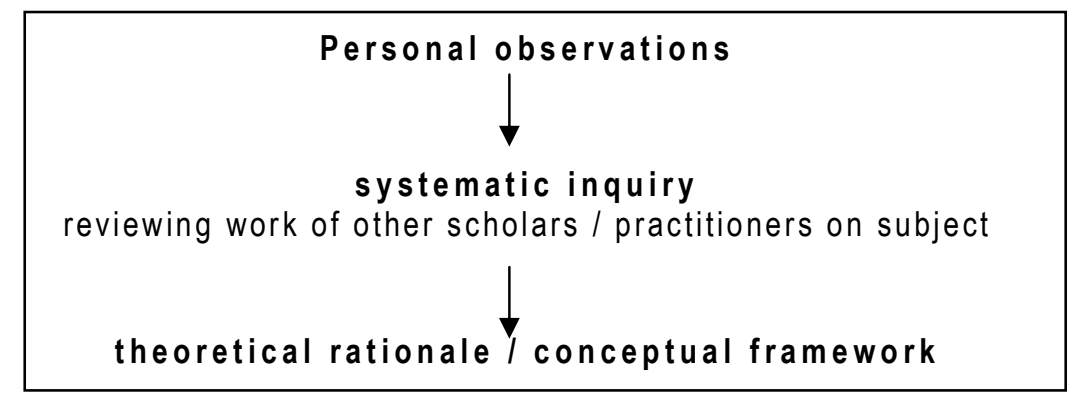

Figure 4.2: From observation to theory

Adapted from Marshall \& Rossman 2006:31

The origin of this research is based on personal observation during the experience of conducting end-user training in Vanuatu and Tanzania. I am aware of biases and assumptions I bring to the study based on this experience, and was aware of the need to remain sensitive and flexible to what the participants contributed to the study's findings. My research outcome need was a description of process of pursuing the question rather than specific findings, therefore the results did not need to 'fit' my viewpoint, which assisted in downplaying any temptation to impose external ideas. 


\section{Researcher Role}

The researcher was a full participant in the process as initiator/facilitator.

However, there were definite roles the researcher played that were different to other participants, namely 1) gaining entry to the site, 2) relationship building, 3) catalyst to the process and 4) following up, including the writing up of the research.

\section{Accessing the site}

A research visa was necessary to gain access to do research in Port Vila. Application was made according to the Vanuatu Cultural Research Policy (VNCRC 2004) and approval granted prior to entry in the field (see details, p 69). Actual site, industry and participant arrangements were made through local contacts at the DFL of USP and CNS, a private business. Both are in Port Vila and are well known to me from previous experience; their assistance was valuable in securing participants for this research.

\section{Relationship building}

Paramount to the successful outcome of this research was building solid rapport with all participants, those in focus groups and interview contributors. Trust can be built through rigorous attention to mutually set goals, culturally appropriate behaviour at all times during the research and the delivery of purposeful group facilitation (Creswell 2003:179). This is emphasised by Scheyvens et al. (2003:139) as being the primary imperative above and beyond achieving ethics approval by sponsors or sending institutions. It is, in effect, personal ethics being practiced.

Closely aligned with ethics was the remuneration of the time participants spent supporting the research effort. Funding was not available for payment other than transport to and from each meeting, including arranged meetings between usual group times. To compensate for the lack of payment, arrangements were made for certificates of participation signed by prominent local people (Appendix 4.3) to be 
presented to each participant who completed the process and a small ceremony of food sharing and gift-giving was held at the time of the final presentation ${ }^{21}$.

\section{Catalyst and facilitator}

Initiating the process and identifying and arranging facilities was the responsibility of the researcher; this included preparing questions to start the sessions and providing resources for use in the work, for example providing rooms, writing materials, forms for research notes, booklets for research diaries and refreshments for break time.

As catalyst and facilitator, it was the researcher's role to ensure power shifted during the process, from the researcher/catalyst to the participants. To empower participants there is an issue of how to frame the project and take positive action (Crotty 2003:58) and this was attended to from the start by clearly explaining that the purpose was not just to look at training, but also to see if there was a shift in expectations about the trainees' role in it. Each focus group participant was assured their ideas had value and this was established in the first instance by giving each a blank notebook that was referred to as their research journal (ref. p 104) and following up to encourage their use of it.

\section{Follow up}

A follow-up procedure was negotiated with participants to ensure that there was regular, continued communication during and after the research finished. The actual follow-up is continued contact with participants via email and occasional mail-outs to those without email access. The local context is such that a few participants have neither email nor postal addresses; contact with them is continued through a liaison in Port Vila.

Follow-up with local stakeholder interviewees was established while in the field. Each interviewee, including the employer interviewees, was invited to a presentation of findings and recommendations given by the focus groups at the completion of the research. Local stakeholder interviewees requested in ethics forms to receive a summary of the thesis when complete. A copy of the actual

\footnotetext{
${ }^{21}$ Unfortunately sharing kava was not a part of this as it was not able to be arranged due to timing of the presentation.
} 
thesis will be given to the Vanuatu Cultural Research Council, accessible by any interested party. Each stakeholder will be informed of the delivery of the thesis to the council by the researcher.

\section{Exit strategy}

In fieldwork an exit strategy is a vital consideration to a researcher and can be an ethical issue. Leaving is not only a phase of the research, it also has a part in shaping experiences and understandings (Kindon and Cupples 2003:197, citing Maines et al. 1980).

Kindon and Cupples (2003) cover five important considerations for leaving: 1) reasons for leaving, 2) factors that influence the type of exit strategy, 3) emotions involved for researcher and participants, 4) strategies, and 5) practical concerns. The type of research process also affects exit strategies. This research was shortterm but intense, the researcher closely involved with the participants who are relatively well-educated. Considering those factors in the context, a mixture of exit strategies was used, some negotiated during the process. A presentation was scheduled in the week following the last focus group meetings; the intention of this presentation was to bring the focus groups, the employers interviewed and the local stakeholders together to discuss the findings and recommendations of the focus groups. This provided an opportunity for the researcher to formally thank and farewell all who participated by a gift-giving to participants and an informal small offering of refreshments to all. During the final week, the researcher remained available for 'periodic leave taking' (Kindon and Cupples 2003:207), a gradual finishing off of the process and availability for any 'unfinished business' or relationship needs.

\section{Ethical issues}

Ethics Approval was sought and received prior to departure for research according to Victoria University of Wellington (VUW) policy (Appendix 4.4). Ethics approval in this manner binds the research to an ethics framework that balances the needs of different stakeholders in the research being undertaken (Scheyvens et al. 2003:40). 
Approval was also sought and received prior to departure from the Vanuatu Cultural Research Council in Port Vila. On arrival, a research agreement was negotiated and signed, based on the standard research contract for Vanuatu (Appendix 4.5). The agreement included the use of a collaborative method with local people (ref. p 63) and a promise that the council will receive a copy of the completed thesis.

The discussion of ethics during the interviews and focus groups process was based on ethics forms obtained from the School of Geography, Environment and Earth Sciences (SGEES) at Victoria University of Wellington. Each participant received either the Stakeholder (interviews) or Participant Information Sheets (focus group members) and an Informed Consent Form (Appendix 4.6 a, b and c). Not having experienced this process before, I was less critical of the forms than I would be in the future. In actual use, the forms were in English and translated using Bislama in verbal explanations. I noted questions two and three seemed redundant. In focus groups we verbally agreed the meanings, in Bislama, and agreed to override question three.

As mentioned in Chapter six and of ethical concern, I requested feedback during the entire process. During the final session, I used evaluation forms to get written feedback from participants (Appendix 4.7). These were written in English and Bislama and responses were written in either language. Responses were positive, as seen in this summary of evaluations (Appendix 4.8).

I was unable to pay focus group members for their time but was able to provide each participant with money for their transport costs. At the end of each session I gave each member VT200 (NZD3.30) to cover the actual cost of their bus transport to and from the session.

\section{Informed consent}

Consent with participants was negotiated verbally in both English and Bislama (in most cases) and in written form in English at each interview and at the initial meeting with focus group members. The purpose, aims and processes were explained openly as well as acknowledgement of their right to withdraw at any time, assuring protection of their ownership of any information given by them 
should they withdraw. In this communication, understanding was explicitly sought before consent was signed.

Each focus group participant used the written ethics forms described above in employer interviews. The participants explained these to their interviewees before seeking a signed agreement. They were the same forms used by the researcher with research participants, the only difference being the employers received the information sheet for stakeholders while the focus group members received the one for participants.

\section{Researcher intent}

Marshall and Rossman (2006:5) mention issues of power, reporting and exclusion (race, class, gender) based on the negative historical record of research's beneficiaries. In this research, the researcher's personal connection to Vanuatu contributes to intentions for the betterment of an aspect of local adult professional development through the involvement of the participants. Researcher purpose was focussed on the process, even if the information about end-user training could be considered to have 'failed' or if it disagreed with the researcher's thinking.

\section{Focus group process}

Communication and group activities were negotiated with participants in all meetings but especially when there was a shift in communication style. Shifts in style occurred when it came to preparation for their interviews, our presentation preparation when the two groups came together for the first time and shifts in leadership occurring as the participants assumed more of the activity generation in the meetings. It is one thing to 'hand over the stick' (Chambers 2005), but quite another to have the stick taken. In research situations like this it may not occur for a considerable amount of time or, when time is limited, it can feel like a considerable amount of time.

\section{DEALING WITH DATA}

\section{Data Collection}

Data was collected in the field from 21 October through 23 December 2007, a total of nine weeks. Methods used were interviews, focus groups and document and facility analysis. 
The first weeks in the field were used for information gathering and setting up for the focus groups: facilities, resources and participants. Local stakeholder interviews were held for the first three weeks and during the rest of the time in the field were held between focus group meeting days. Each focus group met once a week for four weeks starting 17 November and ending on 12 December. Meetings were organised to fit the schedules of the participants who were either working or involved in regular training. One group met Wednesdays $2 \mathrm{pm}-6$ pm; the other met Saturday 9 am - 1 pm. Employee interviews were scheduled and held by each focus group participant during the third week of focus group sessions.

Local stakeholder interviews used open-ended questions, meaning interviewees responded in their own words, and on their own terms (Patton 1990:297). Each interview was guided by a list of issues based on expected information type and information gained during the data collection process.

Key questions for the employer interviews done by the focus group members were based on the information needed; for example how their staff is trained, whether training provided by institutions meets their needs, and what factors they consider important to improve training provision. Specific questions used by each groups are included in Appendix 4.9.

Two focus groups were used for the main information gathering; one group had three participants, the other eight. Creswell (2003:185-6) advises 6-8 members in a single group, Marshall \& Rossman (2006:114-5) suggest 7-10 with a noted variation of 4-12 being realistic. The number of focus groups was based on the number of willing participants and their preference for numbers in the groups, as long as no group exceeded 10. The groups met on different days, each group covering the same focus point during the same week. Using focus groups was chosen over individual interviews to collect information for the benefits of participants building ideas off others' and being able to compare and discuss individual and collective experiences in depth in a lively, productive social situation and to encourage awareness raising. This required attention to group dynamics and it required facilitation by the researcher without being controlling (Marshall and Rossman 2006:114-15; Waldegrave 1999:234). 
The intent of the groups was to: 1) discuss present training methods, 2) interview industry contributors, 3) view and analyse training facilities, 4) view and analyse training-related documents and 5) make recommendations for training changes based on group analysis of findings. Focus group activity included agreeing an action plan, group needs and means of communication and feedback, and setting criteria for analysis at different stages in the process. The researcher attempted to make clear that open investigation of the situation was the primary concern, not adherence to a particular viewpoint (Waldegrave 1999:235).

Focus group members discussed the initial plan drafted by the researcher and changes were made as agreed by them.

Interview protocol and observation protocol forms were used by the focus group members for taking notes during their employer interviews (Appendix 4.10). These protocol forms were adapted from Cresswell (2003:189-190), modified by 'translating' the Reflections section with 'tingting blong yu' and labelling the three sections of the Observational form in Bislama. Interview forms are useful for the interviewer to note key questions planned and probing questions they may have used during the interview as well as notes they made after reflection; observational forms are useful for recording interviewer observations of the interview and interviewee and are normally of a descriptive and reflective nature. As mentioned, each participant was given a small notebook to use as a research journal and encouraged to record their reactions, perceptions and ideas generated by the process in their research journal notebooks. I used my own during the sessions, intending to illustrate their use in noting observations as they occurred.

Training documents and facilities were assessed. The groups had access to training materials from USP, VIT, ECF and printed pages from AUF's online site. HRD's materials were not available but were similar to the others, based on a description of them received during stakeholder interviews. The USP computer training lab was available for viewing by both groups. Those who received training at ECF drew floor plans of their training facilities and the researcher provided pictures and descriptions of the labs at VIT, HRD and AUF, which were not possible to visit by the groups. 
There was opportunity throughout the process for spoken and written feedback from the participants so they could comment on their observations of the process. Details of this are in Chapter 6.

During and after data collection in the field, I joined an online ICT forum, VIGNET (Vanuatu Internet Group Network), that was created and is dominated by a Vanuatu local computer group, VITUS (Vanuatu Internet Users Society). This is another source of information related to ICT in Vanuatu, more a technical viewpoint but it does contain local experience that differentiates the reality of ICTs in Vanuatu from elsewhere.

\section{Data Recording}

Notes were used to record interviews, supplementing the use of a digital recorder with attached omni-microphone. In focus group sessions the data recorder was used and data was also obtained from observations written in the researcher's journal during and after sessions. The journal was entered in both notebook and computer file formats. Written work of the participants was kept in a group collection, a plastic-sleeved binder made up of the data from focus group sessions. The binder was kept and brought to each session by the researcher, being part of the groups' resources. Digital pictures were made of participants' work on the white and chalk boards, complementing and making up part of the group collection.

A base record of raw data was kept in the researcher's journals, interview summaries and written output from focus group members. This raw data provides both the information generated about the focus question and a record of the process based on actual events and researcher observations.

In this research process, forms of information generated were results of focus group work, which were written lists and short written works based on their research journals that were given to them for this research; interview summaries; and analysis of documents and training facilities.

In order to make easy text searching possible, the researcher transcribed some written data during the time in the field, using MSWord and MSExcel as a computer recording tool. These applications allowed searching capability in a 
one-dimensional form as well as provided the opportunity to stay close to and manually handle the information generated.

\section{Data Analysis}

The type of analysis used in this research was qualitative in nature. 'Qualitative analysis is a process that happens throughout the research' (Creswell 2003:190; Tesch 1990:90-91). There is no clear division between the data collection and analysis stages of this research. As John Seidel (1998) says, qualitative analysis is as simple as noticing, collecting and thinking with discoveries emerging at all stages of the process.

Analysis in this research occurred during interviews prior to the focus group meetings beginning, which helped to focus down to relevant themes on the topic within the context as did discussions and observations during focus group meetings. Focus group members carried out analysis of the main focus question based on their collective information, completing this during the research process. The researcher also analysed throughout the process, in preparation of summaries used in the focus group work and in reflecting on observations made during the process in daily journal entries. This analysis was in part used to nurture the individuals in the process and was vital to successful facilitation.

Reflecting on the experience in its entirety, 'actions, events, beliefs, attitudes, social structures and processes' (Marshall and Rossman 2006:34) helped to shed light on the significance of the experience. Categorisation of data was based on themes that came from the information gleaned from interviews and focus groups as well as observations of participants in focus group interactions. This research had a two part analysis: that of the focus question ${ }^{22}$ and that of the process used in seeking answers to that question.

Notes were created from focus groups' work, matched and analysed in order to generate categories, themes and patterns for the focus group's presentation of results and is being used similarly for the preparation of this thesis.

\footnotetext{
22 'What methods for training Information and Communications Technology (ICT) users in developing countries are relevant to their needs?
} 
Specifically, analysis flows in this research as a cycle described as data collection, including note-taking and researcher's observations during the pre-focus group interviews, interwoven with interpretation and analysis at a surface level. It is assumed there will be bias involved so care is taken to have collected information on a theme from various sources before an interpretation is blended with activity, such as focus groups or writing. Categories are made at the level of the main focus question while the process level is left to run its course before categories are made. After leaving the research context, Vanuatu, process is interpreted through materials collected from sessions including group work, written observations and notes made from verbal feedback, evaluation forms and collected email communication.

\section{REFLECTION ON METHODS}

The original design for this research was deliberately written to be flexible and this proved valuable as there were shifts necessary in intent and method; these shifts were dependent on the setting in a broad sense.

The choice of a participatory method was based on my experience having done end-user training in two developing country contexts. Having studied development gives me theoretical knowledge of participation and awareness of its faults; my practical experience gives me knowledge of its fruits in informing sustainable change in context.

\section{Process}

\section{Interviews}

Interviews ranged from casual discussions for information and insights, with colleagues and friends from my previous experience in Vila, to semi-structured interviews with a range of local stakeholders, those interviews aimed at learning more about a specific type of information. Many of the early interviews were also to do with identifying participants for the focus groups.

The range of input into the interviews and the semi-structured method were helpful in learning as much as possible around the topic. What was also useful was a mixture of local and expatriate input in the opinions being presented. 
Limitations of interviews

I was unable to interview some who I consider were important to two aspects of my original intent: teacher trainers and actual trainers of end-users. I was able to interview only two trainers; the others having either left Vila or were unable to make time. My original plan included at least one teacher-trainer in each focus group to get a viewpoint of what sorts of ICT training was felt desirable in schools. Meeting the end-user trainers was intended to establish their views toward training. I feel these would have been valuable inclusions in the research and would have offered a useful contrast to having only trainees involved in focus groups.

\section{Focus groups}

My original intention for using two different focus groups was as a method of testing the data for triangulation of information sources. When arranging the focus groups, the unfeasibility of this in this context became apparent. My sources for focus group members meant that many of the individuals work together during the days or could have possible casual meetings. Port Vila is small and there is a great deal of openness and sharing of information. To keep the focus groups' work confidential for four weeks in this atmosphere was questionable. Therefore I amended my plan to include bringing the groups together after their final meetings to join their material and prepare a presentation. It was a question of following theory to the letter or amending it somewhat to bring data closer together during the process, rather than only during analysis. Therefore, this form of triangulation was sacrificed.

\section{Participation of focus groups}

The nature and the depth of the actual participation was a factor. As Brohman (1996:52-3) states, participation should be at all levels, from planning to implementation and maintenance, not just for the achievement of development, or in this case research, objectives. In this case, the plan I had drafted was the direction we took. The participants were accepting of this, although I would have liked them to be more critical. However I accepted this as a starting point toward raising awareness. I would expect that if I, or someone else, continued to work with this same group they would be able to become more critical of the original 
plan and shape it themselves. This is part of the shifting of power: from the starting point, where power is uneven, in favour of the catalyst of the process.

Tactics towards power shifting

I considered it important to generate respect for their way of working, which I believe in turn encouraged the focus group members to consider the work seriously. From the first session I made it clear they could move the furniture around as they liked. I placed the resources where they had access and encouraged them to use the chalk- and whiteboards in the room.

Feedback from them started with my asking how they liked the way we had done something soon after we finished it. I noticed that our break times midway through was a time we discussed things more openly, around drinks and biscuits, each taking turns to mix the drinks and wash up after. It became a time for them to give spontaneous feedback and generate ideas and it was very much a together, or 'we', time.

The use of notebooks as journals was an idea to help make this truly more collaborative; I was doing research, so were they. I gave them the next focus topic in question form at the conclusion of each session so they could consider it before the next session. When I repeated the question in the next session and asked them to work with it, I noticed they often used their journals to write from. I noticed as well that they used the journals more frequently during sessions as the weeks went by.

If done again, I would consider asking to see their journals as part of my own research but this time I respected their privacy as an act of trust. I felt that if I told them I would look at their journals, they may have produced only what they thought I might want.

The use of the same ethics forms for their employer interviews that they themselves had signed for their interviews led to a session on clarifying the forms' meaning. This session included interview techniques, the use of open and closed questions and concluded with the participants writing the questions they would all use for the interviews. I noticed their manner changed from being set for activity toward a more lecture style, even though this was relatively brief. They sat up to 
their desks and took notes where before they had been seated in group, not classroom fashion.

The presentation was also a tactic, it being used as a way of bringing the local stakeholders together with focus group members. For the focus group individuals it was a way to more publicly show the interest they have in their training and for the potential benefits of being recognised and respected as stakeholders with a voice in end-user training.

Limitations of the focus groups

The fact that we were unable to have equal types of documents from training institutions and could not all visit other facilities meant some things were measured by sight where others were by drawings, pictures or examples found online. I believe this could have an unequal affect on perception. The most outstanding comparison was that done on the basis of sight and experience: USP and ECF, both for resources available and for our sighting the facilities.

\section{Focus group members}

The research design was written with the intention to select participants for focus groups from people in the workforce who had received computer training at a local training institution. This was meant to consider if the training was considered helpful to their work. For the actual choice of participants I was limited to using younger people either receiving training at the moment or who had recently finished and were working. This contributed to a change in dynamics and shifted the focus somewhat from focussing on the fit of training to considering the usefulness of involving trainee 'stakeholders' to contribute to evaluating training in more detail.

I was able to obtain a list of 20 past trainees from USP and 41 present trainees from ECF for choosing participants. This was many more that I had expected. Due to the timing of the focus groups, November and December becoming much hotter and people living in Vila often returning to their islands to start their summer break prior to Christmas, I was prepared to expect fewer participants ${ }^{23}$

\footnotetext{
${ }^{23}$ I had discussed this with my supervisor and had decided if I could get five people total, I would still be able to do the research.
} 
than I would have liked and knew it was possible many who started would not finish. 20 were invited to join, 18 agreed, 15 attended the first meetings. By the time of the final meeting, three were still attending the Saturday meeting; eight on Wednesday. I felt my final total of 11 was better than expected.

Limitations of focus group members

I was aware of the possible limitations in getting information in such a short time from a) a group this age and b) a mixed gender group. I had spoken to two USP lecturers who confirmed the difficulty in mixed-gender groups talking openly and who suggested dividing the genders because the girls are afraid the boys will gossip so they remain quiet. Due to schedules, it was not possible for me to do this for my Wednesday group, in which three out of the ten scheduled were male, due to training schedules. While I noticed the initial reticence of the females in Wednesday's group, by the fourth week, this was not a problem.

When the two groups came together for the first time to prepare for their presentation, I believe the maturity of the participants as well as the excitement they felt by this time meant there was very little group building necessary. Again, the break time, the mixing of 'tasks' and the use of Bislama as the language of our work seemed to assist in the participants' comfort.

\section{Timing of the research}

Timing revolved around local and international issues. Locally, there was the timing of Christmas and cyclone season, both out of the hands of the researcher. The Christmas spirit often arrives in Vanuatu earlier than the holiday season starts; this is largely due to weather. Internationally, it coincided with study and work commitments as well as seeking funding to cover the costs of the research. Assurance of funding not being entirely clarified before departure meant that work commitments had to be respected. The original plan for amount of time in the field was twelve weeks but, because of risks associated with costs and flight arrangements, was shortened to nine. Because of the limited timeframe much of the planning before and the in-depth analysis after the research was done by the researcher. This is not ideal but required because of the shortened timeframe. This shortened time of researcher/participant contact creates limitations for the cycles of action and reflection that are a vital part of the PAR process. Even 
twelve weeks is limited for this, but certainly gives that extra time for fact- and participant-finding interviews at the start.

Another departure from the original plan was the focus group meeting timing. Originally it was set for a full day with a lunch and mid-morning and midafternoon breaks but this was not possible given the schedules of the participants. I also believe, after cutting the time to four hours with one break, that there would have been a reduction in attention and activity in a full day schedule. As it was, our time was intense and there was heightened activity to complete our tasks, despite the rising temperature over the weeks.

\section{Exiting issues}

Related to participant follow-up contact, a more intense focus-related follow up would be ideal. Cupples and Kindon (2003:229-230) state it would be ideal to revisit the site to assess effects of research if funding and time allow. In this specific case it would be ideal to expand and continue this PAR process with the same focus group members to mark the effects of computer training now, and again after changes had been made, as well as effects towards empowerment with a longer period of activity. This would require a great deal of funding and a lengthy time commitment but could have valuable, sustainable outcomes.

The feeling of extraction existed as I was writing this thesis. Writing and the literature-based research takes considerable time from the finish of fieldwork and, being done so far from the site of research, makes me feel severed from the participants and people I felt quite close to in the field. While I maintain written contact with them, I cannot easily express to them how their importance to the research continues in this long, field-separated phase of the research process.

\section{Power relations}

Power differentials were expected within the focus groups as well as in the setting. My observations were that the group differentials may have been successfully underplayed as there was the covert existence of a power balance within the focus groups within a short time. It was important to ensure equality within the groups and desirable to focus positively on the place of this research in the hierarchies that surround institutions in Vila. In the focus groups that place 
was always portrayed as a foundation level, and that it was very important to consider the question we were asking about end-user training in Port Vila.

I believe my own comfort in the setting contributed to the participants' willingness to open themselves to the process. I also observed these participants were especially mature about this new experience and also very respectful of each others' right to be involved. There were a few participants who were less outgoing than others and were involved on the outskirts of activities but this was accepted and their contribution occurred in different parts of the process, in different ways.

I made it known where I was staying and that they were welcome and I received social as well as research-related visits from participants at my accommodation, which became an extension of the formal meeting space we worked in.

From the start, there was a question of involvement and open sharing of information and to encourage this I weighed their reaction to activities in the first sessions and found that having them work individually on paper, then shifting that to pair work and after to pair-share (Ledlow 2001) did achieve a shift toward more participant-led and group-involved activities. At the end of the first session, I purposely set a project where they all had to leave their places and work on the black- and whiteboards together. After this, their working freely around the room became the rule and resources were available for them to use whenever they wanted. This, perhaps, contributed to successfully shifting the power relations in groups, and perhaps their maturity and comfort level with each other and the comfort I perceived them to have with me also contributed.

The fact that this was not a controversial subject but was of high interest to stakeholders at all levels assisted in the cooperation I had in setting up and carrying through this research.

\section{Location}

The distance factor of this collaborative fieldwork posed limitations, one being the limited timeframe of actual researcher/participant contact. Also, the context of this study is not the complete Vanuatu ICT user environment although it is still one of the few main environments for ICT activity. If this sort of activity could be expanded and made to contribute to wider user-involved planning and locality- 
specific training, there may be opportunity to widen the scope to include other local communities in similar studies.

\section{Personal factors}

My familiarity with the setting helped all parts of this process but was especially evident in the ease with which I was able to get the interviews I wanted and access to the things I requested. I am able to speak and write Bislama to a fluent level which minimised communication problems and provided a common language of engagement that was familiar to the participants. Participants included both Francophones and Anglophones and Bislama is the unifying language. Not only could I speak a familiar language, I also understood local behaviour in gaining appointments and meetings, which takes patience and persistence, not to mention a bit of ingenuity.

\section{Conclusion}

The focus of this study was to apply a qualitative PAR methodology to discover local methods that would suit the Port Vila context for ICT user-level and business-focussed training.

The research question was: 'What methods for end-user computer training in developing countries are relevant to their needs?' The aim is to discover how training is now being done; what factors work and which are missing and how training might be improved. This also included considering the copycat competency-based training systems brought in and to consider having more locally-based objectives and resources rather than western training models, western resources and depending on western trainers and/or methods.

Specific objectives included initiating a PAR process with a cross-section of users who have experienced some user-based computer training. Two focus groups explored methods of training for users of ICT in Port Vila by discovering and describing patterns, common categories or themes. These focus group participants interviewed local employers to learn industry needs for user training, studied a range of documents and assessed training facilities for appropriateness to training. Alternatives for training provision were considered. 
Methods used were focus groups, interviews and document analysis. Data collection and analysis was done qualitatively.

This research design fits well with a development approach that corresponds with point 7 of the Vanuatu Cultural Research Policy's guidelines (VNCRC 2004) that stipulates Ni-Vanuatu participation in research projects (ref. p 63). It fulfilled the research question by focussing on local needs, informed through participation by ICT-users and industry contributors. 


\section{CHAPTER 5: Results of focus groups}

This chapter offers a summary and an analysis of results from focus group sessions and concludes with reflections on the results. It illustrates the depth of exploration achieved in a short participatory process involving the researcher as catalyst, and the focus group members whose experience is at the heart of the relevance of the question. In Chapters six and seven, which offer a narrative of the process followed by discussion of the significance of that process, the question becomes immaterial and acts only as the point of common interest.

\section{FOCUS ON THE QUESTION}

The main purpose of the focus groups was to address the question What methods for end-user computing training in developing countries are relevant to their needs? The groups focussed specifically on Vanuatu, even more specifically on Port Vila.

The questions explored are presented in Appendix 5.1. Following the two groups' four sessions each, the groups joined to prepare and give a presentation of results to local stakeholders. Following is a complete summary of the results.

\section{Summary of research results}

Results from focus group sessions were the outcome of questions explored in the groups' meetings and were presented to a group of stakeholders at the completion of the research in Port Vila in December 2007. These questions included reflections on what the purpose of receiving training for the individuals was, what jobs for computer end-users there are in the industry in Vila, what skills these jobs require, how local training fits the kinds of skills that were described as needed by employers and what the training might lack. This is a summary of results taken from observations, notes and the PowerPoint slides (Appendix 5.2) from the presentation preparation meetings and the final presentation. These sources were the work of the researcher and the focus group members. The summary is structured from the presentation's outline: Why do we need to use a computer?, Why do we want training?, Findings, Conclusions, and Recommendations. 


\section{Why do we need to know how to use a computer?}

Most people who use a computer do so for professional and personal reasons. Professional reasons are defined as employment, research and communication. Personal reasons were identified as communication and entertainment.

\section{Why do we want to receive training?}

This was a personal question members reflected on in meetings. Their main reason for receiving training was based on the perception that computing is important and is growing in importance for people's livelihoods. Professional needs were seen as vital, their belief that it will increase their chances for job opportunities. Leisure activities were also considered important. These included the ability to communicate and network with people worldwide. Knowledge of using the internet is desired for its wealth of information.

\section{Findings from the research}

Findings include skills needed, types of training available, course materials, trainers and training methods, training facilities and what is required of the trainees themselves.

Skills needed

From employer interviews, the groups found the skills employers looked for in employees were basic computer literacy, which involves ease of using hardware (e.g. mouse and keyboard); navigating through an operating system and through software with a basic understanding and use of Microsoft Office tools; keyboard skills; a moderate amount of technical knowledge of the hardware and programming skills to assist troubleshooting and basic configuration; telecommunications; self management skills including time management, planning and organising and study skills; communications skills, especially good oral and written English and/or French with the preference being both; and customer service.

Training types

Information about available training types in Port Vila were based on outlines and verbal descriptions of courses provided by ECF, USP, VIT, HRD and AUF. AUF was included in this assessment as it is an alternative type of training available. 
AUF's courses are web-based literacy issues such as web design, e-commerce and how to access and use online information and online forms. There is or will soon be a selection of types of training available to users in Vila; these include short courses in office software (EUT), certificate courses in hardware and software, International Computer Drivers License (ICDL) courses, computer performance development short courses, use of the internet, networking administration and advanced courses which include advanced levels of office software, and diploma or higher-level certificate courses for more technical pursuits. International standards are preferred by trainees because there is a feeling that there is a lack of good local standards for training.

Course materials

Course materials reviewed included those provided by ECF, USP and obtained online (ICDL of VIT Training and materials such as those found at Thomsonlearning.com). Materials were unavailable for HRD, however the researcher learned that HRD used the same sort of materials as the others (videos and step-by-step instruction). AUF's course outlines were available online.

The criteria used to compare course materials was based on layout and clarity; type, such as step-by-step or explanatory; sufficient explanation at each level of training; its carrying out of stated objectives; inclusion of practical application elements for each level; effective testing of skills and knowledge; and elements that the trainees did and did not find helpful. Course outlines were available online in French and English.

Outcomes of this investigation were that some of the listed objectives in course materials are not fulfilled in the material and professionalism in production was lacking; for example, in some materials the table of contents and page numbers did not coincide. Few of the course materials were easy to understand because of wording that was confusing. More explanation of each topic was considered helpful and some materials lacked detail, such as explanation, suitable for the level at which it was aimed. There was a lack of explanatory information in the course materials, which are primarily based on a step-by-step method. Participants felt this style was less likely to help them retain skills after training was finished. One participant noted that after completing a step-by-step short 
course 'the certificate [certifies] that you pass but actually [you] cannot use the computer.'(FG15). The expense of and the lack of up-to-date, good quality text books were considered important deficits. Handouts of main points were found to be useful for books as well as materials given during sessions.

Trainers and training methods

The training method of trainers is based on the recent experience of trainees from two providers: ECF and USP. The main findings about trainers included their possessing positive attributes toward students' learning, such as sincerity and involvement. Focus groups agreed there are well qualified trainers available in Port Vila but a common problem is that it is hard to understand expatriate trainers because of accents and pronunciation. They are easier to understand if they speak slowly and clearly. There was an expression of the need for trainers to be able to understand and speak Bislama. Members note that trainers are very hard working and this may cause them at times to become impatient or cut short their explanation of concepts. This is especially true when there is only one tutor to teach all courses. This puts pressure on that person and affects the training quality. There are times when trainers don't manage their teaching schedules well and are sometimes late and some trainers miss entire training sessions. When there is much information to learn the trainers sometimes rush and this makes it hard to understand. There is often not time for trainees to ask questions because of the need to rush but also because the trainer does all the talking.

Longer training times than the two-hour sessions common in short courses would be helpful. Two hours training once a week is not enough to grasp concepts and put into practice. The method of spoon feeding, or simply following written instructions, is not a good method to use for remembering and using the information later. Having demonstrations, explanations, written instructions and set tasks is helpful in training. The preference for training was to be guided by the trainer with written instruction and demonstration, given real tasks and left to find answers by working through questions or case studies. When it comes to exams based on the courses taken, some exam questions include topics that have not been discussed in training. 


\section{Training facilities}

The critique of training rooms and equipment was based on discussions and drawings made by the trainees from ECF, a visit to the USP lab by focus groups members, pictures and descriptions of VIT and HRD provided by the researcher and a brochure from AUF obtained during an interview by the researcher with the institute's manager.

Facilities were rated on cleanliness; ventilation; sufficient and organised space for the number of trainees; standard of equipment available; enough but not too much lighting; seating; and whether there is a quiet place to work. Non-functioning equipment was a source of frustration, from computer hardware and peripherals, especially printers, to projection equipment.

Some labs are clean and tidy, others are dirty, untidy and disorganised. Those without air conditioning or fans were very hot, making concentration difficult. Many have new computer equipment but those with old computers have hardware failure and maintenance issues. It is frustrating to have equipment or functions like the internet not working or projectors not available when needed. Labs that have fewer computers than the number of students are not helpful for learning. There is a desire for more hands-on practice and therefore access to computer labs outside of training times. The environment in training labs is considered central to enhancing learning. This includes a quiet place to work, room arrangements that make it easy to move around and non-glare lighting to help minimise eye-strain and fatigue.

\section{Trainees}

Focus group members recognised that their own attitude and behaviour is important to successful training. Active involvement during the courses and good attendance were the highlighted attributes of this attitude and behaviour component. 


\section{Conclusions}

Skills needed

There are a variety of computer skills needed in Port Vila and these are often job specific. Most jobs require basic knowledge of office software like MSWord or MSExcel.

\section{Training types}

There were more types of training than the focus group members were aware of and they felt it was good to know of this. It would be useful if there were a clear local standard as a foundation for training certificates would improve the perceptions they have of local training standards.

Course materials

Course materials would be greatly improved if they were written in simple language, containing only what is needed to explain what is required at a certain level. There was a unanimous feeling that course materials would be helpful if written using Bislama, and if they included local examples and case studies that trainees could work to solve.

Trainers and training methods

A good method of training is to have trainees explore solutions to questions rather than being told too much by the trainer. Trainers may need to prompt trainees to ask questions. It is best if training is done using Bislama or simple English. It would be useful to have field trips to businesses that use computers and internships to back up in-classroom training.

Training facilities

Good maintenance of computer lab equipment was thought important to support learning and neatly organised, clean, cool labs make a more positive environment to work in. Labs with good ventilation and up-to-date computers assist trainees' comfort and ability to work on what is required and also helps them concentrate for longer periods. 
Trainees

The trainee's attitude toward learning and attendance enhances their learning outcomes.

\section{Recommendations}

Skills needed

Recommendations were that employers should support their staff with regular computer training programmes, either on site or accessed through training providers. Employers would encourage professional development by actively encouraging more Ni-Vanuatu to learn or improve their computer skills at work.

Training types

In general the focus group members, once aware of the variety of training, thought coordination between training organisations would be useful.

Course materials

More low cost, up-to-date resource materials for trainees could be made available. Perhaps this could be achieved by having a common library that holds up-to-date material or in-house collections at workplaces that have resources supporting their applications. The government might support an online database of course materials available through the internet. More locally-written course materials with Bislama and local examples would help make learning accessible by more $\mathrm{Ni}$-Vanuatu and would make materials more locally relevant.

Trainers and training methods

Courses should include a mixture of step-by-step instruction, explanation, demonstration and practical work. If a trainer's first language is not English, he or she should remember to speak slowly and clearly and to clarify what is being said and to prompt trainees' for questions several times during training. It is most helpful if trainers learn to use Bislama. Also, the trainer's schedule should allow them to be available to talk to trainees outside of training.

Training facilities

There should be fans in all labs, if not air conditioning. This helps the trainees as well as being better for the hardware. Room arrangement was an important aspect 
of a good training facility. Labs should have enough space for the number of students and be large enough to allow trainees to move around and be active. Lighting should be sufficient but not too bright and window light should not shine on screens or in trainees' faces.

Trainees

Trainees also have a responsibility to participate fully in the courses they take if they want to be truly successful.

\section{ANALYSIS OF RESULTS}

\section{Skills needed}

The participants' results indicate their awareness of a need for a wider repertoire of skills than simply knowing how to use a computer. This is consistent with the belief that competency alone is not sufficient; that capability, or a wide range of skills other than technical competency, is a desired goal (Phelps et al. 2005; Aggarwal 2003; Denning 2001; Sein et al. 1999). The employer interviews reinforced this by indicating a specific need for skills to include self management, communication and customer service. With the local lack of employment opportunities and, therefore, on-the-job training, it seems to suggest these skills ought to be included in training programmes. Included in the self-management category of skills needed by employers was the desire for an employee to have good study skills. This expresses the need for a lifelong learning capacity to be built into training at this level. This is beyond technical competency.

\section{Pedagogy and methodology}

The major problem expressed about foreign trainers is understanding, referring to their oral delivery. Most Ni-Vanuatu speak several languages from a young age and speak some level of English. But accents make a difference to understanding so speaking English does not ensure the ability to understand and be understood. The most repeated complaint was that the trainee could not often understand what the trainer was saying so they relied on the written material.

Is the continued dependence on foreign trainers necessary? There were a few local trainers and more in the process of securing qualifications to do training. The most often repeated complaint about local trainers was their commitment to 
training. It was observed that not all, but many, local trainers were unreliable. One observer also commented that trainers are expected to teach many hours of training each week but this fact does not condone the lack of reliability as those same hours are being taught in technical schools overseas (Moon 2007, pers. com.).

Perhaps the question should be, what qualities do the best local trainers have that the unreliable ones are lacking? Or perhaps, what do local trainers need in order to be committed to the task? The researcher observed that there seems to be a status attached to computing in Vanuatu and, once that status was achieved, there was no longer motivation by some to fulfil work obligations. They often, once the status is achieved, (using an often repeated comment) sit at their desk with their feet up.

\section{Course Materials and Facilities}

Step-by-step materials were considered easy to follow but it was felt they were insufficient in helping the learner to retain skills as they lacked challenge or direct application of relevant concepts. One participant described the results of step-bystep instructions: 'I am not able to work in the office using the skills I learned, I need to re-read the book again myself' (FG15). The problem with step-by step materials is their prescriptive nature. In computer training, scenarios are often used to emulate actual tasks. In the materials obtained from outside sources these scenarios are often irrelevant to local workplace realities.

Participants commented about a lack of good, up-to-date texts to complement the materials available. Where there are texts for sale, the participants find they are expensive. There is also a limited selection of topics due to the small size of the text-buying public. The National Library has a few computer books but these are out-of-date; the same is true of the library at USP, whose main computer education centre is in Suva.

Negative qualities for facilities were found to be crowding, noise, lack of lighting, fans and ventilation. One computer per trainee was considered vital for learning and overbooking sessions was therefore seen as counterproductive to learning because of the necessity for practical exercise by each individual. 
The lab at USP was considered by the participants to be an excellent prototype due to its layout, spaciousness, lighting and ventilation. There was a criticism of number of equipment failures at USP and ECF but we did not have information of this for the other institutions so it was not a valid comparison. VIT was newly built at this point and not yet in operation.

\section{REFLECTION ON RESULTS}

Skills, pedagogy, methodology, course materials and facilities are at the surface of providing effective localised training. Observations of the ICT industry over the years in Port Vila and revelations from participants during focus group meetings start to delve into the levels of training practice where differences are more significant. At one level is the ecology of computing and end user training in Vanuatu and those factors that influence dependence, demand and delivery. At another level is the existence of a strong cultural philosophy linked with a striving for local voice in decision-making, a voice that needs to be recognised.

\section{Type of skills delivered through training}

One of the things lacking in end-user as well as technical ICT in Vanuatu is a history of embodied skill in ICT (Denning \& Dunham 2001). The technology is new in the developed world but is even more so in the developing world.

Therefore the older guides to ICT are lacking in the local population which means they are dependent on outside guidance.

However, the desire for 'international standards' is seen to be delivered with international trainers, but they rarely have the time or inclination to pursue, or simply do not respect, what may be needed locally. This can perpetuate a homogenisation of application and skills in using the technology and this could diminish the potential local 'adoption' of ICTs in the context. The strong desire for international standards is very possibly heightened by the importance given to computer training in developing contexts. It seems to be an outlook with little weight given to local needs, held both by those in training and those providing training options. This attitude is shared by those who rush to narrow the 'digital divide' with equipment and to adopt this technology at all costs. In this rush, there is little local research or experimentation of alternatives. 


\section{The impact of technology on young Ni-Vanuatu}

'mi wantem usum komputa from mi ting se komputa tede hemi laef blong yumi. Tede technology i kam antap bigwan' (FG7). Translation by author: 'I want to use a computer because I think now computers are our life. Technology has now become very important'. This is the perception, right or wrong, of the importance of this technology.

Responses by the participants to being asked why they desired to learn to use computers was overwhelmingly based on the 'need to know' for employment opportunities and their own well-being within the new technological community. One participant's comment reflects a modern reality: 'When I finish training I would like to work, Because [sic] nowadays people live only on money or survive only on money - Without [sic] money you can't survive' (FG2). There is the clear perception that getting work is linked directly with computer skills: 'When you have access in computer [sic], you can find a job easily. If you don't have access in computer [sic] you can not find a job' (FG1).

In comparing local qualifications with international, the feeling was that the local certificate indicates only that you have received some kind of training but the international certificate '..hemi blong showem wanem kaen training yu kasem' (FG2). Translation by author: 'is useful to show details of training you have received'.

\section{Access to training materials and opportunities to apply skills}

A 'downloading' mentality, being the ease with which materials can be taken from the internet, seems a profit-centred short-cut geared toward the training institutions' needs and wants rather than the users'. It is supply-oriented training and not at this point geared toward the local industry. The materials available are easy to use by trainers but are made elsewhere and not altered to fit the locale. No real thought or expense is required; it is truly a profitable business. Sein et al. (1999) expresses the thought that the training for business gets in the way of truly considering local and individual needs. It becomes much easier to download competency-based-training materials than to 'reinvent the wheel', so to speak, by writing materials to suit the local situation. 


\section{Language of delivery}

The language of training delivery is not given consideration. A possible reason for this is the common assumption that computing has a language of its own and this is established in English. Other underlying assumptions are that nothing in this technology originates (or can) in other places or other languages and that there is no reason to create materials in other languages since what is there is universal in today's new, globalised world (i.e. where everyone speaks English). This implies that the 'construction' of ICT is complete and/or dominated only by the English speaking world.

There are those in education and training institutions who feel Bislama is not an important enough language to retain and so a choice is made to exclude creating materials in Bislama to force a language migration of the young to either English or French.

Therefore the measure of a trainer imported to work in these institutions in Vanuatu is that they are capable of speaking English, with no regard to the level or clarity of their English. In one situation in Port Vila, trainers are volunteers from Japan who are in the role for only a year or two. English is their second language, they do not know Bislama. They start training immediately and are very busy so learning Bislama is put second. In another situation, a trainer from India is brought in purposely to offer a wider range of training possibilities. The trainer's standard of knowledge is high, as is competency in training, yet much of what is said in training by this trainer is outside the understanding of trainees because of accent and lack of Bislama. There is little evidence of language of delivery being an important measure of training quality to these institutions.

Bislama is an important language in Vanuatu, not only for communication but for the connection that is valuable between trainers and trainees. This connection is one of the important positive attributes in training. It is the trust and understanding that helps solidify relationships.

\section{Conclusion}

These findings may seem mundane and simplistic but what is significant is the process of which they are the result. The focus group members were transformed through this process from interested young people who wished to learn more 
about research and ICT in Vanuatu to active explorers whose interaction and activity made them more aware recipients of end-user training. Their recommendations reflect the very participatory process they were part of, seen in their suggestions to implement a more active, exploratory and localised approach to end-user training in Port Vila.

While the question of end-user computing training remains relevant in this and many developing contexts, the methods for pursuing it demonstrate the need for a different primary question, that of how a process of participation that seeks empowerment of those 'affected' by the practice in question is an overriding concern to the question itself. The next chapter presents a narrative of the process that highlights the transformation, through empowerment, of the focus group members through a participatory approach to research 


\section{CHAPTER 6: Research process}

"It takes two studies to present one in qualitative research. One...is the "official" research project and the other...is the study about that study.' (Chenail 1995:2 citing Harries-Jones 1995).

\section{INTRODUCTION}

The research for this study was based on the question whether the pedagogy and methodology of computer end-user training would be better changed to a more local style. This question remained the focus of the project but the group dynamics were such that the method of gathering this information became as interesting as the question itself.

This chapter gives a narrative account of the process of pursuing the question by the focus group members and attempts to show details of a participatory approach employed to empower the individuals involved in focus groups. It differs from the methods and process described in Chapter four in its attempt to illustrate specific points that support the shift in the focus of the thesis from the research question to the significance of the process used. The main focus of participants was to address the question 'What methods for end-user computer training in developing countries are relevant to their needs?'. In doing this, the researcher focussed on encouraging a true participatory process for the purpose of empowering the participants and giving them experience of a type of agency that gives empowerment an outlet, the presentation of their findings.

An overview of framing questions and choosing participants is presented, followed by a chronology of events from the start of focus group sessions through to the groups' final presentation to local stakeholders of the results. This material is presented in four parts: Setting, Identity, Focus and Task. The setting includes pictures of room arrangements for each week to illustrate the freedom of movement and the shifts from individual to group work. The Identity section involves the 'forming' of the individuals into groups and suggests a shifting of power. 
This narrative will present the process as it occurred. The key points it raises will be discussed in the following chapter to critique the points that supported the individuals' shifting power throughout the process.

\section{FRAMING QUESTIONS}

Prior to meeting with the focus groups, the researcher had spent four weeks gathering background information from local stakeholders to re-familiarise herself with the local ICT situation from various viewpoints. Questions used in the focus group sessions were written only in general terms before entering the field and often the specific questions were written by both the researcher and the focus group members as the weeks progressed. Questions evolved, based on information gained in stakeholder interviews and focus group members' experiences.

Stakeholder interviews gave a better understanding of local issues regarding training, helping to frame these issues for examination by the participants.

\section{THE PARTICIPANTS}

Methods used to select participants are detailed in the Methodology section as well as details about the methods used in the research (Chapter four). In this chapter there is a detailed narrative that relates to their starting with and working in the research process.

Twenty people were asked to join the group in the week before meetings were to begin. The plan was to split them into two groups of ten. Prior to focus group meetings there were 18 agreements to participate: seven females and 11 males. Based on comments about their availability, one meeting was set for Saturday mornings and the other for Wednesday afternoons.

The focus group members who completed all sessions were between the ages of 18 and 23. There were six males and five females. All but one were receiving formal training at the time of research; two were employed. Two were at a more advanced level of training; four had received software training only, at no more than intermediate level; and five had software, software configuration and hardware training, which tends toward more technically-oriented skills. Six had secondary school exposure to computing and two had received training at rural training centres. 


\section{FRAMEWORK FOR SESSIONS}

\section{Setting}

There were two possible venues for meeting the focus groups. One was a room at ECF's downtown headquarters in the business CNS, the other a small seminar room at USP on the outskirts of Vila east. The ECF room was on the top floor of a building downtown, above the CNS offices and workshops. It had fans and a whiteboard but lacked tables and chairs and these would not be available. There was access to a place for coffee outside of the room. It was offered to use at no cost. The room at USP was one part of a duplex in the classroom area at Emalus campus. At ground level, it had tables, chairs and fans, a blackboard and whiteboard. The staff room with coffee jug, chairs and tables was available to use. There was a charge to rent this room. Two days before the pre-session meeting (details following) the room at USP was booked. Later USP's Konfrens Rum (Conference room) was booked for the focus groups' presentation.

\section{Identities}

The setting was used as a form of building participants' identities within the group and the research. To encourage their feeling of belonging in the setting they were encouraged to re-arrange the tables and chairs how they liked and resources were kept in a central location with open access. The folder that held group work from past sessions was available to them as a resource to use. They were told they could come and go as they needed and the door was left open during the sessions.

The researcher was aware of the stages of groups dynamics, based on the Forming, Storming, Norming and Performing sequence described in Smith (2003:369 citing B W Tuckman 1965:348-399).

There were water jugs and cups in the room. Each had a cup to use for drinking. Participants spent some time decorating their drinking cups using whiteboard markers. These cups were used each week and the 'artwork' on them was added to from time to time. Participants took turns to fill the water jugs from a rainwater tank during break times, others carried tea supplies to and from the staff room where we had breaks. 
To further their identities as participants in something significant, part of one session was spent naming the groups. This is described in detail below. The Saturday group became Matangi ${ }^{24}$ and the Wednesday's was $Y$-grup ${ }^{25}$.

\section{Sessions plan}

A matrix was prepared by the researcher that indicated what the groups would cover in each session and what resources were needed (Appendix 6.1). This was stated in general terms. Changes to items on this matrix were noted from the first meeting onwards. Throughout the sessions, the general plan guided the sessions but became more detailed. The matrix included an overall focus point for each session and a question or task to consider before the next meeting. This was posted on a wall of the room along with a poster with the participants' pictures, their group and individual names (detailed later).

The sessions were four hours, starting with a 2 hour focus session, a 30 minute break and a final 1.5 hours activity session. The focus sessions included discussion and writing. Strict time limits were not set on activities but indicated what to accomplish for that day with flexibility to let participants work out how they wanted to use their time.

In the activity sessions, the participants used a variety of tools to record their ideas. They often wrote papers which they put in the group's collection either at the end of the session or in the following sessions. They wrote ideas on the chalkand whiteboards in the room and pictures were taken of these with a digital camera.

The start of each meeting included a summary of the information gained in the last session. These summaries were prepared from the papers they had written and the pictures from the chalk - and whiteboards.

\section{SESSIONS}

To accentuate a shifting in an I/they/we focus, this section will be written in first person.

\footnotetext{
${ }^{24}$ meaning wind, in the language of Emae island.

${ }^{25} \mathrm{Y}$ signifying the shape of the islands of Vanuatu, grup being the Bislama (perhaps more Bishlish) word for group.
} 


\section{Pre-session: meeting and administration}

I arranged a pre-sessions meeting three days before the first group meeting. This session was organised to make the most of the short time I had with the participants to explore the questions I came with. I arranged for use of the classroom that we would meet in, and had not scheduled specific times for meeting them (I was available from 8:30 - 3pm). I wanted to meet them individually before they met as a group. For some, it would be my first face-toface meeting with them. I had verbally invited those I had made contact with and had sent an invitation via email through my liaison at ECF.

The focus for this meeting was both personal and administrative. I considered what might be important for participants to know and thought they would want to know what to expect, to consider what was in it for them and to consider their part in the process. The administrative tasks to address were a brief explanation of the research and introduction of ethical considerations and forms. I gave each a onepage overview of my research proposal, written in English and a paper 'card' with my local contact details (Appendix 6.2). Each participant received their copy of the Participant Information Sheet and Informed Consent form (ref. Appendix 4.6 $\mathrm{b}$ and $\mathrm{c}$ ). I asked them to sign when they felt comfortable with the information. I explained this in Bislama, the forms are in English.

If/when they agreed to be part of the group I gave them a task question to take with them; it was written on a piece of A4 paper. I asked them to consider this question and write down their thoughts on this paper for the first session and that I would ask for the papers to put in the group collection, which would also be my research data collection. To make sure they understood the question, I repeated it in Bislama and asked them if they understood what I meant. The first task was to consider 'Why are you interested in helping with this research?'.

Five participants came to the pre-session. Those five were those I had made contact with myself. No participants I had contacted through the ECF liaison attended. I later learned that the liaison was not able to open the emailed invitation. 


\section{Session 1: Information, administration, introductions, motivations and reflections on training}

This was the true starting point for the focus groups' sessions. One aim of this first session was to start to build group dynamics. Some of this was knowing one another, much more was openness and trust between us all.

Saturdays would be the first of the two sessions for the week; each group would focus on the same point each week. I took a picture of each person with a digital camera. We exchanged introductions and established the use of language for the groups. They were comfortable with my using Bislama. In reality we used the more accurately described Bishlish. Bishlish is a mixture of English and Bislama, also some French. This term was used by Miles (1998) to note the difference in the type of Bislama used in the main centres of Vanuatu and describes well the more dynamic centre-shaped Bislama. You might not have a komputa in a remote area, therefore do not need a word for it. When they addressed me, they used Bishlish; when they worked together they spoke a purer form of Bislama, which I found harder to comprehend, especially from the Francophones.

The first part of the session was used for administrative matters as most of the participants had not attended the pre-session. This was the same detail as described in the pre-session meeting. I explained my role as researcher and student and described my research question from its origin, which included previously training in Port Vila. I outlined what part in it I thought they would play. I presented the research background and ideas verbally, in Bislama/Bishlish. I mentioned my degree in Development studies and explained briefly what that was. We had a brief discussion about what development means and whether they think of Vanuatu as a developing country. They were unaware of their country's 'developing' status.

I asked for and received permission to record the sessions using a digital recorder. 


\section{Setting}

I had the tables arranged so they sat slightly separately from each other, each at a table, but the tables were connected. I sat at tables in the upper middle of this setup, closer to the front of the room (see Figure 6.1, below).

Rather than settling into a routine, I wanted to ensure the process each week was left open and wanted to encourage decentralisation of our setting and leadership. I invited them to consider the room layout and to feel free to arrange tables and chairs as they liked. They left the room as I had arranged it.

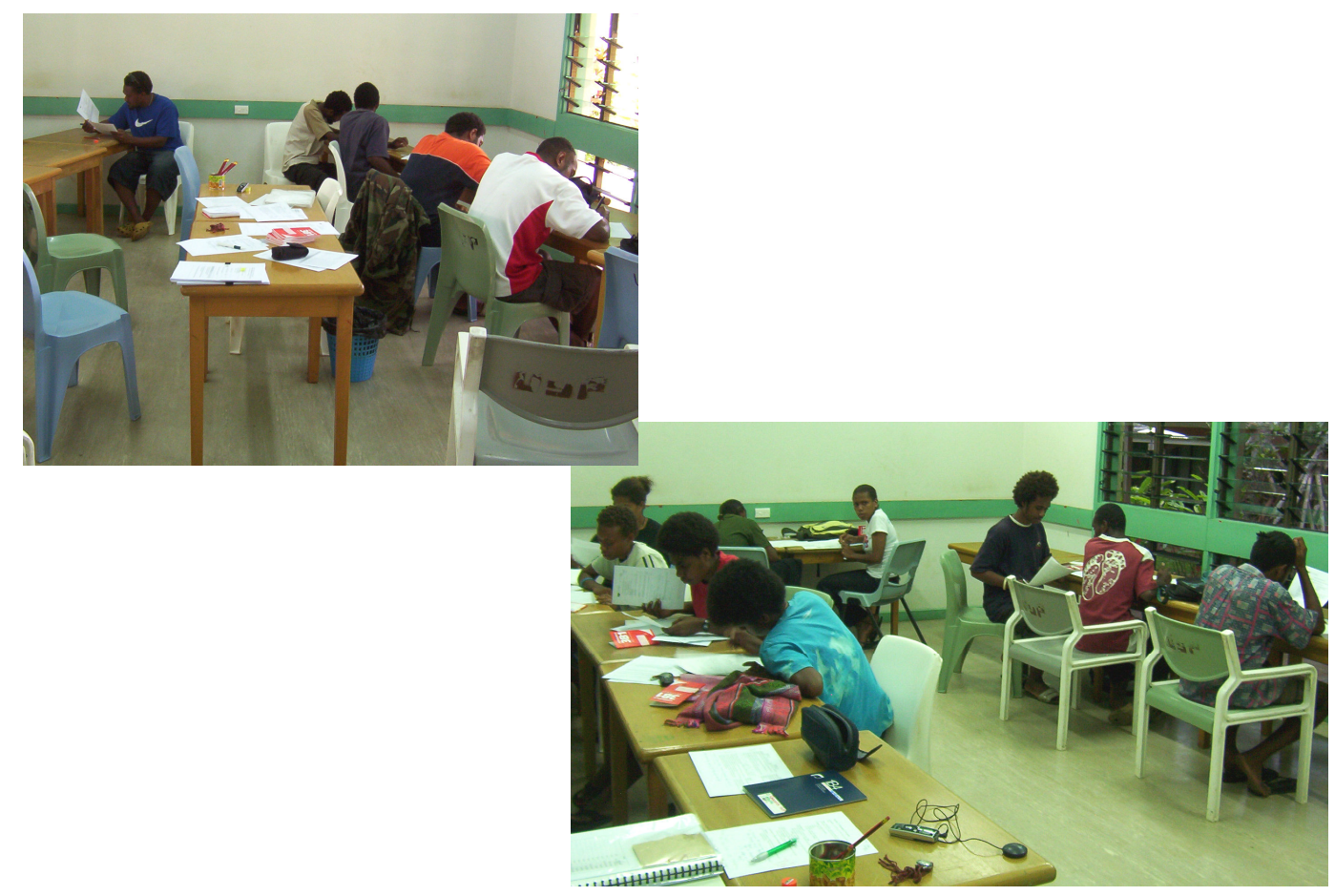

Figure 6.1: Session 1 room layout. Matangi, top; $Y$-grup, bottom.

\section{Identity}

I gave each participant a blank notebook and asked them to consider this their research journal. Throughout the sessions, I reminded them they were doing research rather than just supporting mine. I dubbed them ol riseja (researchers) and explained this was because we were all searching for answers to the questions. In explaining the process, I mentioned that at the end our goal was to make a presentation to local stakeholders and that they would have the opportunity to present the information we developed 'upward'.

Six out of eight participants scheduled for the first meeting on Saturday attended (Matangi) and nine out of ten scheduled for Wednesday (Y-Grup). 


\section{Focus activity}

The first focus question I asked was the task question I had given those who attended the pre-session, 'Why are you interested in helping with this research?'. I wanted individual answers and noted they were not yet comfortable with each other to discuss openly so I asked them to write their responses. They sat quietly and worked intently on this task.

After the break I presented the second question: 'Describe the training you've had and the training you are doing now. Where? (describe things about this); who is teaching? (describe things); is it easy or hard?; why?' They worked on this individually. After they wrote, I attempted to discuss this as a whole group. Seeing that they were still shy about talking, I asked them if they would like to work in groups. They agreed and I suggested we break into pairs/triples (Saturday/Wednesday) first to consider the question and make a list. Next the pairs/triads changed tables, each considering, adding to or commenting on the others $^{26}$, then they used these lists to come up with what they liked and did not like about the training, then the whole group wrote their final lists on the boards after all pairs/triads had considered all the lists.

The last focus question I asked was for them to think about how their training could be improved. They discussed this actively, using the lists on the boards for ideas and checking what they had written, some making notes in their journals. They all worked together at the boards after I got them started. My role diminished once they were active; I observed, sitting slightly apart from them.

\section{Task}

Before we parted, I wrote their task for next week on the chalkboard: 'Think about what you will do when you finish training: where would you like to work (doing what)? What would you like to do with your skills? What skills do you need for this work?'. I asked them to write their ideas about this in the journals.

\footnotetext{
${ }^{26}$ This is a variation on 'think, pair, share', developed by Frank Lyman (1981); The responsive classroom discussion: The inclusion of all students, in A. Anderson (ed.) Mainstreaming Digest (pp. 109-113), College Park: University of Maryland Press); and introduced to me in EDUCATION 569, April 2007, Karori campus, Victoria University of Wellington.
} 
At the conclusion of the first meeting of the $Y$-grup, the participants requested me to make a calendar of events to put on the wall, based on the matrix similar to the one I had as part of the group collection (ref. p 106).

\section{Session 2: Reasons for training in computing and employment prospects}

At the start of this session, I asked them for verbal feedback of the last session. They tentatively responded that they liked working in groups best but that they also wanted time to write individual responses.

\section{Setting}

I put on the wall for each group the printed pictures I had taken of them with their first name as a picture caption. I also put up the weekly-plan matrix the $Y$-grup participants had requested, written in Bislama (ref. Appendix 6.3).

I encouraged them to rethink the room if they liked soon after we had started.

Matangi rearranged the room after an initial pause in which they 'connected' with each other using eye contact. They put two tables together lengthwise in the middle-back area of the room. The table for resources and the recorder sat not far from that, toward the front of the room. Y-grup rearranged the room in a similar fashion to Matangi with the exception of there being a double row of tables rather than single, including the resources table in the grouping (see Figure 6.2, below).
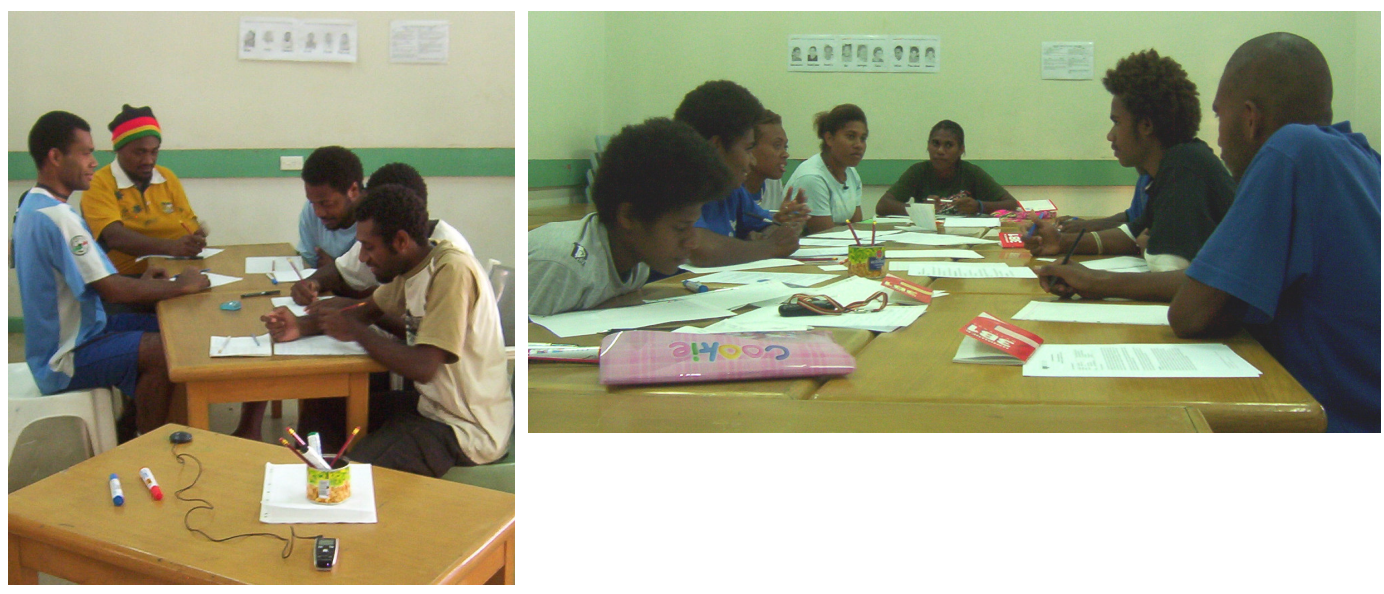

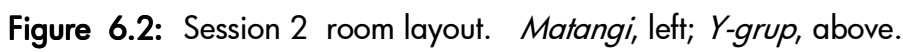




\section{Identity}

To illustrate the island of origin spread in the group, I passed around a blank map of Vanuatu for each to identify where they were from. They drew a line to very specific places on the islands and put their names next to the lines. Because the map was not very detailed, smaller islands were missing; I asked them to draw in the relative location of their island. While doing this, we talked openly about where they were from, sitting together at the tables.

In this session I asked them if they would like to name their group, giving them an example of Nawita (meaning octopus), an artists' association in Vanuatu. They liked the idea. I had them write ideas for names on strips of paper and when these were collected, I spread out the strips and we read them out, asked for meanings behind the names and then held a private ballot to choose a name. We used strips of paper for the voting. Saturday's group didn't need to vote, they all liked the name Matangi. Wednesday's group had a ballot, choosing Y-grup.

In this session one person in Matangi who had attended the first session did not attend the second and another left the second session before the midway break and did not return ${ }^{27}$. Attending: four. In $Y$-Grup one person who had attended the first did not attend the second session. I did not have contact with this person again. Attending: eight.

\section{Focus activity}

They spent time writing their thoughts individually on the task question I had given them last week about their training. I noticed some of them refer to their journals. I added the questions 'Why do you want to use a computer?, For whatwhy?, What do you need to know to get what you want/need? and What makes you think/believe this?', 'What training is important for you to get: local or international qualifications?', 'from wanem?' (why?) and 'What skills are you gaining that you didn't have before?'.

This week they started taking their papers home to work on them longer rather than putting them immediately in the group collection. They were diligent about

\footnotetext{
${ }^{27}$ I met this person at a function 20 days later and he made a point of apologising, telling me he had become very busy with his work.
} 
giving their written comments to me to put in the collection, either at the next session or before our meetings were finished.

The next part of this session was spent discussing the upcoming employer interviews that each would do before the next session. I explained the difference between open and closed questions.

We discussed employers they might interview and I wrote their ideas on the board. They each considered for a few moments before circling the one they would interview. The list of employers is detailed in Appendix 6.4.

There was discussion of the purpose of these interviews and what types of questions, open or closed, were useful for types of information sought. I had prepared general guidelines and example questions that the participants used to write the actual questions used for their individual interviews. The groups took slips of paper and worked between the tables and the boards to write up a list of all questions they could think of. Once they had a wide choice, they discussed and made a final form and all agreed to use this list of questions. Matangi wrote their questions quickly. Y-grup worked an extra hour on theirs. I worked at the tables with them but they lead and were engrossed in this activity. It ended up Matangi and Y-Grup used the same questions for their interviews. I was unaware of this as it occurred outside of the meetings times, attesting to the fact that they were actively engaged between groups outside of session times and that they felt comfortable with the process being theirs ${ }^{28}$. The questions used by the groups are included in Appendix 4.9.

I gave them each an interview protocol and observational protocol form (Appendix 4.10) to make notes from their interview and explained how to use it. There was discussion about how and where they would hold the interviews and I assured them they could interview in a kava bar if they needed, wherever they could meet and talk to the person they had chosen.

I also explained the relevance of ethics and gave them each a copy of a Stakeholder Information Sheet (Appendix 4.6 a) and Informed Consent form for their interviewee (Appendix $4.6 \mathrm{c}$ ).

\footnotetext{
${ }^{28} \mathrm{I}$ had not told either of the groups who the others were. This is testament to the nature of close relationships in Port Vila.
} 
We discussed a date for preparing the presentation, the first time the two groups would formally work together, and a date for the final presentation. For preparation both groups agreed Friday 14 December. Matangi suggested Thursday 20 December for the presentation and Y-Grup accepted that date.

T a sk

Before next week's session they were to interview someone in the industry who employs people with computer skills.

I asked them to bring examples of any course materials they had to the next meeting.

\section{Session 3: Training materials, facilities and qualifications}

I asked for verbal feedback from the previous session. Those who had finished the interviews (all but two) had considered interviewing to be the highlight of this process so far.

\section{Setting}

Matangi rearranged the tables similar to last session but with a double row. This time the row was longer and I sat at the table with them at the start of the session for the first time. I had placed the tables for Y-Grup into three small clusters as the work today was done in small groups (see Figure 6.3, below). As soon as they arrived I suggested they move them how they liked, as long as they worked in groups. They did, eventually moving the tables into two long rows. I was located in the group toward the front of the room, also starting out next to them for the first time.

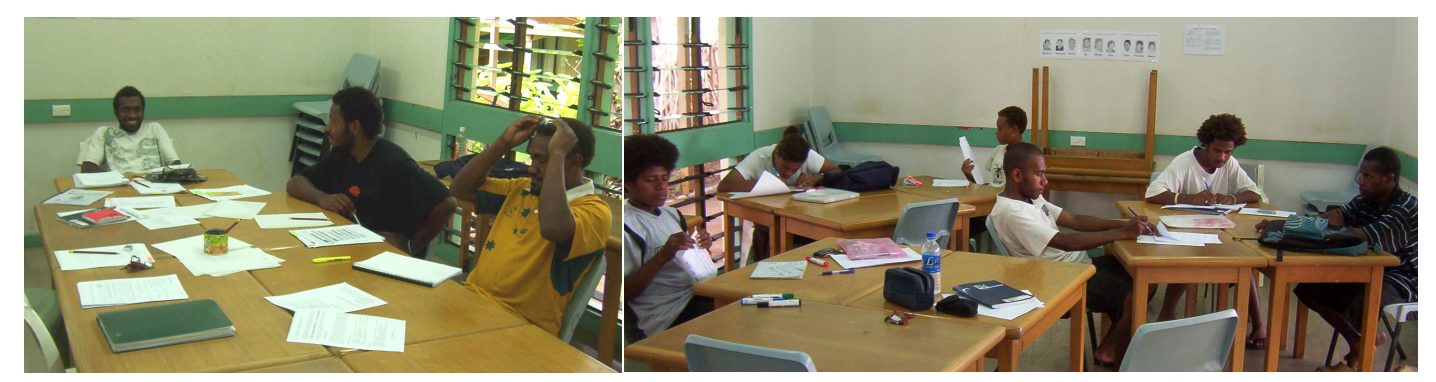

Figure 6.3: Session 3 room layout. Matangi, left; $Y$-grup, right (still in clusters). 


\section{Identity}

The poster with their pictures was updated to include the groups' new name and only those who remained in the groups.

In this session, only one person from Matangi did not attend but another participant explained that they had sent apologies and would return next week. The participants, one who had missed and the other who left early last week did not attend. Attending: three. I had received an apology from one $Y$-Grup member as well for this week; all others attended but the one who had not attended last week. Attending: seven.

\section{Focus activity}

I gave all focus group members a questionnaire, written in Bislama (Appendix 6.5). This contained more detail about them, such as their age, whether they had computers in their primary and secondary schools, their opinions about when to start computer training and where they planned to live after training.

We discussed their interviews. I had prepared a grid (Appendix 6.6) to focus them on this. They worked in groups, comparing their results and prepared the grid with a group summary of their individual results. Y-Grup was the only group to use this process as two from Matangi had not yet held their interviews so we started earlier to analyse course materials and lab details (details below).

I received their completed interview and observational protocol forms and seven Informed Consent forms.

Course materials were assessed by the groups and they also visited the USP computer training lab. Grids for analysing facilities, course outlines and materials, and training costs were used. Appendix 6.7 shows the actual analysis done. Matangi worked singly and Y-Grup in small groups to fill these in. I participated in this task, fully in Matangi, partly in Y-Grup.

The date of the presentation was changed as a conflict with another organisation came up for the participants. We discussed alternatives and agreed to present one day earlier, 19 December, if I could make the venue change. 


\section{T a sk}

Our task was to consider the grids we had developed and to think about what they had learned from the employer interviews and then to write down what they thought we might tell someone who asks how training in Vila could be improved.

\section{Session 4: What have we found out? How will we present this?}

\section{Setting}

Matangi moved to a different room this session ${ }^{29}$. We moved to the USP computer lab where the group set tables in a single row of two with four seats around it at the front of the lab. Y-Grup set up a double row of four in the middle of the classroom. They worked in two groups at this table, talking across and working between the groups. By the end of the session, they were working as one group in active discussion (see Figure 6.4, below).
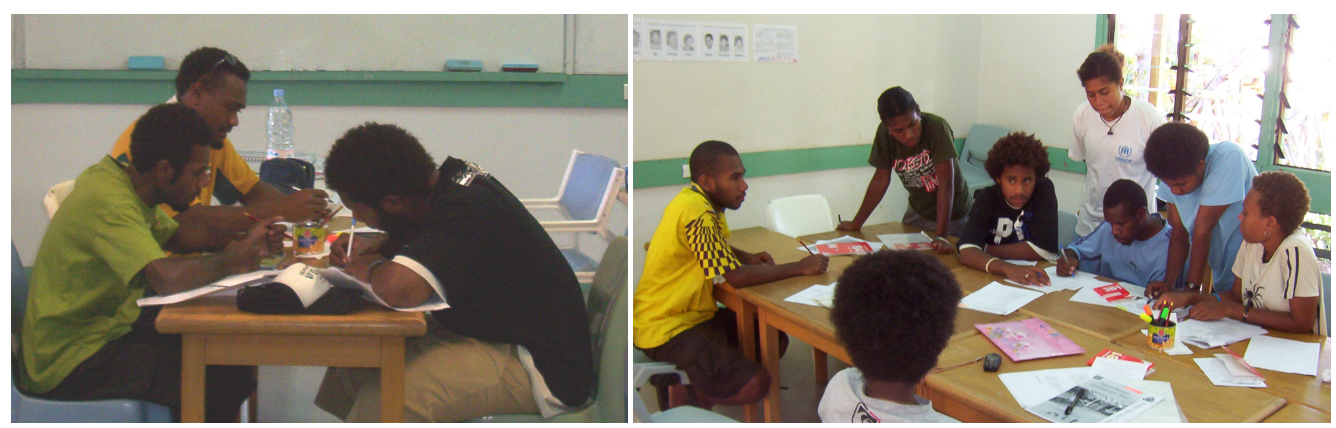

Figure 6.4: Session 4 room layout. Matangi, left; Y-grup, right.

\section{Identity}

The person who had missed last week's Matangi session returned but another was absent $^{30}$. Attending: three. The person who had missed last week returned to $Y$ Grup. Attending: eight.

\section{Focus activity}

This session was used to tie all of our work together, to plan and start writing the presentation. They worked with strips of paper to write out findings based on

\footnotetext{
${ }^{29}$ because of a double booking for a seminar group that was discovered on the day.

${ }^{30}$ I was told 13 days later by another that he had returned to his island.
} 
categories I had prepared from a summary of their written work from the previous weeks: skills needed, training objectives, course materials, training rooms, teaching, language and methods. They worked from the materials collected over the past sessions. We completed the findings. We had arranged a special meeting the following Friday to continue the presentation preparation.

Before closing the session I gave each a written form for evaluation of the process, written in both Bislama and English (ref. Appendix 4.7). I received back seven completed forms written in English, three in Bislama, one remained unreturned. The evaluations were positive, with many commenting how much they got out of the interviews they did between weeks two and four.

\section{Task}

Both focus groups were to meet together for the first time on Friday to work on their presentation. I asked them to consider 'How you feel about your training. What kind of jobs are there - what kind of skills do you need for these jobs? How can training be better to prepare you for these jobs?. Write down any ideas about how training is done now (Findings) and how it could be improved (Recommendations)'.

\section{Special session: presentation planning}

\section{Setting}

The groups organised the room into four clumps with tables around the outer edges and space in the middle. The small room made it feel very active and noisy and there were frequent crossings between the groups; all participants were actively involved (see Figure 6.5, next page).

\section{Identity}

All participants from both groups attended this session. Attending: 11. I provided resources and suggested procedure. They decided what each of the newly amalgamated groups would do and worked quickly and easily between three main groups. Quieter individuals roamed between groups more, those who took leadership roles tended to remain in the group they started with. I had a separate role. Three distinct leaders emerged and took more of the role I had previously 
played; they essentially were requesting from me things they needed me to do to help them carry out their tasks.

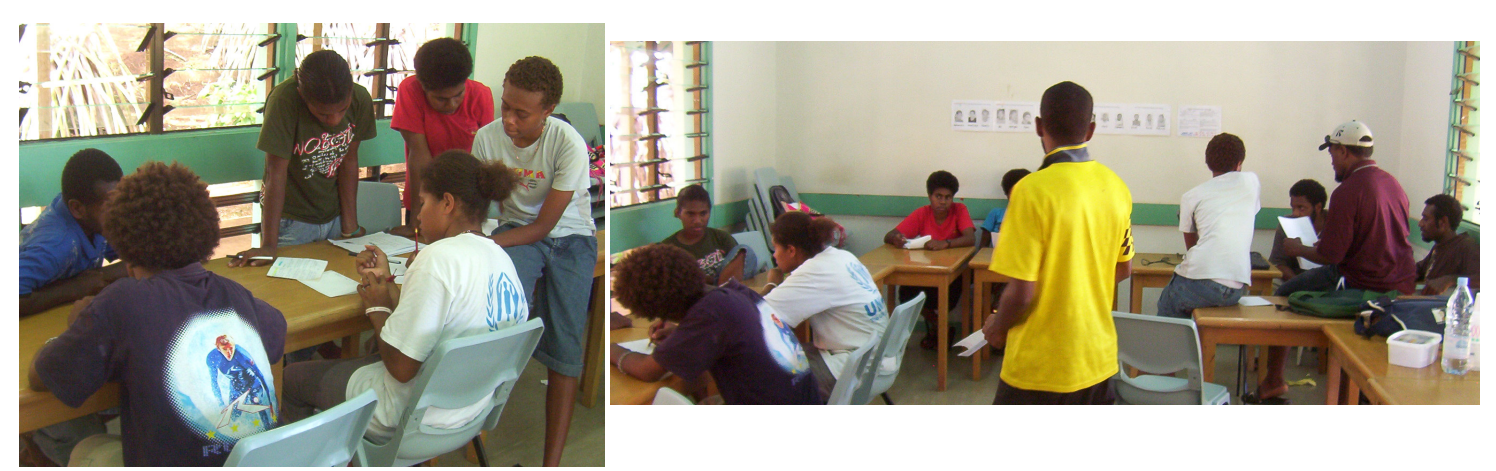

Figure 6.5: Presentation preparation with workgroups mingling. Matangiand $Y$-Grup combined.

\section{Focus Activity}

The groups worked on separate parts of the presentation that they had decided to deal with, talking together and answering the questions: 'Why do we need to use a computer?' and 'Why do we need/want training?'. They had the group collection of resources from the past weeks to draw from. I had brought my laptop and one group used it to make PowerPoint slides for the presentation.

I worked on the outline of the presentation programme, writing it on the board for the participants' feedback. We discussed and they agreed on the programme, writing copies of it to take with them.

\section{Task}

During this special session they decided they wanted more time to work on the slides so planned to meet on their own at the National Library the following Monday. Two of the participants led this. They planned to bring their PowerPoint file to me for printing the day before the presentation.

We agreed to meet at the venue on the day of the presentation two hours before the start time to set up and practice. I gave invitations to the participants to give to the employers they had interviewed.

\section{A presentation: an opportunity for agency}

In preparation I printed invitations and distributed them to all the local stakeholders I had interviewed during the research and to my partner, an IT 
manager from New Zealand who arrived in Vanuatu in time for the presentation. I made programmes to give to those who attended, based on the outline the groups had agreed on.

\section{Setting}

We used the USP Konfrens Rum. Being a large room, I had borrowed a projector and screen.

The participants arrived two hours early to help set out chairs for our guests. There were tables with catered refreshments. I had prepared three posters with pictures of the participants and photos of the groups working together. These were placed on makeshift display boards behind the refreshments.

\section{Identity}

I received one apology for attending the presentation due to a work commitment. Attending: 10. The participants used the time before the start to allot roles for presenting our information.

\section{Activity}

I gave a printed copy of the presentation slides that the two new group leaders and I had printed out the previous day to each participant. They talked together and made a plan that they would each discuss two of the slides in the Findings and Conclusions and two others would discuss the entire Recommendations section. The participants individually wrote their plans next to the slides they were allotted to speak to, asking me questions that had to do with giving examples and presenting. They went to different parts of the room and 'talked' through their parts.

We agreed they could present in Bislama if they wanted; they had written the slides in English.

When the guests were seated, one of the participants opened the presentation with a prayer. My role was to introduce the background of the research, to describe the groups' part in it and to introduce the participants. The participants each stood in front of the guests and talked about their assigned slides, giving examples or extra information about the points on the slides. When it was finished, I summarised the benefits of the research and we had a time for guests' questions. 
As this was our formal finish of the research process, I thanked the participants for working with me and presented each with a certificate of participation that was signed by three leading local professionals that were involved in research or training. I also gave each a gift of a locally made passport basket with the word Risej woven on it and a locally purchased AF-FM radio as a Christmas gift. We shared refreshments with the guests and a group picture was taken of us, the participants proudly holding their certificates (see Figure 6.6, below). The presentation was the last time I worked with these participants.

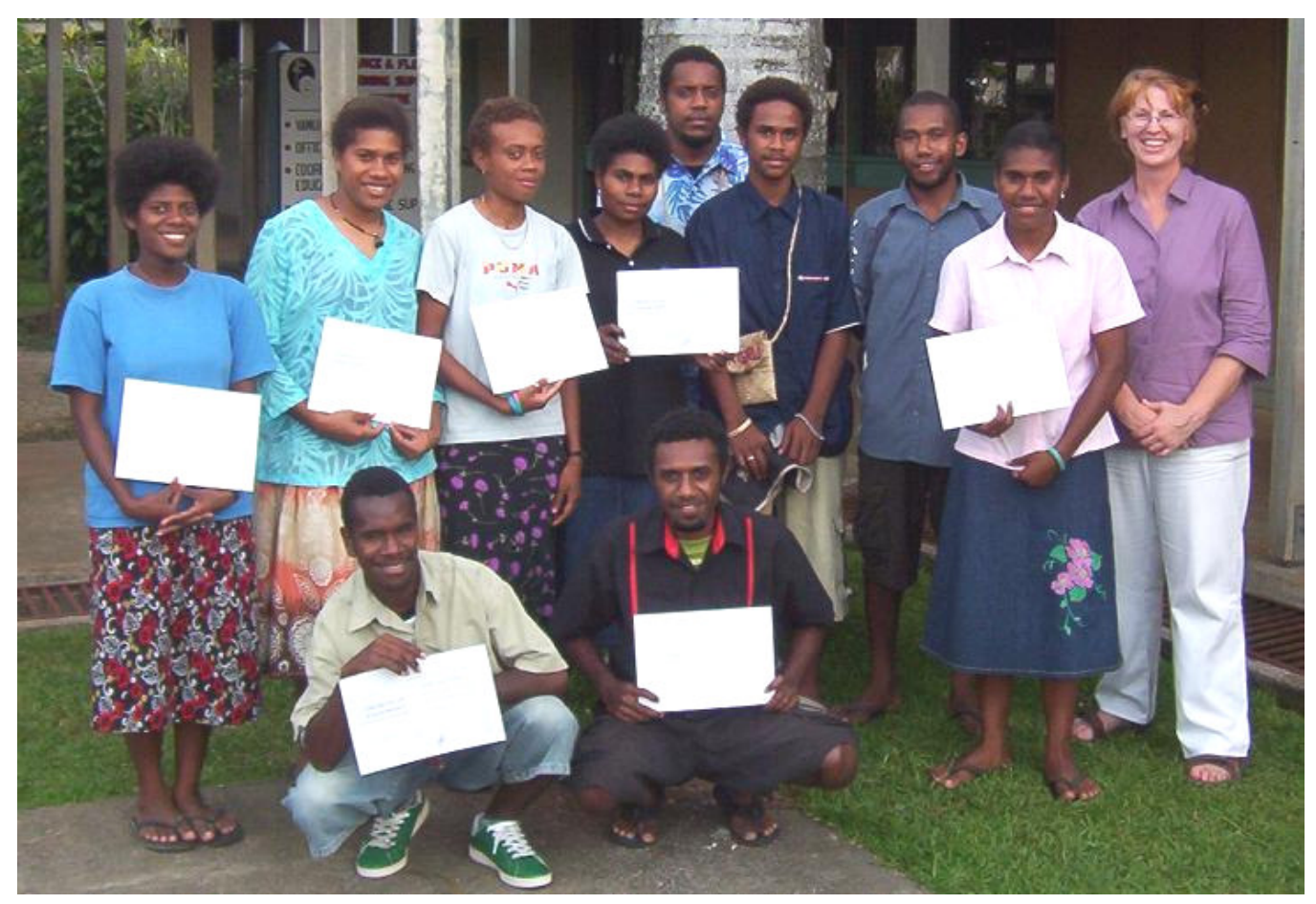

Figure 6.6: Researcher and focus group members with their certificates after their presentation. USP Emalus campus, 19 December 2007

\section{EXITING THE FIELD AND CONTINUED CONTACT}

I remained in Port Vila for a week following the presentation. I had extended an invitation for them to visit me at my accommodation and arranged for the pick up of the certificate and gifts for the participant who missed the presentation.

After leaving Vanuatu, I printed copies of the pictures and made a thank you card for all the participants using the picture we had taken after the presentation. Each participant received this packet, some of them delivered by my liaison at ECF for those who did not have a postal address. 
I have continued email contact with those who have email addresses. Five months after leaving Vanuatu I received an email from one of the focus group members saying 'I still keep that research journal though I've written [research] I did on web design at the back' [FG13]. The research journal is being used for more research. I take this as a small indication of sustainability: a nail for one of the ladder's rungs.

A copy of my completed thesis will be presented to the Vanuatu National Cultural Research Council and a summary to all stakeholders and the focus group members.

\section{CONCLUSION}

The role of process in this research verifies what Brohman (1996) said is the defining factor of authentic participation that leads to empowerment, that is that authentic participation must begin in early stages of a venture. The focus group members are on the receiving end of end-user training yet their awareness of how important they are to training's intent was non-existent. Their system gives, they receive. In asking a question about end-user training the researcher intended to explore that question in depth in this thesis; however, the focus group members so clearly transformed in the process of exploration that it seemed far less vital to answer the original question than to pursue the question 'how did this process transform them?'.

Key points from the process are described in this chapter that are considered to have supported the transformation in the individuals. They can be broken down into four headings: direction, environment, personal, and identity. The direction came from the researcher who was the catalyst. Direction was given by organising without controlling. There was benefit in having a framework to work from although this was never used to stifle alternatives. The most important part of this direction was supporting a sense of purpose and ensuring continuity. The environment was used to promote freedom of movement, access to supporting resources and the ability to rearrange the room as needed, which encouraged ownership of the activity and choice in interactive or protective space. It is clear to see in the pictures how the focus group members became comfortable with and used the freedom of their work environment. Personal aspects included the 
researcher's ability to speak their language as well as having a history in the setting. Ongoing contact between sessions by email or meetings in the street encouraged continuity in communication. Personal questions were posed in the process and their answers were respected through updated summaries of their work and their access to the growing collection of their work. Verbal feedback was regularly sought to make them aware the process was theirs to design. The final point, identity, is perhaps the most vital. The identity was personal, from having pictures to naming groups, and professional, as fellow researchers. The bottom line in the process, however, was trust. Each of the key points above helped build and maintain a trust that started with the researcher's trust in the focus group members and was returned as trust in the researcher.

Eleven young trainees stood in front of a group of people they view as the elite of training in Port Vila. They had started as eleven individuals and ended up identifying with their place in Matangi and Y-Grup and feeling proud of the research they had taken part in. Armed with their ideas, a plan and a clearer view of their purpose and place in end-user training they confidently presented their work to their fellow stakeholders.

In the following chapter a discussion of this process is presented. It will highlight aspects of the process believed to have led to empowerment of the individuals. 


\section{CHAPTER 7: Research process discussion}

This chapter provides a discussion of the process used to explore the research question. Points are made for each section identified in the Research Process chapter: Setting, Identity, Focus sessions and Tasks. The chapter ends with reflection on the role of the focus group members, the researcher's position and reflection on the process as a whole. It attempts to illustrate the changes observed in the focus group members' orientation to the topic, from receiver of training to awareness of their importance and relevance in the choices made during planning and therefore to an increased degree of power and opportunity.

\section{FOCUS ON THE PROCESS}

What is important about the research activity and interactions of researcher and the focus group members in this is that it encompasses the view of development as a process rather than an outcome to be attained. Emphasising process over outcome stresses the goal to inspire empowerment and agency in those people dependent on training but who are normally given a marginal role in affecting the choices of training delivery.

\section{Setting}

The choice of venue for meetings and, later, the presentation, did inspire the thought that if the exploration of the value of computer end-user training was the primary focus, both venues considered had a stake in the outcome. Part of the reason in the choice of the USP as the venue was that computer end-user training was only one small facet of the work at the university; the other was that the setting potentially brought with it an air of seriousness and opportunity to the focus group members. I felt this was the case because of an often apparent attitude of quiet concentration as we worked in our small classroom while other students were studying in rooms around us. This could also have backfired as it may have intimidated some focus group members and perhaps was why some eventually chose not to come.

The setting also provided an excellent means of giving the process to the focus group members. The first week was researcher-organised to fulfil the 
administrative necessities. After that the focus group members increasingly knew how they preferred to work and were not afraid to rearrange the room to suit their needs or to wander about and write on the boards if they were exploring an idea. Openness and wandering about the room or stepping out the door was commonplace and it encouraged an ease and ownership at an individual and a group level. Focus group members worked hard, some best as individuals during thinking tasks and more quietly with the group during activities; others showed facilitation and leadership strengths. There was not an individual that did not contribute to the process. All voices contributed yet individual working preferences were manifest often by where they placed themselves in the setting, and were accepted.

\section{Identity}

The first question I asked focus group members, 'Why are you interested in helping with this research?' was for them to explore what they expected from their commitment of time and what motivated them to participate. For me it was an indication of their understanding of the research based on my description to them and a way to understand their motivations. While their motivations reflected the introductory talk I gave about the research, which indicated how carefully they listened, their embellishments were quite personal.

Examples of actual answers focus group members gave to this question follow:

'I will learn something new from each other and maybe from my mistake[s]. Not only to learn [sic] but I know that all the information given by me will help ICT in my country and needs of ICT user[sic]' (FG9).

'I want that computing business know about my idea[s], what is [inside] my head and what I can do as a computer studen' [sic] (FG7).

'I want to face my problem ... [I want] not [to be] afraid[of] standing in front of people again' (FG8).

Their answers to this question covered eight key areas. Expectation of learning new things about ICT or about research; simple curiosity about research; networking with others; a means to improve their chances at getting a job; to improve ICT in Vanuatu, especially computer training; helping me with my 
research; a good use of free time; and to be able to communicate his/her ideas about training. Of these, learning new things was the most repeated comment, improving their job prospects and as a means to help Vanuatu's growth in computer training were the next most repeated.

The focus group members were all computer trainees, important stakeholders in training delivery. They benefit from the training by building their skills. The training institutions, also stakeholders, profit by providing training but also ostensibly believe in building skills for the benefit of individuals and the country. Industry stakeholders employ the trainees and are affected by the quality of local training. The largest stakeholder, the country, benefits from training programmes by a growth in human capacity that contributes to the country's functioning and growth.

When it comes to planning for and delivering training, trainees are given a minor role in being offered a say in short evaluation forms at the completion of each training course. Appendix 7.1 is an example of the sort of standard evaluations used. These evaluations are not, from what I could observe, considered important enough to inspire changes in training and delivery methods. Perhaps the structures in place that provide training opportunities for young trainees do not inspire the kind of critical feedback that would induce the need for change, thus assuring silence in the form of non-critical evaluations because of trainees not knowing what else to expect. This lack of in-depth exploration and critical feedback of training is where I see a marginalisation of the role of end-user trainees to exist.

The focus group members in this research are concerned for their future. While they are perhaps not able to articulate specific expectations of where they might apply their newly gained skills when finished, they are, when given a chance, able to articulate what works and what does not and are the ones with first-hand experience of training programmes. They have a large stake in this and, when given the opportunity to explore questions about their training, are capable of identifying needs. 


\section{Focus sessions}

In the first two sessions, focus group members often worked individually to write responses. Toward the end of the first session they worked in pairs and began to use the room's resources with increasing freedom, although tentatively at first. By the fourth week, sessions were actively in the hands of the focus group members, with the researcher providing the session's aim and focus group members deciding how they would work to explore the focus points. In preparation for the presentation, the group took the task on themselves, deciding to meet on their own to finish their PowerPoint slides. Two group members took a leadership role to organize this meeting, finish the presentation and liaise with the researcher who had resources necessary for the finale. This was their initiative.

The decision to have them write individually was in recognition of their shyness with each other and me at the start. Also, I wanted to ensure I got more accuracy by having their work in written form to clarify my understanding. Using Bislama as our main mode of communication made me unsure I was getting details. At times focus group members were hard to hear and to understand because of pronunciation. Their comfort in speaking to me in Bislama meant they spoke quickly at times. They wrote in English and Bislama but the difference was in having the written details to work through at my leisure. Their written Bislama was more formal than their spoken. It also gave them the opportunity to choose more precisely what they wanted to say.

The planning matrix that focus group members requested I put on the wall at the back of the room as well as the photographs of groups members were eagerly scrutinized by them at the beginning of the sessions. I updated the information each week to reflect changes and marked completed tasks. The focus group members seemed to respond to having a clear direction to guide them, the activities being where more direct group co-construction occurred. The matrix was general enough to leave room for group (or individual) creativity.

Break times were held in a different room during sessions and were a time when there was relaxed interaction. In the first week I believe this was the best ice breaker and during the remaining weeks we talked more about what we were 
working on during the break times that in the first week which was more general conversation. We shared tasks: carrying supplies, pouring drinks, cleaning up and this seemed to be a bonding mechanism.

\section{Task}

Participation in sessions and in preparing and presenting the Results was centred on the focus group members. Their participation was genuine to the point it could be in the short time we worked together. That the focus group members felt empowered was noticeable, especially at two points: following the employer interviews and after the presentation. Both were points of practicing a newfound agency, to communicate to fellow training stakeholders, albeit upward. It would seem, if this process could be practiced for a longer period of time with these same people, that there would be a strengthening of their empowerment and agency and that this continuity would enforce these qualities to the point of nurturing a transformation in both their personal recognition and the recognition of others as to the importance of their input as stakeholders in local end-user training.

To be more effective, this empowerment and agency would best be directed at the policy and political level, as Hickey and Mohan (2004) and Brohman (1996) state. The researcher has been content with taking a step toward securing empowerment at a speed fitting the context and natures of the people involved and introducing active agency on a small scale. Rather than working toward a political level of influence in this short time, working toward the establishment and awareness of empowerment was sought, which is a stage necessary to fulfil a sustainable transformation. The local involvement and interest in this process was encouraging, but it is still very much a starting point.

\section{REFLECTION ON THE FOCUS GROUP MEMBERS The makeup of the focus groups}

There was an unnecessary fear of being able to find enough focus group members who could afford the time to stay through the project. I had an ample list of possible members and many of them were keen to participate. After sorting through and choosing focus group members from the many questionnaires I had 
received, I wondered about those I had not chosen. Reflecting on how the focus group members interacted with each other and with me, I wondered how it would have been different if I had chosen others from the list.

The focus group members I worked with were younger than I had first envisaged for this research. Although not all were from Port Vila, they were exposed to the centre (Port Vila) and perhaps therefore were accustomed to more modern ways of life than their counterparts on their islands of origin or older people who had grown up in villages but who now worked in the centres. Having access to the centre, having all had a secondary education and being able to afford higher-level training means they were likely from a higher socio-economic level than many $\mathrm{Ni}-$ Vanuatu of their age group and many older people who had not had these opportunities. Perhaps for these reasons, they seemed less prone to holding back with their voices than older or village-dwelling Ni-Vanuatu might have been.

\section{Focus group members' realities}

From the opening statements in the first session, there was the strong impression that the young men and women I worked with are not aware of Vanuatu being a 'developing nation' or what the implications are for them. They are only eager to 'get ahead' in this new, economic world. Their village lives might be very different from life in Port Vila but they can see some form of Port Vila's more monetary reality trickling into the villages as they now perceive education as a need and that education costs money. Their village food supplies are expanded with imported goods and that, too, costs money. Their health may or may not still be primarily dealt with in the kastom way but they may at some point require medical care that costs money. And certainly they are tempted by the new communications links, i.e. mobile phones and the internet, which cost money. Wherever they may live, they perceive the need for earning money as being important. This is consistent with Niroa's sentiment (2004:27) about the changing perceptions of success in Vanuatu.

\section{Individual and group interactions}

Ideally I would have liked two fairly equal groups in terms of number of focus group members and gender. However, the activities and interaction of each group 
were quite consistent in terms of their results, even if the two groups worked differently. Matangi, a small all-male group was serious, worked quietly and very well together. I sensed a strong feeling of significance to them in their being focus group members in this research. Y-Grup was a group of five females and three males. While neither gender was dominant, the most actively dominant individuals were female. This group worked boisterously and their interactions were more challenging of each other. There was a distinct difference in individual preferences for activity in this group and more guidance was needed at the start to ensure all felt they had a voice. However, the quieter personalities were not voiceless nor were they excluded; they dominated on overview where the more active worked best on details.

When the groups joined to combine their work and prepare the presentation, there was little hesitancy. They seemed to share an equal goal and separated themselves into work teams with ease, the two groups mingling from the outset.

On reflection, I suspect my having given them the role of fellow-researchers, encouraging their use of research journals and having received instruction on new elements such as interviewing and the use of matrices for analysis assisted in a sense of learning and of purpose. I was impressed at the seriousness with which they entered the sessions each week, looking to the back of the room where the posters and sessions' matrix were and addressing each question with earnestness. The depth of their observations noted in observational protocol forms completed for their interviews showed their ability to apply research concepts quickly.

It also seemed important that there was a presentation to aim for, a vehicle for them to report on their work very soon after completing it. Grave attention was paid to the preparation and presentation of their results to fellow stakeholders and this was where the leaders in the group really emerged. I began to follow their lead, something that seemed to have altered in the weeks following the employer interviews. They saw this as their work and their responsibility, not mine.

\section{REFLECTION ON THE RESEARCHER'S POSITION}

\section{The importance of the research}

The original question grew out of my experience providing end-user training in educational institutions in Vanuatu and Tanzania between 1997 and 2005. Before 
I was in the field to research, I wrote, 'will I disappoint?', 'will I promise and not deliver?' Reflecting on this, I realised I may have been as concerned about disappointing or not delivering to myself as the idea for this research had been germinating for years before I began pursuing it. I realised the time in which I was attempting to explore the questions was meagre compared to the time in which the questions were forming.

Because of the years I had spent training in these contexts I was aware of the potential for doing harm and a desire to avoid it. I also realised the time in the field was short to do research from the perspective of relationship building and I felt there was more potential harm done in rushing to get information without that relationship. The reason why I chose to carry out the research in Port Vila was because I had lived there for six years, knew how to speak Bislama and felt somewhat more integrated than if it would have been a new environment. However my fear of disappointing was based also on the fact that the topic of enduser training was very interesting to me from the personal experience of training in this setting and I therefore had a bias about the potential answers to my questions. Another bias was having a desire for results of my research to offer something positive and practical to the focus group members.

\section{Power starts here}

In planning the focus matrix I felt a bit overly directive. Reflecting on this from the first meeting onward, I questioned how to achieve authentic participation. The reflection helped me to allow that directive-ness not to stifle any emerging angle the groups might wish to pursue and to emphasise the process rather than the outcome.

During the focus group sessions, I felt my way with respect to how focus group members wanted me to be involved. At the start I was dominant, leading the group through a schedule I planned. This made sense as I, the researcher, had ownership of the question at that point and ideas about the process and I was enlisting their cooperation. I was concerned whether they felt my questions were relevant to them. I wanted them to take ownership of the process and, if possible, to start to form their own questions. 


\section{Shifts in power}

After the second meeting in both groups, I observed that the focus group members were working together with little hesitation and were less reserved by my presence in the room. In evaluations at the end of the process a common phrase was that focus group members felt encouraged and appreciated the freedom of movement and talking in the meeting room. One participant wrote that the best thing about the process was 'to share ideas and [talk] to people I have never talk[ed] to. We can do thin[g]s freely like tell jokes and laugh. [It was] encouraging. I can do things without shame or being afraid of people.' (from evaluations). From these evaluations, I believe an important aspect of the participatory approach in this context was the small yet sufficient amount of guidance given; the large amount of freedom in focus group members' movement and ideas-sharing; and an appreciative quality to our interactions. Scharmer (2007:384) says of shifting power, 'You lead by painting a picture that is intentionally incomplete; you make a few strokes; and you leave lots of blank space that others can add and participate in'. Once the focus group members got a sense of belonging to this 'painting', they could see their place in the research process and more actively started to fill the space they were given. Through this, they started to see a place in the training they receive, shifting from passive to active involvement in caring about their options.

The shift from I/they/we mentioned in Chapter six is representative of a bonding as well as a 'shifting of the stick', or sharing the power (Chambers 2005), from the catalyst - me, to the focus group members in the process - they, and then to the immediate outcome activity, the presentation - we. Very much of this shift rests in the relationship between each of us in the groups rather than our relationship to the question we were pursuing.

One situation when I felt I had experienced a new use of power by the group was in the second $Y$-Grup meeting when they were writing the questions they would use for their employer interviews. We were sitting together around tables, I as an observer after introducing the task. They had written questions on the chalkboard and were now deciding on which they would use. They had gone a different direction on the type of person they would be interviewing, more technical than end-user, and were writing questions that would give them that different focus, 
different than what I had considered important. I remained quiet. They were struggling. Finally one of the focus group members asked me 'Are we off the track?'. Had the question not been asked I would have remained quiet; being voiced, the question allowed me to give feedback and suggest for them to review their purpose for the interviews. They considered this and a moment of 'aha!' occurred and they were back on the end-user track. Had they not asked, I would have remained quiet and would have encouraged them on the route they had followed.

\section{Reflection on the Process}

\section{Language}

A huge benefit of the process was that we were able to interact using Bislama, a language more familiar to them than to me. They interacted comfortably with each other in Bislama during the sessions. At times I could not clearly understand them and asked them to clarify when it was important to but believed our adopting Bislama as our main group language helped the shift of power to them.

Left on their own it is likely focus group members would have defaulted to Bislama as their only language of interaction. It was the presence of the researcher that raised the possibility of using a language alternative. In this case the researcher chose to be included in the language they were more adept at than otherwise. This raises an interesting question about language and development relationships when it comes to language (Scheyvens and Storey 2003:5) as it does in research relationships between insiders and outsiders (Cram 1997). In this case, the important information was less about the research question than about the process. This became the vital data and the process was better for having been conducted in a language more familiar to the focus group members.

\section{The presentation}

There was the usual pre-presentation adrenaline, most of the focus group members ${ }^{31}$ not used to speaking in front of groups, especially groups of 'elders' and important professionals. Focus group members were encouraged that the

\footnotetext{
${ }^{31}$ All but one participant presented; the one who missed had a valid reason to do so.
} 
opportunity of presenting their ideas was more important then the quality of their personal presentation, although we discussed basic presentation skills.

The presentation slides were prepared in English. The presenters were invited to speak in Bislama. Our guests were competent English speakers with varying levels of Bislama but the recognition and comfort of the Francophone focus group members and guests was important. Some focus group members presented in Bislama, some chose to speak in English and two repeated their parts in both Bislama and English.

At the conclusion of the presentation I felt all were equally pleased to have taken part and the feedback from our audience was positive. The refreshments at the end of the presentation gave us a chance to mingle with the guests to discuss the experience and the findings. All involved in this event took it seriously.

The focus group members' response to preparing and presenting their results at the end of our process indicated a true shift in power. A group leadership formed, crossed from the two-group to one-group amalgamation, and they organised and prepared the presentation without requiring much input from me. The role that I played was providing resources, listening, giving feedback and reminding them they were the experts as the information was theirs, and.

There was a strong sense of this being both exciting and terrifying. The general impression was that the focus group members had enjoyed being a part of the groups and were proud of their opportunity to speak about their computer training experience and this process of research they had been involved with.

A personal note that seemed to offer gravity was my telling them that my partner was coming from New Zealand and would attend the presentation. They were aware from my initial talk that he was now an IT manager in New Zealand and had been the IT manager for USP Emalus campus some years before. It was his professional attributes, not his relationship to me, that piqued their interest. Perhaps they saw him as a locally-knowledgeable, outsider ICT professional who considered their work important and for them this had clout. 


\section{Empowerment to transformation}

During this process I noticed we moved through stages in reaching for the greater process of transformation. I recognised there were levels of outcomes, but they were naturally occurring steps, not well planned, predictable steps.

There were also levels, or steps, of agency, from individuals starting to work in groups to the group that presented at the final presentation. We presented as a unified group who had agreed on facets of their experience and presented these to stakeholders at other levels. This was a step. Who knows where these individuals, the focus group members, will go from here, having had this experience? What is important is that they realise there is fear in speaking upward, but that there are those in upward places who do care to hear their voices and perhaps this realisation will encourage them to overcome debilitating fear and reach for the agency they do have to grow more and different agency from there. It is working at change at two levels: top-down and bottom-up, opening up awareness and opportunity structure for both.

\section{SCOT: another name for the process}

This process is an example of the social construction of technology, seen here as both know-how and tangible technology (Bijker et al. 1989). It is also an application of capability training in their experiencing a form of research related to their training. The expectations of focus group members were that they might learn more about computing and assuage their curiosity about 'research'. During their interactions, they reacted with excitement about how personally informative their employer interviews were, how varied their training could be, the choices that were available for training and what was possible in this small centre. I received an email from one focus group member after the employer interview: 'my interview [worked] out very good [and] it's really an interesting one I mean, I have the privilege to [hear] more about [the] vision yet to be done here at the office in the future, so I suggest it [really worked] out good' (FG14). Their awareness and more active part in their training and work seemed a form of power. As one focus group member said, [I thought the research was good because it helped me] 'to develop my communication skills and research skills, 
[to] talk publicly and [to] share ideas. It helps me to solve solutions to any future research in my training career or even my workplace' (from evaluations).

\section{Conclusion}

It was evident there was a shift in power in this process from being researcherdriven to having a shared purpose. The setting allowed individual differences in work style yet it encouraged working together. Interest was shown in the ideas that emerged, ideas that were brought forth by individual and collective thinking and doing. Individuals responded to the similarity, the difference and the amount of ideas that occur when working in a group. The researcher was a participant as facilitator, an important role of organising, ensuring resources and maintaining open interaction and communication between individuals. The focus group members responded to facilitation rather than direction by their burgeoning energy and commitment to the purpose.

Turning points in engagement were those times when the focus group members were given a task that challenged them and that they were trusted to prepare and perform. These were points that encouraged power shifting through growing confidence in focus group members' ability to talk with people who were more experienced in ICT. Those instances were the employer interview and to some degree the presentation to stakeholders.

What is interesting in looking over the points being made in this and the previous chapter is the similarity between this participatory process with the focus groups and the recommendations that are the results of their research. Focus group members as trainees saw benefit in trainers giving more challenges to their trainees, in finding out what the trainees want/need, in providing a comfortable, organised and open environment in which to interact with others and to explore questions. 


\section{Chapter 8: Conclusions}

The research undertaken for this thesis explores the relevance of end-user computer training to the needs of trainees and the industry that requires computer literate employees in Port Vila, Vanuatu. Local realities of training were explored in interviews with stakeholders who gave an institution-focussed perspective, followed by focus groups that pursued the question of relevance from a trainee-focussed perspective.

Stakeholder interviews provided a broad overview of the range of training available; course materials and facilities used in training; and the types of certificates, whether internationally or locally recognised, earned by trainees. Focus groups reflected on the local experience of training, examining their expectations, realities of their training experience and their ideas for improving training. The greatest difference between the two views was stakeholders' perception versus trainees' experience of pedagogical style and of material and facility provision.

Using a participatory process, focus group members each interviewed an employer about their organisation's computer skills needs. This gave participants the opportunity to hear for themselves how ICT is being used and the planning that goes into it in government and business settings. Feedback from the participants reveals this as one of the 'altering' events for them during this process.

The thesis relies on the original research question but it is the pursuit of it that is the more profound outcome of the research. The question of end-user training was the focus that sustained the participants' interest, but what became clear was the importance of the process of interaction and exploration undertaken by them in their attempt to transform end-user computing training. The process was dynamic and clearly showed a difference in participants' engagement from start to finish.

The research process in fact resembled teaching. This was evident in participants' exposure to techniques and processes of interviewing and of 
critiquing training by using matrices for measuring qualities of course materials and facilities. However, the method used was vastly different than participants were used to. The root of the Russian word for education is to 'mould' whereas a more appropriate description would be a 'drawing out ${ }^{\text {, }}$. It is an approach consistent with Freire's (1970) appeal for the rejection of the 'banking system' of education in favour of a liberating education. By having a researcher-participant role in exploring the question participants became an active part in a process of discovery. In the process the learning was vigorous, participants 'took the stick $^{33}$ more readily once they perceived the researcher was not correcting, criticising and looking for a 'right' answer but supporting their discoveries. They were given the time and the place to explore, to work as individuals and in groups, and they noted the benefits and output gained from this approach. This research process, in fact, was an alternative pedagogy in practice, an alternative approach to learning. Participation by the researcher diminished from being a direct participant in the discovery process, withdrawing in stages from active involvement when discoveries were being made by the groups, to becoming more of a facilitator.

There is a direct link of the process employed in the research to the focus group members' results which recommended a more active, exploratory and localised approach to end-user training. The participatory approach was used as a research methodology for this thesis but it is clearly a process that can be as useful as a pedagogical approach or as a development practice. It is a valid method for finding knowledge through interaction and for empowering those whose knowledge is furthered as a result.

Chambers' (1997:104) description of participation being 'malleable', 'a sculptor's clay' and 'shaped as it passes from hand to hand' is an apt way to describe the process in this research. ICT is a piece in the puzzle of development (Raiti 2007), as is participation and the many ways it can be called into action and transformed by use.

\footnotetext{
${ }^{32}$ Psychologist Dorothy Rowe was my source for the Russian word, BBC Forum, 6 October 2008.

${ }^{33}$ This refers to Robert Chambers' (1997:117) PRA method of 'handing over the stick'.
} 
The analogy of participation being like a ladder has been carried through this thesis, based on Chambers' (1997:104-5) description of types of participation. The ladder represents participation as a construction exercise carried out by those who participated in the research. There was a sketchy blueprint to build from so the ladder emerged based on materials and construction skills at hand. The ladder leans up against a body of literature that supports the rungs participants construct. At the base there are rungs representing the growing sense of awareness. The work the participants carried out and the presentation to stakeholders added rungs. This thesis is a rung the researcher contributes. Yet there are more rungs possible for the original question after this, the ladder is in a continuing state of construction. It could be continued by $\mathrm{Ni}-\mathrm{Vanuatu}$ for the topic of end-user computer training and potentially could be used for building similar ladders using this construction approach on other issues.

This process attempts empowerment and agency. Transformation is a bigger impact that will require numerous successful repetitions of empowerment and agency to contribute toward a sustainable outcome, as Kabeer (1999) points out. It is not good enough to make a quick change and to think something has been transformed, but requires a longer process of developing empowerment and agency so that transformation is understood to be happening and is at a pace where there can be reflection on what is being transformed, taking steps toward the transformative empowerment that comes with substantial change on a more political level.

The view of empowerment set out in the Introduction of this thesis coincides with the participatory activity in this research. There was awareness-raising, which activated the critical consciousness regarding training choices in Port Vila. Training choices are actually rather limited because of their similarity of purpose, training, materials and facilities which are all based on external standards. There was a process which witnessed individuals taking more of the initiative in pursuing questions and preparing a report of the process. Agency was provided as openness in the nature of the process and through realisation of an opportunity for the groups to present results. Empowerment was observed throughout this process with a growing tendency toward group autonomy from the researcher. However, there is a question of this empowerment being sustainable. 
The title of this thesis includes the research focus: 'Transforming end-user computing training in Port Vila, Vanuatu', which is a very ambitious goal. It was clear from the exploration of the question that a transformation in the pedagogy and methodology of end-user training should and could be pursued but that it is a transformation best done in a deliberate manner. This means recognizing the importance of inclusion of all levels of stakeholders, including trainees, and the necessity of a process to be done longitudinally. A longer time period would enhance the empowerment of the trainees' voices and build a strong, cooperative institutional structure that assures agency to those involved, a transformational agency as described by Kabeer (1999). The research attempts a small step in a direction that could one day equip these young adults to be the transformers of their country's training and also could be applied to questions in a variety of sectors.

I do not feel there was a transformation as this would require repetitions of the process with the same people until there is a sustainable relationship between the power they displayed in this process and improved agency through changes to their opportunities to practice agency. I believe this will not be possible at this stage, that there would need to be many rungs added to the ladder to enable a steady climb toward higher levels of agency. Empowerment is a process and that implies an on-going state; this ladder is still under construction.

I do feel this process showed that empowerment is possible in this setting, that the alternative method of research, which is seen as an alternative pedagogy, showed an encouraging local response.

The formal and informal institutions, or the opportunity structure, that affect the agency (Chambers 1997; Alsop et al. 2006) of these young trainees is an important consideration. Reflecting on Port Vila's more articulate computer training stakeholders, they appear to be interested in the input of people who are willing to become involved in the planning of and choices for training. I observed a keen interest in and awareness of doing what is best locally and 
recognition of the benefits of user input in the kinds and methods of training that are offered them ${ }^{34}$.

Active, regular dialogue would open the possibilities for local construction of issues concerning Ni-Vanuatu. Ideally it would include trainees, training institutions and their trainers, related government organisations (eg. VNTC, Ministry of Education), and industry that employs skilled computer users. This dialogue could monitor current and changing needs to assure local quality of training. This thesis shows that the users display a strong capability and desire to be a part of this process. It is my viewpoint that what is lacking is a catalyst active in facilitating a continual convergence of stakeholders in a participatory manner.

It should not be necessary for an outsider or a more powerful local to advocate on their behalf yet for Ni-Vanuatu this happens time and again due to their dependence on aid and perhaps years of indoctrination about the merits of 'Western' systems. To this end, it is and has been seen from within Vanuatu to be important to them that a greater number of locals learn research and writing skills in order to construct their own arguments. They might consider adopting a more participatory local pedagogy in their education and training so this active, collaborative research is at the forefront of their education and training. Remove elitism from research.

The growth in the services sector in Vanuatu will bring with it an increased need for locals with computer skills. With the increase in the numbers of youth entering the labour force, their training opportunities are an important consideration, especially if it gives them skills and the opportunity to increase local input in decisions about issues that affect them. Now is better than later to provide training to fit their environment rather than to conform to an outside environment. Raising their awareness will have far-reaching effects on their computer training as well as on their increased involvement in Vanuatu's social and economic growth.

A final note about the process was the personal nature of the qualitative approach taken in this research. Working closely together and using a familiar language to

\footnotetext{
${ }^{34}$ Oudshoorn and Pinch (2003) demonstrate the validity of user input.
} 
the participants enabled the development of a personal bond between researcher and participants. This was more than accessing knowledge, it gave the participants a space in my life. As individuals they remain with me through the writing as if we were producing this work together. The experience has had a profound effect on me, convincing me of the validity of using qualitative research with focus groups as a method to gain local knowledge and to help uncover, collectively, the often hidden, sometimes ignored wisdom at the root of this knowledge.

One young ni-Vanuatu wrote: 'I [learned] how to do research and analyse the results and [how to ] work in a group. The focus groups [sic] ideas can change the way we do computer training in Vanuatu' (from participant evaluations). 


\section{List of References}

ADAM, M. S. \& URQUHART, C. (2007) IT Capacity building in developing countries: a model of the Maldivian tourism sector. Information Technology for Development, 13:4 315-335.

ADEYA, C. N. (2002) ICTs and poverty: a literature review. International Development Research Project.

AGGARWAL, A. K. (2003) Internetalization of end-users. Journal of End User Computing, 15:13.

ALSOP, R., BERTELSEN, M. \& HOLLAND, J. (2006) Empowerment in practice, Washington, DC, The World Bank.

BAKER, A. (2005) A Woman's Place. Time. 19 September.

BALIAMOUNE-LUTZ, M. (2003) An analysis of the determinants and effects of ICT diffusion in developing countries. Information Technology for Development, 10:2003 151-169.

BEDFORD, S., SPRIGGS, M., REGANVANU, R., MACGREGOR, C., KAUAUTONGA, T. \& SIETZ, M. (2007) The excavation, conservation and reconstruction of Lapita burial pots from the Teouma site, Efate, Central Vanuatu. Oceanic Exploration. ANU E Press.

BELL, D. (1973) The coming of post-industrial society: venture in social forecasting, New York, Basic Books.

BEVAN, S. (1990) Vanuatu, Rozelle, NSW, Australia, Other People Publications, Ltd.

BIBI, F. (2004) Education Statistics, 1998-2002. In Sanga, K., Niroa, J., Matai, K. \& Crowl, L. (Eds.) Re-Thinking Vanuatu Education Together. Suva and Port Vila, Institute of Pacific Studies (University of the South Pacific) and Vanuatu Ministry of Education.

BIJKER, W. E., HUGHES, T. P. \& PINCH, T. (Eds.) (1989) The Social Construction of Technological Systems, New Directions in the Sociology and History of Technology, Cambridge, Massachusetts, MITPress.

BONNESMAISON, J. (1994) The tree and the canoe, history and ethnogeography of Tanna, Honolulu, University of Hawaii Press.

BOSTROM, R. P., OLFMAN, L. \& SEIN, M. K. (1990) The importance of learning style in end-user training. MIS Quarterly, 14:1 101-119.

BOWDEN, R. (2002) Young people, education and development. In Desai, V. \& Potter, R. B. (Eds.) The Companion to Development Studies. London, Arnold.

BROHMAN, J. (1996) Popular Development: rethinking the theory \& practice of development, Oxford, Blackwell Publishers.

BROWN, P. (1990) Big men: afterthoughts. Ethnology, 29, 3.

CAMPBELL, D. (2001) Can the digital divide be contained? International Labour Review, 140:2 119-141.

CARR, N. G. (2003) IT Doesn't Matter. Harvard Business Review, 80:5.

CASTELLS, M. (1996) The rise of the network society: the information age: economy, society and culture, Massachusetts and Oxford, Blackwell Publishers. 
CHACKO, J. G. (2005) Paradise lost? Reinstating the human development agenda in ICT policies and strategies. Information Technology for Development, 11:1 97-99.

CHAMBERS, R. (1997) Whose reality counts? Putting the first last, London, ITDG Publishing.

CHAMBERS, R. (2005) Ideas for development, London and Sterling, Earthscan.

CHAMBERS, R. (2006) CID workshop. Wellington. 27 November 2006.

CHENAIL, R. J. (1995) Presenting Qualitative Data. The Qualitative Report, 2:3 1-9.

COWAN, R. S. (1989) The consumption junction: a proposal for research strategies in the sociology of technology. In Bijker, W. E., Hughes, T. P. \& Pinch, T. (Eds.) The Consumption Junction: A Proposal for Research Strategies in the Sociology of Technology. Cambridge, Massachusetts, MIT Press.

CRAM, F. (1997) Developing Partnerships in Research: Pakeha Researchers \& Maori Research. Sites, 35:44-63.

CRESWELL, J. W. (2003) Research design: qualitative, quantitative, and mixed methods approaches, Thousand Oaks, Sage Publications.

CRESWELL, J. W. and CLARK, V. L. P. (2007) Designing and conducting mixed methods research, Thousand Oaks, Sage Publications.

CROSSLEY, M. \& TIKLY, L. (2004) Postcolonial Perspectives and Comparative and International Research in Education: A Critical Introduction. Comparative Education, 40:2 Special Issue (28) 147-156.

CROTTY, M. (1998) The foundations of social research: meaning and perspective in the research process, Crows Nest, Allen \& Unwin.

CUPPLES, J. \& KINDON, S. (2003) Returning to University and Writing the Field. In Scheyvens, R. \& Storey, D. (Eds.) Development Fieldwork: A Practical Guide. London, Sage Publications.

DAHLERUP, D. \& NORDLUND, A. T. (2004) Gender quotas - a key to equality? European Political Science, 3, 11.

DAVIS, P. (1999) How undergraduates learn computer skills: Results of a survey and focus group. T.H.E. Journal, 26:9 68-71.

DAVISON, R., VOGEL, D., HARRIS, R. \& JONES, N. (2000) Technology Leapfrogging in Developing Countries - An Inevitable Luxury? The Electronic Journal on Information Systems in Developing Countries (EJISDC), 1:5 1-10.

DENNING, P. J. \& DUNHAM, R. (2001) The core of the third-wave professional. communications of the ACM (Association for Computing Machines), 44, 21-25.s

DESJARDINS, R. (2008) Researching the links between education and well-being. European Journal of Education, 13, 23-35.

DUFFY, T. M. \& CUNNINGHAM, D. J. (1996) Constructivism: Implications for the Design and Delivery of Instruction. In Jonassen, D. H. (Ed.) Handbook of research for educational communications and technology: a project of the Association for Educational Communications and Technology New York Macmillan Library Reference USA.

ESCOBAR, A. (1992) Reflections on 'Development': grassroots approaches and alternative politics in the Third World. Futures, 24, 411-436.

FINK, A. (1995) The survey handbook. Thousand Oaks, Sage. 
FISCHER, S. R. (2002) The history of the Pacific islands, Hampshire, Palgrave.

FLETCHER, R. J. (1923) Isles of Illusion: Letters from the South Seas, David \& Charles.

FLOR, A. G. (2001) ICT and poverty: the indisputable link. Third Asian Development Forum. Bangkok, Asian Development Bank and UNESCAP.

FREIRE, P. (1970) Pedagogy of the oppressed, London, Penguin Books.

FRIEDMANN, J. (1992) Empowerment: the politics of alternative development, Cambridge, MA and Oxford, Blackwell Publisher.

GATTIKER, U. E. (1989) Computer technology and end-user training: an integration of information processing and man-machine interface perspectives. International conference: 'Computer, man and organization II'. Ottawa, Social Sciences and Humanities Research Council of Canada.

GOTTSCHALK, P. \& KHANDELWAL., V. K. (2002) Global comparison of stages of growth based on critical success factors. Journal of Global Information Management, 10:2 40-50.

GUPTA, S. \& BOSTROM, R. P. (2006) End-user training methods: what we know, need to know. Special Interest Group on Computer Personnel Research Annual conference on computer personnel research: Forty four years of computer personnel research: achievements, challenges and the future. New York, Association for Computing Machinery.

HARRIS, M. (2008) personal communications during the months of March - July.

HEEKS, R. (2007) Theorizing ICT4D Research. Information Technologies and Informational Development, 3:3 1-4.

HERES, J. (2004) ICTs, quality of life and social capital. In Mante-Meijer, E. \& Klamer, L. (Eds.) ICT capabilities in action: What people do. 2nd of 3 ed. Luxembourg, COST European cooperation in the field of scientific and technical research.

HERES, J., MANTE-MEIJER, E., TURK, T. \& PIERSON, J. (2004) Adoption of ICTs: A proposed framework. In Mante-Meijer, E. \& Klamer, L. (Eds.) ICT capabilities in action: What people do. 2nd of 3 ed. Luxembourg, COST European cooperation in the field of scientific and technical research.

HETTNE, B. (1990) Development theory and the three worlds, New York, Longman Scientific and Technical.

HICKEY, S. \& MOHAN, G. (2004) Towards participation as transformation: critical themes and challenges. In Hickey, S. \& Mohan, G. (Eds.) Participation: from tyranny to transformation? exploring new approaches to participation in development. London and New York, ZED Books.

IGBARIA, M. \& GUTHRIE, R. (1999) End user computing: clarity, change, choice (Technology information). Journal of End User Computing, 11, 3.

ILLICH, I. (1992) Needs. In Sachs, W. (Ed.) The Development Dictionary. 2005 ed. New York, Palgrave.

KABEER, N. (1999) Resources, agency, achievements: reflections on the measurement of women's empowerment. Development and Change, 30 435-464.

KABEER, N. (2005) Gender equality and women's empowerment: a critical analysis of the third millennium development goal 1. Gender \& Development, 13, 13-24. 
KINDON, S. \& CUPPLES, J. (2003) Anything to declare? The politics and practicalities of leaving the field. In Scheyvens, R. \& Storey, D. (Eds.) Development Fieldwork: A Practical Guide. London, Sage Publications.

KOTHARI, U. \& MINOGUE, M. (2002) Critical perspectives on development: an introduction. In Kothari, U. \& Minogue, M. (Eds.) Development Theory and Practice: Critical Perspectives. Houndmills, Basingstoke, Hampshire, Palgrave.

LAMBUKLY, D. (2007) interview. VNTC, Port Vila. 25 October 2007.

LANGE, F. \& TOPEL, R. (2006) The social value of education and human capital. In Hanushek, E. A. \& Welch, F. (Eds.) Handbook of the Economics of Education. Elsevier B.V.

LAU, J. (2006) Guidelines on information literacy for lifelong learning. Veracruz, International Federation of Library Associations and Institutions (IFLA).

LEDLOW, S. (2001) Using think-pair-share in the college classroom. Arizona State University, Center for learning and teaching excellence.

LINDSTROM, L. (1981) "Big man:" a short terminological history. American Anthropologist, 83, 900-905.

LINDSTROM, L. (1990) Big Men as ancestors: inspiration and copyrights on Tanna (Vanuatu). Ethnology, 29, 13.

LYNCH, J. \& CROWLEY, T. (2001) Languages of Vanuatu: a new survey and bibliography. Pacific Linguistics. Canberra, Research School of Pacific and Asian Studies (ANU).

LYON, D. (1998) The Information Society: Issues and Illusions, Cambridge, Polity Press.

MACDONALD-MILNE, B. \& THOMAS, P. (Eds.) (1981) Yumi Stanap: Leaders and Leadership in a New Nation, Suva, Institute of Pacific Studies, University of the South Pacific and Lotu Pasifika Productions.

MACKENZIE, D. \& WAJCMAN, J. (Eds.) (1985) The social shaping of technology: how the refrigerator got its hum, Philadelphia, Open University Press.

MAGUIRE, P. (1987) Doing participatory research: a feminist approach, Amherst, The Center for International Education.

MAIAVA, S. (2001) A clash of paradigms: intervention, response and development in the South Pacific, Hampshire, Ashgate.

MARSHALL, C. \& ROSSMAN, G. B. (2006) Designing qualitative research, Thousand Oaks, Save Publications.

MARTIN, W. (1988) The Information Society, London, Association for Information Management.

MAYOUX, L. (2006) Quantitative, qualitative or participatory? : which method, for what and when? In Desai, V. \& Potter, R. B. (Eds.) Doing development research. London, Sage.

MBARIKA, V. W., BYRD, T. A. \& RAYMOND, J. (2002) Growth of teledensity in Least Developed Countries: need for a mitigated euphoria. Journal of Global Information Management, 10, 25.

MILES, W. F. S. (1998) Bridging Mental Boundaries in a Postcolonial Microcosm, Identity and Development in Vanuatu, Honolulu, University of Hawaii Press.

MOON, D. (2007) interview. VIT, Port Vila. 26 November. 
MUJEE, R. (2007) interview. ITS, USP, Port Vila. 23 October.

MURRAY, W. E. \& OVERTON, J. (2003) Designing Development Research. In Scheyvens, R. \& Storey, D. (Eds.) Development Fieldwork: A Practical Guide. London, Sage Publications.

NAKO, A. (2004) Vernacular Language Policy in Vanuatu. In Sanga, K., Niroa, J., Matai, K. \& Crowl, L. (Eds.) Re-Thinking Vanuatu Education Together. Suva and Port Vila, Institute of Pacific Studies (University of the South Pacific) and Vanuatu Ministry of Education.

NAKO, S. (2007) interview. VRDTCA, Port Vila. 5 November 2007.

NIROA, J. (2004) Why we need to rethink Vanuatu education. In Sanga, K., Niroa, J., Matai, K. \& Crowl, L. (Eds.) Rethinking Vanuatu education together. Suva and Port Vila, Institute of Pacific Studies and Vanuatu Ministry of Education.

NIROA, J. (2007) interview. Ministry of Education, Port Vila. 2 November.

NIRUA, J. P. (2004) A Mountain of Opportunity and Hope. In Sanga, K., Niroa, J., Matai, K. \& Crowl, L. (Eds.) Re-Thinking Vanuatu Education Together. Suva and Port Vila, Institute of Pacific Studies (University of the South Pacific) and Vanuatu Ministry of Education.

NIRUA, J. P. (2007) interview. DFL, USP, Port Vila. 22 October 2007.

OUDSHOORN, N. \& PINCH, T. (Eds.) (2003) How Users Matter: The Co-construction of Users and Technology, Cambridge, Massachusetts, MIT Press.

PATTON, M. Q. (1990) Qualitative evaluation and research methods, Newbury Park, Sage Publications.

PHELPS, R., HASE, S. \& ELLIS, A. (2005) Competency, capability, complexity and computers: exploring a new model for conceptualising end-user computer education. British Journal of Educational Technology, 36, 67-84.

PIERSON, J. (2004) ICT adoption and use by small businesses. In Mante-Meijer, E. \& Klamer, L. (Eds.) ICT capabilities in action: What people do. 2 nd of 3 ed. Luxembourg, COST European cooperation in the field of scientific and technical research.

PIETERSE, J. N. (2000) After post-development. Third World Quarterly, 21, 175-191.

PIFS (2005a) The Pacific Plan. Pacific Islands Forum Secretariat.

PSACHAROPOULOS, G. (1988) Critical issues in education: a world agenda. International Journal of Educational Development, 8:1 1-7.

RAHMAN, M. A. (1993) People's self-development: perspectives on participatory action research, London, Zed Books.

RAHNEMA, M. (1992) Participation. Development Dictionary: A Guide to Knowledge as Power. 2005 ed. Johannesburg Witwatersrand University Press.

RAITI, G. C. (2007) Forum: the lost sheep of ICT4D research. Information Technologies and International Development, 3:4 1-7.

REGENVANU, S. (1980) Kraon (Les Terres/The Land). Vanuatu - twenti wan tingting long (sic) blong Independens. Suva, Institute of South Pacific Studies, The University of the South Pacific and The South Pacific Social Sciences Association.

REPUBLIC OF VANUATU (1988) Article 32 , Chapter 163: Land Leases of the Laws of the Republic of Vanuatu. 
REPUBLIC OF VANUATU (1999) Vanuatu National Training Council, Act 13. Laws of the Republic of Vanuatu.

REPUBLIC OF VANUATU (2000) Programme of Action for the Development of Vanuatu 2001-2010. E. A. S. (Ed.), Republic of Vanuatu.

RODMAN, M. (1995) Breathing Spaces: Customary Land Tenure in Vanuatu. In Ware, G. R. \& Kingdon, E. (Eds.) Land, Custom and Practice in the South Pacific. Cambridge, Cambridge University Press.

ROWLAND, J. (1997) Using the model: empowerment, gender, and development. In Rowland, J. (Ed.) Questioning Empowerment: Working with Women in Honduras. Oxford, Oxfam.

SACHS, W. (1992) Introduction. In Sachs, W. (Ed.) The Development Dictionary. 2005 ed. New York, Palgrave.

SANGA, K. \& NIROA, J. (2004) First steps and small beginnings in Vanuatu education research. In Sanga, K., Niroa, J., Matai, K. \& Crowl, L. (Eds.) Re-thinking Vanuatu Education Together. Suva and Port Vila, Institute of Pacific Studies and Vanuatu Ministry of Education.

SANGA, K. \& PEER, L. V. (2008) Re-thinking development practice: A progress report on the NZAID supported "Re-thinking Pacific Education Initiative". DevNet 2008: Peripheral Vision. Victoria University of Wellington, Aotearoa New Zealand, DevNet.

SCHARMER, O. (2007) Theory U: Leading from the future as it emerges, Cambridge, Society for Organizational Learning.

SCHEYVENS, R., NOWAK, B. \& SCHEYVENS, H. (2003) Ethical issues. In Scheyvens, R. \& Storey, D. (Eds.) Development Fieldwork: A Practical Guide. London, Sage Publications.

SCHEYVENS, R. \& STOREY, D. (2003) Introduction. In Scheyvens, R. \& Storey, D. (Eds.) Development fieldwork: a practical guide. London, Thousand Oaks and New Delhi, Sage.

SCHUMACHER, E. F. (1973) Small is beautiful: economics as if people mattered, New York, Harper Torchbooks.

SEIN, M. K., BOSTROM, R. P. \& OLFMAN, L. (1999) Rethinking End-User Training Strategy: Applying a Hierarchical Knowledge-Level Model (Technology Information). End User Computing, 11:132.

SEIN, M. K. \& HARINDRANATH, G. (2003) Conceptualizing the ICT Artifact: Toward Understanding the Role of ICT in National development. The Information Society.

SEN, A. (1997) Editorial: Human Capital and Human Capability. World Development, 25, 1959-1961.

SHING, P. (2007a) interview. ICT Consultant, Port Vila. 21 October.

SHING, P. (2007b) personal communication. ICT Consultant, Port Vila. 19 December.

SHING, P. (2008) personal communication. ICT Consultant, Port Vila. Emails during the month of March.

SMITH, L. (2003) Teamwork. In Chase, P., O'rourke, S., Smith, L., Sutton, C., Timperley, T. \& Wallace, C. (Eds.) Effective Business Communication in New Zealand. 2nd ed. Auckland, Pearson Education New Zealand Ltd. 
SOPE, M. M. (1980) Ol Man Ples (Les Habitants/The People). Vanuatu - twenti wan tingting long (sic) blong Independens. Suva, Institute of South Pacific Studies, The University of the South Pacific and The South Pacific Social Sciences Association.

SPRIGGS, M. (1997) The Island Melanesians, Oxford, Blackwell Publishers.

STEINMUELLER, W. E. (2001) ICTs and the possibilities for leapfrogging by developing countries. International Labour Review, 140:2 193-210.

STEWART, F. (1996) Globalisation and education. International Journal of Educational Development, 16:4 327-333.

TAMASHIRO, H. (2007) interview. Human Resources Development Unit, Port Vila. 19 November.

TAMATA, M. (1980) Solwora (La Mer/The Sea). Vanuatu - twenti wan tingting long (sic) blong Independens. Suva, Institute of South Pacific Studies, The University of the South Pacific and The South Pacific Social Sciences Association.

TAUROKOTO, P. (1980) Neson (La Nation, The Nation). Vanuatu - twenti wan tingting long (sic) blong Independens. Suva, Institute of South Pacific Studies, The University of the South Pacific and The South Pacific Social Sciences Association.

TESCH, R. (1990) Qualitative research: analysis types and software tools, New York, The Falmer Press.

THOMAS, A. \& ALLEN, T. (2000) Agencies of Development. In Thomas, A. \& Allen, T. (Eds.) Poverty and Development into the 21st Century. Milton Keynes, Open University.

TREND, D. (2001) Welcome to cyberschool: education at the crossroads in the information age, Lanham, Maryland, Rowman and Littlefield.

TURK, T. (2004) Utility revealed: Economic factors in adoption. In Mante-Meijer, E. \& Klamer, L. (Eds.) ICT capabilities in action: What people do. 2nd of 3 ed. Luxembourg, COST European cooperation in the field of scientific and technical research.

VAN DER VEEN, R. \& PREECE, J. (2005) Poverty reduction and adult education: beyond basic education. International Journal of Lifelong Education, 24:5 381-391.

VILA, L. E. (2000) The non-monetary benefits of education European Journal of Education, 35:1 21-32.

VILA, L. E. (2005) The outcomes of investment in education and people's well-being. European Journal of Education, 40:1 3-11.

WALDEGRAVE, C. (1999) Focus groups: participation in poverty research. In Davidson, C. \& Tolich, M. (Eds.) Social Science Research in New Zealand. Auckland, Longman.

WIJKMAN, A. \& AFIFI, M. (2002) Technology leapfrogging and the digital divide. Sustainability at the Speed of Light. Sweden, WWF.

WILSON, M. (2003) Understanding the international ICT and development discourse: assumptions and implications. The Southern African Journal of Information and Communication, 314.

WOZNIAK, G. D. (1987) Human Capital, Information, and the Early Adoption of New Technology. The Journal of Human Resources, 22:1 101-112. 


\section{Electronic sources}

ADB (2007) Fact Sheet: Asian Development Bank and Vanuatu. Accessed 11 March 2008, http://hdrstats.undp.org/countries/country_fact_sheets/cty_fs_VUT.html.

ADB (2008) Vanuatu: Country Information. Asian Development Bank. Accessed 25 March 2008, http://www.adb.org/Vanuatu/country-info.asp.

CIA (2007) World Factbook: Vanuatu. Accessed 13 June 2007, https://www.cia.gov/library/publications/the-world-factbook/geos/nh.html.

COUNTRY WATCH (2008) Country watch social overview. Business Source Premiere. Accessed 26 February 2008, http://helicon.vuw.ac.nz/login?url=http://search.ebscohost.com/login.aspx?direct=tru $\mathrm{e} \& \mathrm{db}=\mathrm{buh} \& \mathrm{AN}=27899294 \&$ site $=$ ehost-live.

DAILY POST (2008) Telecommunications regulator appointed. Vanuatu Daily Post. Online ed. Port Vila. Accessed 26 January 2009, http://www.dailypost.vu/index.php?news=2156.

DFAT (2007) Vanuatu Country Brief - December 2007. Australian Government. Accessed 25 March 2008, http://www.dfat.gov.au/geo/vanuatu/vanuatu_brief.html.

EFA (2000) The EFA 2000 Assessment: Country Reports, W. E. (Ed.). Accessed 8 January 2009, http://www.unesco.org/education/wef/countryreports/vanuatu/rapport_1.html.

EIU (2007) Resources and infrastructure: transport, communications and the internet. (Geographic Overview). Economic Intelligence Unit. Accessed 4 March 2008, Victoria University of Wellington electronic database.

EIU (2008) Country profile. Pacific Islands: Vanuatu [electronic resource]. London : The Economist Intelligence Unit. Accessed 22 January 2009, http://victoria.lconz.ac.nz/cgi-bin/Pwebrecon.cgi?BBID=985984.

FCO (2008) Country profile: Republic of Vanuatu. Foreign and Commonwealth Office, UK. Accessed 24 February 2008, http://www.fco.gov.uk/servlet/Front?pagename=OpenMarket/Xcelerate/ShowPage\& $c=$ Page \& $c i d=1007029394365 \& a=K C$ CountryProfile $\&$ aid $=1019061877425$.

IOM (2008) World migration 2008: Oceania. Accessed 9 January 2009, http://www.iom.ch/jahia/webdav/shared/shared/mainsite/media/docs/wmr/regional_ overviews/ro_oceania.pdf.

KILMAN, S. (2006) Vanuatu statement. Global Review of the Implementation of the Programme of Action for the Least Developed Countries for the Decade 2001-2010. New York, United Nations. Accessed 23 February 2008, http://www.un.org/webcast/ldc2006/pdfs/vanuatu-e.pdf

MFAT (2008) Republic of Vanuatu. Wellington, New Zealand Ministry of Foreign Affairs and Trade. Accessed 29 January 2008, http://www.mfat.govt.nz/Countries/Pacific/Vanuatu.php.

MOON, D. (2008) TVL new internet pricing. VITUS IT Users Society of Vanuatu. Accessed 29 January 2009, http://vitus.org.vu/files/2008/09/tvl-new-net-pricing.pdf.

NEF (2006) The happy planet index. New Economics Foundation. Accessed 21 February 2008, http://www.happyplanetindex.org/list.htm.

NZAID (2006) NZAID/Vanuatu development programme strategy 2006-2010. NZAID. 
OXFAM (2006) Briefing note: the 2006 land summit. Accessed 24 January 2009, http://www.oxfam.org.nz/imgs/pdf/onz_vanuatuland_14feb07.pdf.

OXFORD UNIVERSITY PRESS (1989a) Education, meaning 3. Oxford English Dictionary online. Second ed., Oxford University Press 24 January 2009, http://dictionary.oed.com.helicon.vuw.ac.nz/cgi/entry/50072205?single=1\&query_ty pe $=$ word $\&$ queryword=Education $\&$ first $=1 \&$ max_to_show $=10$.

OXFORD UNIVERSITY PRESS (1989b) Training, , meaning 2.a. Oxford English Dictionary online. Second ed., Oxford University Press 24 January 2009, http://dictionary.oed.com.helicon.vuw.ac.nz/cgi/entry/50255865?query_type=word\& queryword=Training $\&$ first $=1 \&$ max_to_show $=10 \&$ sort_type $=$ alpha\&result_place $=1$ \&search_id=vLTB-vUPOkd-14039\&hilite $=50255865 \mathrm{~d}$

PIFS (2005b) PP: Digital Strategy. Pacific Islands Forum Secretariat. Accessed 10 March 2008, http://www.pacificplan.org/.

REPUBLIC OF VANUATU (2009) Telecommunications and radiocommunications regulation act. Government of Vanuatu, Telecommunications authority. Discussion commenced September 2008,_http://lists.spc.int/mailman/listinfo/vignet_lists.spc.int

SEIDEL, J. V. (1998) Qualitative Data Analysis. Qualis Research. Accessed 22 December 2008, ftp://ftp.qualisresearch.com/pub/qda.pdf.

UN (1948) The Universal Declaration of Human Rights, Article 26. UN website, UN. 24 January 2009. Accessed 24 January 2009, http://www.un.org/Overview/rights.html.

UN (2008) UN Statistics Division - Vanuatu Country Profile. Accessed 27 February 2008, http://unstats.un.org/unsd/snaama/resultsCountry.asp?Country=548\&Year=0\&SLev $\mathrm{el}=99 \&$ Disp $=$ Million.

UNESCAP (2006) Asia-Pacific in figures. Accessed 29 January 2009, http://www.unescap.org/stat/data/apif/2006/Vanuatu-apif2006.pdf.

UNESCO/IFIP (no date) Approaches to ITC Development in Schools. Curriculum Information and Communication Technology in Secondary Education. Accessed 23 August 2006, http://wwwedu.ge.ch/cptic/prospective/projets/unesco/en/table1.html.

UNESCO (2003) Education Today newsletter. UNESCO. 27 May 2008, http://portal.unesco.org/education/en/ev.phpURL_ID=20263\&URL_DO=DO_TOPIC\&URL_SECTION=201.html

USP (2005) Developing Information Technology in education. Accessed 23 January 2009, http://www.usp.ac.fj/news/story.php?id=15.

VIGNET (2008) Online forum. Port Vila. Regular access via email, http://lists.spc.int/mailman/listinfo/vignet_lists.spc.int

VIGNET (2009) Online forum. Port Vila. Regular access via email, http://lists.spc.int/mailman/listinfo/vignet_lists.spc.int

VNCRC (2004) Vanuatu Cultural Research Policy. Vanuatu National Cultural Research Council. Accessed 13 June 2007, http://www.vanuatuculture.org/research/050520_culturalresearchpolicy.shtml

VNSO (2007) Vanuatu Statistics. National Statistics Office, Government of Vanuatu. Accessed 24 February 2008, http://www.spc.int/prism/Country/VU/stats/.

VTO (no date) Vanuatu tourism office: Discover the islands of Vanuatu. Port Vila. Accessed 18 February 2008, http://www.vanuatutourism.com/vanuatu/cms/en/vanuatu.html. 
WHELAN, R. (2007a) Pacific eLearning Observatory: Challenges. Suva, University of the South Pacific (USP). Accessed 9 June 2007, http://www.usp.ac.fj/index.php?id=4775.

WHELAN, R. (2007b) Pacific eLearning Observatory brief: Vanuatu. Suva, University of the South Pacific (USP). Accessed 9 June 2007, http://www.usp.ac.fj/index.php?id=4776.

WORLD BANK (2006) ICT at a Glance. Accessed 29 January 2009, http://devdata.worldbank.org/ict/vut_ict.pdf.

WSIS (2004) Vanuatu ICT issues in regards to its ICT development activities. World Summit on the Information Society (WSIS) 2nd phase. Suva, UNESCAP. Accessed 20 September 2007, www.unescap.org/icstd/events/WSIS_2nd_Phase/docs/Suva/Vanuatu.ppt

ZWIMPFER, L. (2003) Point of View: ICTs for Development: Towards a Connected Pacific. Communication and Information Resources. UNESCO. Accessed 20 September 2008, http://portal.unesco.org/ci/en/ev.phpURL_ID=13258\&URL_DO=DO_TOPIC\&URL_SECTION=201.html. 


\section{Appendices}

\section{APPENDIX 4.1 Questionnaire for potential focus group members}

Questions - please fill in as much information as possible: About you (long saed blong yu nomo)

1. What is your full name? (wanem nem blong yu?)

2. What do you like to be called? (wanem pat long nem blong yu, yu likem i moa gud?)

3. What is your contact information?... (wea ples mi save kontactem yu long...)

4. ...post address (...post?)

5. ...phone number (...fon?)

6. ...email address (if you have one) (...email?)

7. Where are you from (yu blong wea?)

8. Where do you stay in Vila (yu slip wea long Vila)?

About computer training you have done.

(Long saed blong trenem long komputa blong yu)

9. How long have you been training to use a computer? (yu bin trenem long komputa hao long finis?)

10. Where have you taken this training (name all places)? (trenem blong yu, i hapen wea ples evri wan?) 
11. What courses have you taken? (yu bin stadi wanem kos long komputa?)

12. What is your favourite computer course? (wanem kos yu likem i moa gud?)

13. What else do you want to learn about computers? (yu gat wan nadafala samting we bae yu likem blong lanem long komputa?

14. Why do you want to get training in how to use a computer? (from wanem yu wantem blong lanem komputa?)

About your job if you have one (long saed blong wok blong yu, sipos yu gat)

15. Do you have work that you are paid for? If yes, what and where is it? (yu gat wok blong yu wea oli pemaot vatu long yu? Sipos yes, wanem wok blong yu?)

If yes, please fill in questions $13 \& 14$.

(sipos ansa blong yu i yes, anserem namba 13 mo 14):

If no, you are done. (sipos no, yu stap finis)

16. Do you use a computer at your work? (yu usum komputa long wok blong yu?)

17. Have the courses you have taken helped you at this job? (ol komputa kos wea yu bin takem finis, i givhan long wok blong yu?) 


\section{APPENDIX 4.2 Description of research for potential focus group members}

Focus groups for research

I would like to find twenty (20) of you to work with me for a short time to talk about your training in computer skills. We'll talk about what you like, what you don't like and what you think could be better. We will go talk to business people in Vila who have jobs where computers are used and ask them what kinds of skills they look for in people who use some kind of computer at their work.

I am hoping to meet with you for up to four (4) hours a day, one (1) time per week, for the next five (5) or six (6) weeks. But this will depend on the group's decision also, on when we can meet.

You don't have to do any study but just come to the meetings and work with me and the others in the group. We will think and talk and write things down. We will sometimes meet other people and ask them questions about computers.

You will learn a little bit how to do small research. This research is about using things that you think about the training you've had and using this to help trainers in Vila know how to make your training more good.

At the end we will make a presentation to interested people in Vila. These will include people from places that provide training, some government departments and anyone else interested in our work.

I will have to make a choice of just 20 people but that choice will not be made based on your grades or your work but rather on things like where you are from (I want to have a mix of people from different places) and how much time you can spend with the group when we meet. I wish I could invite you all but that is not possible.

\section{Gayna Vetter}

My email address is: veevette@paradise.net.nz

My phone number is (678) 24684, ask for Gayna 
oे APPEndiX 4.3 example certificate of participation given to focus group members

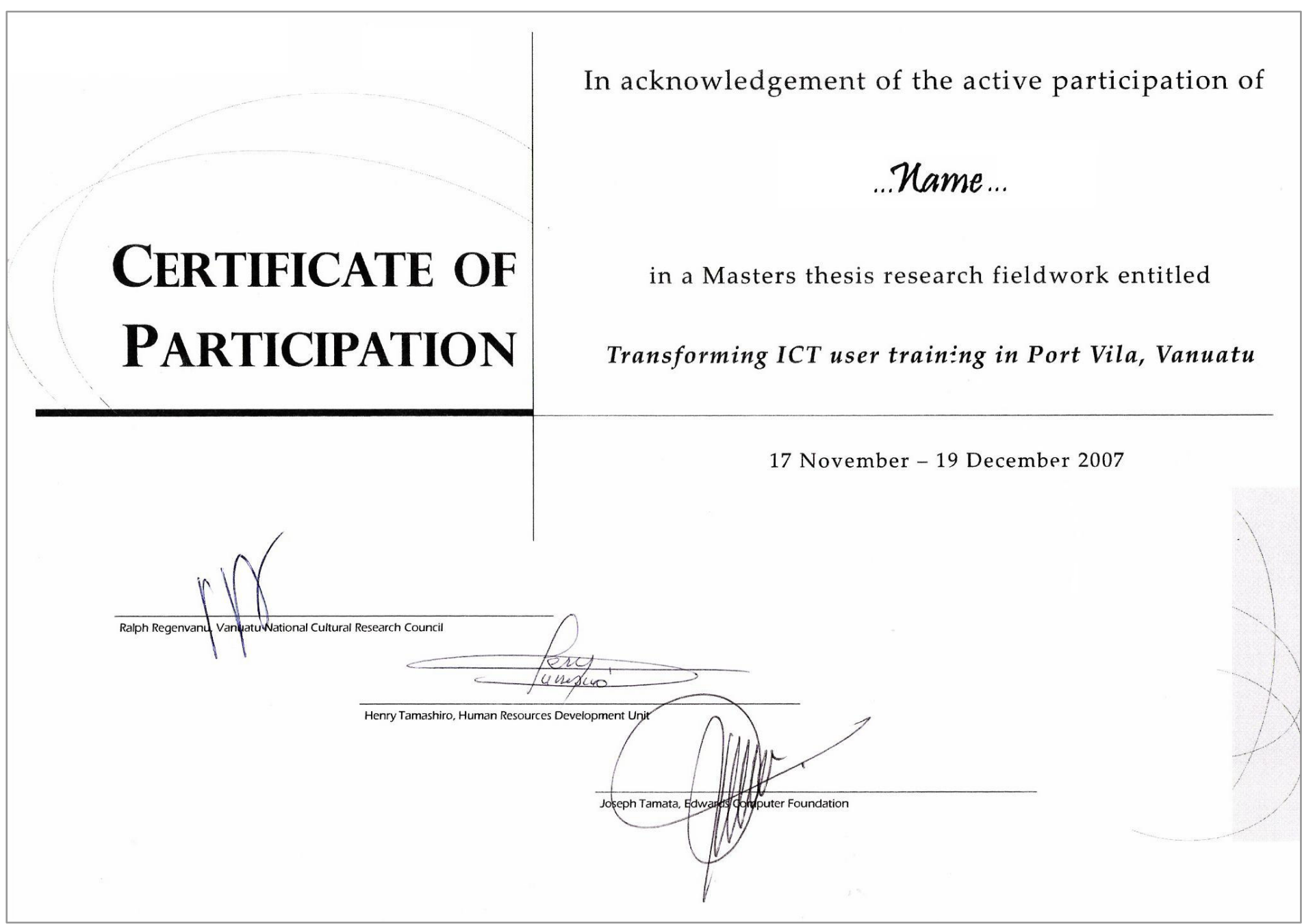




\section{APPENDIX 4.4 Victoria University of Wellington ethics approval}

TE WHARE WĀNANGA O TE ŪPOKO O TE IKA A MĀUI

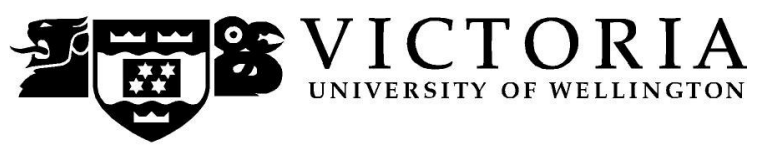

MEMORANDUM

\begin{tabular}{l|l}
\hline TO & Gayna Vetter \\
\hline COPY TO & Professor John Overton \\
\hline FROM & Dr Allison Kirkman, Convener, Human Ethics Committee \\
\hline
\end{tabular}

\begin{tabular}{l|l}
\hline DATE & October 17, 2007 \\
\hline PAGES & 1 \\
\hline
\end{tabular}

\begin{tabular}{l|l}
\hline SUBJECT & $\begin{array}{l}\text { Ethics Approval: No 0000015215, Transforming ICT User } \\
\text { Training in Vanuatu. }\end{array}$ \\
\hline
\end{tabular}

Thank you for your application for ethical approval, which has now been considered by the Standing Committee of the Human Ethics Committee.

Your application has been approved and this approval continues until 30 June 2008. If your data collection is not completed by this date you should apply to the Human Ethics Committee for an extension to this approval.

Best wishes with the research.

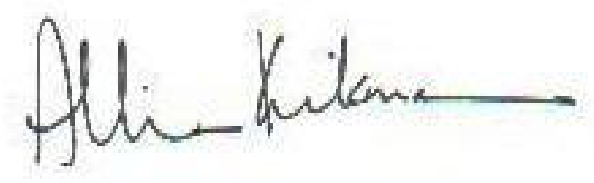

Allison Kirkman

Convener 


\section{APPENDIX 4.5 Research agreement with Vanuatu National Cultural Council}

\section{$\underline{\text { Research Agreement }}$}

AN AGREEMENT made the

$6^{\text {th }}$ day of

November 2007

BETWEEN : THE NATIONAL CULTURAL COUNCIL, representing the Government of the Republic of Vanuatu and the local community, (hereinafter called "the Council") of the one part.

AND: GAYNA VETTER

of (institution) Dept. of Feography, Envivonment and Earth Sciences, Victoria University of Wellington, NZ

(hereinafter called "the Researcher") of the other part.

WHEREAS :

(1) The Researcher has applied to the Council to do research work in the Republic of Vanuatu, and agrees to the conditions placed upon her/him in this document and to compliance with the intent of the ethics described in the Vanuatu Cultural Research Policy.

(2) The Council has agreed to allow the Researcher to do such research, and has agreed to the obligations placed upon it by this document and by the Vanuatu Cultural Research Policy.

AND THEREFORE THE PARTIES AGREED AS FOLLOWS :

(1) The Council hereby authorises the Researcher to undertake research work in Vanuatu on the subject of

Transforming ICT user training in Port Vila, Vanuatu

with the communit(y/ies) of

$$
\text { Port Vila }
$$

on the island/s of

$$
\text { Vanuatu }
$$

in the capacity of (if more than one researcher is involved)

$$
\text { Pincipal }
$$

for the period up until (Specify if research will involve more than one visit)

$$
31 \text { st December } 2007 .
$$

(2) The Researcher has paid an authorisation fee of 25,000 vatu to cover all administrative costs incurred in the setting up and implementation of the research venture, or this fee has been waived by the Council.

waived 


\section{Research agreement with Vanuatu National Cultural Council p 2}

(3) The right to the products of research shall belong to the Researcher who shall be entitled to reproduce them for educational, academic or scientific purposes, provided that traditional copyrights are not compromised and the permission to use material has been obtained, through the Traditional Copyright Agreement, from copyright holders. The products of research shall not be reproduced or offered for sale or otherwise used for commercial purposes, unless specified under section 12 of this agreement.

(4) Copies of all non-artefact products of research are to be deposited without charge with the Cultural Centre and, where feasible, with the local community. Two copies of films and videos are to be provided, one for public screening and the other for deposit in the archives. In the case of films, a copy on video is also required. Any artefacts collected become the property of the Cultural Centre unless traditional ownership has been established in the Traditional Copyright Agreement. The carrying of any artefacts or specimens outside the country is prohibited as stipulated under cap.39 of the Laws of Vanuatu. Artefacts and specimens may be taken out of the country for overseas study and analysis under cap.39(7). The conditions for the return of the following materials are:

(Specify artefacts/specimens/other materials and conditions for return)

The Researcher has either

(a) provided a letter from the institution to which they are affiliated guaranteeing the researcher's compliance with the above conditions, or (to be provided)

(b) provided a retrievable deposit of 40000 vatu to ensure their compliance with these conditions.

(5) The Researcher will be responsible for the translation of a publication in a language other than a vernacular language or one of the three national languages of Vanuatu into a vernacular or one of the national languages, preferably the one used in education in the local community. They will also make the information in all products of research, subject to copyright restrictions, accessible to the local community through such means as audio cassettes or copies of recorded information, preferably in the vernacular. The Researcher will also submit an interim report of not less than 2000 words no later than 6 months after the research period has ended giving a reasonable precis of their work. This will be in one of the national languages and in 'layman's terms' so as to be of general use to all citizens.

(6) There will be maximum involvement of indigenous scholars, students and members of the community in research, full recognition of their collaboration, and training to enable their further contribution to country and community. The Council nominates the following individuals to be involved in research and/or trained, in the following capacities:

- Focus groups, as past of methodology 


\section{Research agreement with Vanuatu National Cultural Council p 3}

(7) A product of immediate benefit and use to the local community will be provided by the Researcher no later than 6 months after termination of the research period. This product is: - recommendations at improving $1 C T$ training (for users) in Poit Vila : these recommendations to be an output of focus groups

(8) In addition to their research work, the Researcher will, as a service to the nation of Vanuatu, undertake to : (section 3(viii) of the Cultural Research Policy suggests possible services of benefit to the nation)

$$
\text { (as above) }
$$

(9) In undertaking research the Researcher will:

a) recognise the rights of people being studied, including the right not to be studied, to privacy, to anonymity, and to confidentiality;

b) recognise the primary right of informants and suppliers of data and materials to the knowledge and use of that information and material, and respect traditional copyrights, which always remain with the local community;

c) assume a responsibility to make the subjects in research fully aware of their rights and the nature of the research and their involvement in it;

d) respect local customs and values and carry out research in a manner consistent with these;

e) contribute to the interests of the local community in whatever ways possible so as to maximise the return to the community for their cooperation in the research work;

f) recognise their continuing obligations to the local community after the completion of field work, including returning materials as desired and providing support and continuing concern.

(10) In all cases where information or material data is obtained by the Researcher, a Traditional Copyright Agreement will be completed by the Researcher and the supplier of data regarding this material. The Researcher has a responsibility to make such informants fully aware of their rights and obligations, and those of the Researcher, in the signing of the Traditional Copyright Agreement.

(11) A breach of any part of this agreement by the Researcher or a decision by the local community that it no longer wishes to be involved in the research venture will result in the termination of the research project.

(12) (Additional clauses/conditions) (This sectuil detail commercial ventures, extra costs incurred by the Cultural Centre, ctc.)

Signed :

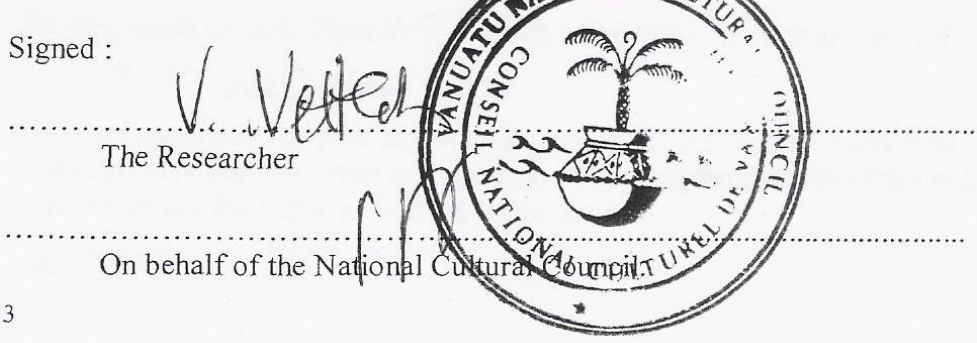




\title{
APPENDIX 4.6 A Ethics: Stakeholder information sheet
}

\author{
Stakeholders Information Sheet \\ Stakeholders Information Sheet \\ Master's Thesis Research Project: \\ "Transforming ICT user training in Port Vila, Vanuatu"
}

October - December, 2007

\begin{tabular}{|ll|l|}
\hline Researcher: & Gayna Vetter & School of Geography, \\
Telephone: & 0064 04 4732554 & Environment and Earth Sciences \\
Mobile: & n/a & (SGEES) \\
Supervisor: & Professor John Overton & Victoria University of Wellington \\
& 0064 04 4635281 & PO BOX 600 \\
Email: & gayna.vetter@vuw.ac.nz & Wellington 6140 \\
& & $(04)$ 463-5337 \\
\hline
\end{tabular}

Dear Project Participant,

You are being asked to take part in an interview for my master's thesis at Victoria University of Wellington. The project will investigate how computer skills training is now being done in Port Vila, to discover what factors work in this training and what is missing or inappropriate. The key words for this research include: professional development, computer skills, local needs, industry-related. The study will answer the following major question: 'What methodologies for training Information and Communications Technology (ICT) users in developing countries are relevant to their needs?'.

The study will use a variety of research methods based on collaborative methods; these include (literature reviews, focus groups, interviews, document analysis (job descriptions, course outlines and training materials) and training facility analysis.

I am inviting you to participate in overall information gathering and consider you to be a stakeholder in the information my research will produce. I will talk to you about your business/organisation's interests for training in computer skills from a training/educational perspective. Any of your opinions or observations may be helpful to identifying needs or things to be aware of while doing this research.

\section{Confidentiality}

At the beginning of the interview, you will be asked in clear, non-technical language whether you wish your identity to remain confidential. I will explain in detail how the results of the research may be used, including the potential for publication in the public domain, in the form of academic papers in peer reviewed journals or presentations at conferences. The Informed Consent Form (attached) will ask you whether you require confidentiality or not, and how you wish to identify yourself in the research. If you require confidentiality you will be referred to as Industry Contributor, or in any other way you request (see \#3. on the Informed Consent Form). If any other person has put me in contact with you and you require confidentiality, I will guarantee that they do not disclose your identity by ensuring that they sign a 'Non-disclosure Form'. If you 
do not require confidentiality, you will be asked to circle the relevant statement (see \#4 on the Informed Consent Form), and only then will your identity be published.

No names will appear on the transcripts. A letter-number code will be assigned to each interview respondent, and only this code, or other title specified by you, will appear in the published results (unless confidentiality is waived as described above).

The real names associated with the codes will be kept securely by me, and never made public without the permission of the individual(s) involved.

\section{Storage and Disposal of Data}

Access to the written and electronic material will be restricted to me. All written material will be kept in a locked file, and all electronic material will be password protected. At the conclusion of the research, any interview material, or similar will be destroyed and the audio recordings of the interviews will be electronically wiped.

The results collected will be reported in my thesis, and will be potentially presented in academic journals and conferences. The thesis will be submitted for marking to the School of Geography, Environment and Earth Sciences, Victoria University of Wellington.

\section{Right of Withdrawal}

During the course of the interviews, you will have the right to withdraw from the interview or refuse to answer any question(s) at any time. You may request that the transcript of your interview be destroyed and not used in the study, for any reason. Your must inform me of your withdrawal within three (3) weeks after the date of the interview.

\section{Provision of Feedback}

You have the right to check the interview transcript, and will be able to provide any corrections at any time, prior to final analysis of data.

\section{Community Access to Research Results}

In order to ensure that the results of this research project are accessible to the participants, a summary of the completed research output will be available. You may request it by circling 'Yes' in Question 7 of the 'Informed Consent Form' (attached), or on later request (by email to gayna.vetter@vuw.ac.nz with "Vila ICT Research

Results" as subject line). Furthermore, copies of the completed research output will be available from the School of Geography, Environment and Earth Sciences Library, and in the Victoria University of Wellington electronic database of theses.

If you have any other questions about this project, please feel free to ask me now, or contact me, or my supervisor, John Overton, later. Contact details are provided on the first page of this sheet.

Thank you for participating!

Sincerely,

\section{Gayna Vetter}




\title{
APPENDIX 4.6 B Ethics: Participant information sheet
}

\author{
Participant Information Sheet \\ Master's Thesis Research Project: \\ "Transforming ICT user training in Port Vila, Vanuatu"
}

October - December, 2007

\begin{tabular}{|ll|l|}
\hline Researcher: & Gayna Vetter & School of Geography, \\
Telephone: & 0064 04 473 2554 & Environment and Earth Sciences \\
Mobile: & n/a & (SGEES) \\
Supervisor: & John Overton & Victoria University of Wellington \\
& 0064 04 463 5281 & PO BOX 600 \\
Email: & gayna.vetter@vuw.ac.nz & Wellington 6140 \\
& & $(04) 463-5337$ \\
\hline
\end{tabular}

Dear Project Participant,

You are being asked to take part in a focus group for my master's thesis at Victoria University of Wellington. The project will investigate how computer skills training is now being done in Port Vila, to discover what factors work in this training and what is missing or inappropriate. The key words for this research include: professional development, computer skills, local needs, industry-related. The study will answer the following major question: 'What methodologies for training Information and Communications Technology (ICT) users in developing countries are relevant to their needs?'.

The study will use a variety of research methods based on collaborative methods; these include (literature reviews, focus groups, interviews, document analysis (job descriptions, course outlines and training materials) and training facility analysis.

I am inviting you to participate in one of the two focus groups that will be engaged in all parts of researching the question (above), from posing questions and gathering data to interpretation, identifying findings, preparing and reporting recommendations. This will not exceed more than twelve weeks, with no more than one working day each week during that time.

\section{Confidentiality}

At the beginning of the focus group, you will be asked in clear, non-technical language whether you wish your identity to remain confidential. I will explain in detail how the results of the research may be used, including the potential for publication in the public domain, in the form of academic papers in peer reviewed journals or presentations at conferences. The Informed Consent Form (attached) will ask you whether you require confidentiality or not, and how you wish to identify yourself in the research. If you require confidentiality you will be referred to as 'focus group participant', or in any other way you request (see \#3. on the Informed Consent Form). If any other person has put me in contact with you and you require confidentiality, I will guarantee that they do not disclose your identity by ensuring that they sign a 'Non-disclosure Form'. If you do not require confidentiality, you will be asked to circle the relevant statement (see \#4 on the Informed Consent Form), and only then will your identity be published. 
No names will appear on the transcripts. A letter-number code will be assigned to each focus group participant, and only this code, or other title specified by you, will appear in the published results (unless confidentiality is waived as described above).

The real names associated with the codes will be kept securely by me, and never made public without the permission of the individual(s) involved.

\section{Storage and Disposal of Data}

Access to the written and electronic material will be restricted to me. All written material will be kept in a locked file, and all electronic material will be password protected. At the conclusion of the research, any interview material, or similar will be destroyed and the audio recordings of interviews and focus group activities will be electronically wiped.

The results collected will be reported in my thesis, and will be potentially presented in academic journals and conferences. The thesis will be submitted for marking to the School of Geography, Environment and Earth Sciences, Victoria University of Wellington.

\section{Right of Withdrawal}

During the course of the focus group's activities, you will have the right to withdraw from the activities or refuse to answer any question(s) at any time. You may request that transcripts containing reference of your activities be destroyed and not used in the study, for any reason. Your must inform me of your withdrawal no more than three (3) weeks after the date of the final group meetings.

\section{Provision of Feedback}

You have the right to check the transcripts, and will be able to provide any corrections at any time, prior to final analysis of data.

\section{Community Access to Research Results}

In order to ensure that the results of this research project are accessible to the participants, a summary of the completed research output will be available. You may request it by circling 'Yes' in Question 7 of the 'Informed Consent Form' (attached), or on later request (by email to gayna.vetter@vuw.ac.nz with "Vila ICT Research

Results" as subject line). Furthermore, copies of the completed research output will be available from the School of Geography, Environment and Earth Sciences Library, and in the Victoria University of Wellington electronic database of theses.

If you have any other questions about this project, please feel free to ask me now, or contact me, or my supervisor, John Overton, later. Contact details are provided on the first page of this sheet.

Thank you for participating!

Sincerely,

\section{Gayna Vetter}




\section{APPENDIX 4.6 C Ethics: Informed Consent form}

\section{"Transforming ICT user training in Port Vila, Vanuatu"}

\section{INFORMED CONSENT FORM}

\begin{tabular}{ll|l|} 
Researcher: & Gayna Vetter & School of Geography, Environment \\
Telephone: & 0064 04 473 2554 & and Earth Sciences (SGEES) \\
Mobile & n/a & Victoria University of Wellington \\
Supervisor & John Overton & PO BOX 600 \\
Tel. & 0064044635281 & Wellington 6140 \\
Email: & gayna.vetter@vuw.ac.nz & (04) 463-5337 \\
\hline
\end{tabular}

\section{Introduction}

The Victoria University of Wellington Human Ethics Committee, which has approved this research project, requires that all research involve Participants who are: 1) fully informed about the nature of the research; and 2) consent to participate. This "Informed Consent Form" has been designed in accordance with these requirements, to inform all Participants about the nature of the project and their participation in it. It is meant to ensure that research Participants and their communities are protected from any harm potentially arising from their participation in the research process.

\section{Purpose of the Study}

This study, for my master's thesis, is intended to answer the following question: 'What methodologies for training Information and Communications Technology (ICT) users in developing countries are relevant to their needs?

Please also see the attached 'Information Sheet

\section{Research Format}

A Participatory Action Research (PAR) process will be used with two focus groups of up to 10 people each. Focus group participants will explore methodologies of training for users of ICT in Vila. The training methodologies include resources, training principles and styles, and methods of training delivery. Local employers will be interviewed, by focus group participants, to investigate industry needs for user training. The focus groups will study a range of documents to assess for appropriateness and intended training outcome; these include: course materials, texts, course outlines, student work, email discussions, software, and job descriptions from the industry contributors. Training facilities will be assed for suitability to training needs. 
1. I agree to an audio recorded interview with Gayna Vetter

Please circle one

$\mathrm{Y} / \mathrm{N}$

2. I wish for my identity to remain confidential.

$\mathrm{Y} / \mathrm{N}$

If yes: $\quad$ (If no, go to question 3)

I would like to be identified as (please circle one):

i) An 'official' from the organisation I represent, or

ii) A letter code, or

iii) Other, please specify:

3. I consent to information or opinions that I have given being attributed to me in any reports on this research.

$\mathrm{Y} / \mathrm{N}$

4. I understand that I will have an opportunity to correct the transcript of the interview before publication.

$$
\mathrm{Y} / \mathrm{N}
$$

5. I understand that the data I provide will not be used for any other purpose than described in the 'Information Sheet' or released to others without my written consent.

$\mathrm{Y} / \mathrm{N}$

6. I would like to receive a summary of the results of this research when it is completed.

$\mathrm{Y} / \mathrm{N}$

If yes, My address is:

My email is:

I agree to take part in this research

Participant:

Name:

Date:

Signature:

Researcher:

I certify that this form and its attached "Information Sheet" cover letter provide a complete and accurate description of the aims and processes of this research project.

Name:

Date:

Signature: 


\section{APPENDIX 4.7 Evaluation forms given to focus group members}

\section{Evaluation of the Risej Focus Grup}

Yumi bin usum focus grup long 4 wik finis. Mi hop se yu bin kasem sam niufala idea long saed blong trening blong yu long Kompiuta we yu no bin gat bifo.

We've been in a focus group for 4 weeks. I hope you've gained some ideas about your computer training that you didn't have before.

Mi wantem askem yu wanem yu ting se long saed blong ol session we yumi bin gat.

I want to ask you what you think about the sessions we've had.

Usum nadafala pepa sipos yu nidim moa rum blong penem ansa blong yu $\rightarrow$

1 Wanem rating yu save giv long saed blong ol wok blong 4 sessions we yumi bin gat?

What rating would you give these 4 sessions we've had? (circle one)

$$
\begin{array}{lllllllll}
\text { no gud } & 1 & 2 & 3 & 4 & 5 & 7 & 8 & 9
\end{array}
$$

Sipos rating blong yu i 5 or moa, i ansa kwestin $2 \ldots$

If you rated 5 or more, go to question $2 \ldots$

1 a Sipos rating blong yu i andanit 5, wanem yu ting se i gud blong mekem ol session i moa gud?

If you rated under $\mathbf{5}$, what do you think would make the sessions better?

2 Wanem yu ting se yu bin lanem long saed blong kompiuta trening blong yu we yu no bin gat bifo?

What do you feel you've learned about the way to think/feel about your computer training that you didn't think about before? 
Yu harem hao nao long saed blong givhan long risej ia?

3 How do you feel about having been a part of this research? (circle one)

$\begin{array}{lllllllllll} & 1 & 2 & 3 & 4 & 5 & 7 & 8 & 9 & 10 & \text { i gud tumas }\end{array}$

From wanem?

Why?

4 Wanem yu ting se sam samting we i gud tumas long saed blong risej ia?

What were some of the things you thought were very good about this research?

5 Wanem yu ting se sam narafala idea we yu ting se i gud blong lukaotem long 5 kompiuta trening long Vila?

What do you think are other ideas that would be good to study about computer training in Vila? 


\section{APPENDIX 4.8 Focus group evaluation results}

\section{Transcribed evaluations from Focus Groups, Port Vila, Nov - Dec 07}

All translations by author and quotes are as written in the evaluations

In the intro to the evaluations: I want to ask you what you think about the sessions we've had...

\section{Emi elpem mi bigwan blong mi save expresem mi about computer training}

'The sessions have helped me a lot because I can share my ideas about computer training.'

I learn[ed] about things in that sessions a lot mostly in my interview and 'i had' (it is hard) work and giving new ideas in computer in this session (in these sessions).

Wanem rating yu save giv long saed blong ol wok blong 4 sessions we yumi bin gat?

What rating would you give these 4 sessions we've had? (circle one)

$$
\text { no gud } 1 \quad \begin{array}{lllllllll}
1 & 2 & 3 & 4 & 5 & 7 & 8 & 9 & 10
\end{array}
$$

Average rating 9.9

1 a Sipos rating blong yu i andanit 5 , wanem yu ting se i gud blong mekem ol session i moa gud?

If you rated under 5, what do you think would make the sessions better?

I[t] will make a good arrangement for computer study. Good understanding in text book, and must be follow step by step. Must have a big classroom for every students to attend class one time. Find a good teacher.

Every[thing] we had was fun and also make the Research/focus group sessions better. Conv[i]ncing - to share ideas and talking to people I have never talk to. Enjoying we can do thinks freely like talking to mobile phone, tell jokes and laugh.

Encouraging - That I can do things without shame or being afraid of People.

2 Wanem yu ting se yu bin lanem long saed blong kompiuta trening blong yu we yu no bin gat bifo?

What do you feel you've learned about the way to think/feel about your computer training that you didn't think about before?

Mi been learnem how blong type in MSWord, calculation in MSExcel, How bin email to another friend in internet and the last one How to make invitation Card in publisher for example (Birthday card, getting married card). 
'I have learned hot to use MS Word, to make calculations in MSExcel, I've emailed another friend on the internet and lastly, how to make an invitation in Publisher.'

Wanem we mi bin laenem long saed blong trening we mi no kat bifo hemi, Trening olsem, typing mo how noa blong karem aot ol parts blong komputa mo putum i ko bak spos komputa ino gud. Hemi long saed blong ol technicians

'What I've learned about training that I didn't know before is things like typing, how to take a broken computer apart and put it back together. This is technical work.'

I learn how to interview a person, which I have [not] did in my life and there's a lot more. Computers I never know I would study computer.

3 Yu harem hao nao long saed blong givhan long risej ia?

How do you feel about having been a part of this research?

(circle one)

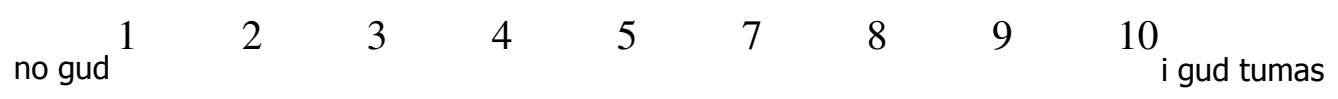

Average rating 10

From wanem?

Why?

From mi been learnem more things about long research ia.

'I have learned about research in these sessions.'

From se mi neva part long wan resej olsem ia mo mi part inside blong risej ia i tuff tumas

'I have never been part of research like this and being part of this research is very difficult.'

Mi been glad mo mi wan lucky man blong givhan long risej ia, from se mi talemout ol samting we i gud mo i no gud about training course blong mi.

'I have been happy and feel lucky to be part of this research because I can tell about what is good and not so good with my training course.'

From sei mi lanem fulap samting long risej mo i givhan plenty long mi. Hemi mekem mi save more.

'Because I have learned a lot about research and it will help me a lot. It will make me more knowledgeable.'

Because I learn how to do research and analyse the results and work in a group. The focus groups ideas can change the way we do computer training in Vanuatu.

It helps me to see the difference, concept's inside each training institutions, and help to meet, more awarness to promote and develop ICT user's in Vanuatu, and even the Pacific countries 
I think this research really help a lot, and gives me an idea of what I can do to improve my skills in computing and also helps me understand what level of computing I am on. The reason for this research help out wasn't curiosity, it's more like very interesting \& important.

I feel great and exciting to learn different things in this Research. And also I like the focusing group

I enjoy it because I learned I've learn thing I've never did in my life.

Because I come to know some of the trainings I didn't know about. Gives ideas about some of the courses that other Training Institutions offer for ex VIT, HRD; Working with others and Mrs Gayna to have ideas and Mrs Gayna giving informations/ideas to help

Because you help us a lot by talking kindly to us and giving some easy questions that we find very difficult to answer. Therefore I feel good and interested to continue in joining the research group.

4 Wanem yu ting se sam samting we i gud tumas long saed blong risej ia?

What were some of the things you thought were very good about this research?

Mi think se ol interview now i good tumas long saed long reseig

'I think the interviews were very good about research.' Mi ting se interview hemi very gud long saed blong risej, mo to grup work hemi gud to.

'I think the interviews was very good about the research and the group work was good, too.'

Mi bin lanem how blong work long group mo work mi wan, Mi bin lanem olsem wanem technologie i grup bigwan long country blong mi, Mi bin lanem ol nara place blong computer training.

'I learned how to work in a group and work as an individual, I have learned how big the technology group is in Vanuatu, I have learned about other places that give computer training.'

Mi tinksei samting we igud tumas long resej ia hemi mekem mifala i tink fast-mo mifala tu lanem new things long resej ia. Annd also I like the grup Y Focusing, I like the Researcher is very good and giving good information about ICT and industry in Vila.

I think what is good about this research is it has made me think quickly and I've learned new things in this research. I like the focus group work, I like the researcher who shared information about ICT in Vila.'

The findings that can help institutions change their training to suite locals.

Comparing different institutions and how they provide training. 
Develop my communication skills and research skills, help's to talk publickly and share ideas. it helps me to solve solutions to any future research in my Training career, or even my work place..

Finding the level of computer industry in Vila. why and how computer institutions could be improved. providing training not only in institutions to help students but also the locals.

Well, I think the very good about this Research is my interview. I experience a lot in the interview's working place and good setting of the interview.

Group work, Interview, Research

Interviewing a person about this job, What is lacking and not talking (eg) computer equipments/materials in a training institution, What must be improved/better in the future, technology is growing in Vanuatu

Some things that are good about the research we found out how Ni-Vanuatu's are in ICT development or their level in learning or working with ICT is not too high and their facilities and materials are not good enough.

Wanem yu ting se sam narafala idea we yu ting se i gud blong lukaotem long kompiuta trening long Vila?

What do you think are other ideas that would be good to study about computer training in Vila?

Mi ting se yumi sud study long side blong grade blong ol employer long computer training, ol study moa long side blong training

I think we should study what the employer needs in computer training and more study about training.

Lanem ol niufala version like Linux, Macintosh, Vista, I mean se givim ol course folem evolution blong technologie.

Learning new technology like Linux, Macintosh and Vista. Our courses should follow the change in new technology.

Don't know.

Home work.

Don't know [NA]

How to chat using the G-mail, Using the internet to get educated with a person from another country (eg) have a tutur online for tutorial, Must introduce degree on computer courses here.

I think we should study more in deep with internet meaning navigating around the world through internet. 


\section{APPENDIX 4.9 Questions for focus group employer interviews}

Matangi \& Y-Grup had this outline of questions for their interviews:

1. Name of organisation

2. How many staff?

3. How many of the staff work with computers?

4. Does the organisation have computer training at work? If yes, describe the type of training provided.

If no, where would they go for training?

5. What kind of work is done electronically with computers (ie.e receipts, payroll, reports, publications)?

6. What computer skill training do they like / want employees to have for their work?

7. What other skills do they want from the employee other than computing?

8. Are their computer users or other workers qualified or experienced?

9. Does computing really help within the organisation? How?

10. Do you have plans to expand computer use in the future? 


\section{APPENDIX 4.10 Interview and observation protocol forms used by the focus group members for interviews}

\section{Interview protocol form Nem blong yu}

Instructions to interviewer (opening statements) (notes blong yu nomo blong talemaot long employer)

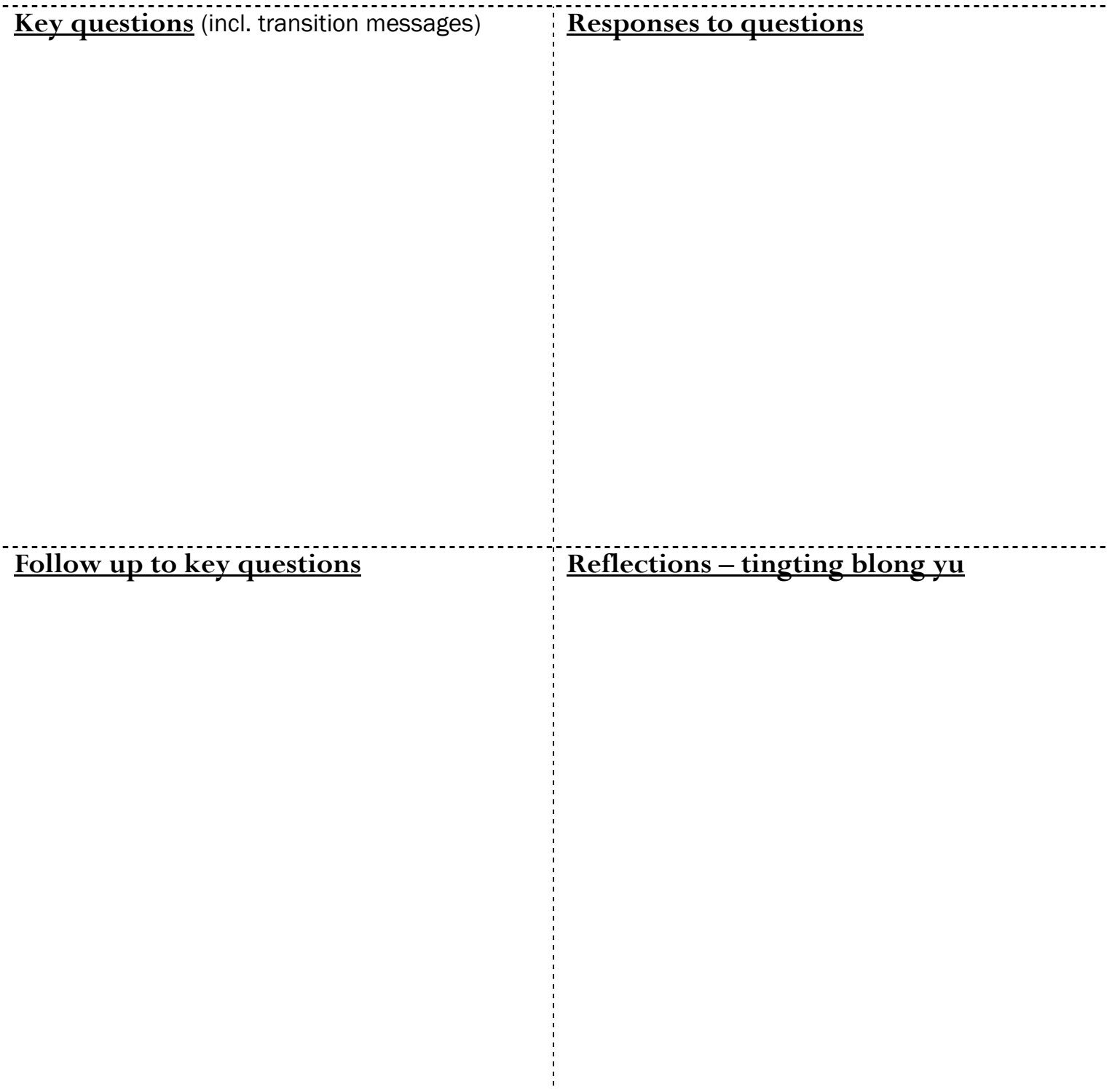

Adapted from Creswell, 2003:190 Page 


\section{Observational protocol form}

Nem blong yu

Demographic information (eg. time, place, date, ...) (Wanem taem long toktok, wea ples, wanem date, ...)

\section{Descriptive notes (descriptions of}

participants, setting, events, activities, ...)

(who ia - talem aot samting long who ia i toktok, wea ples, wanem happen ol raon,...)

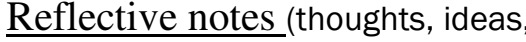

impressions, ...)

(wanem tingting blong yu long saed blong who ia i toktok, tingting blong yu long saed blong tingting blong hem, samting we yu harem letlebet long saed blong who ia i toktok)

Adapted from Creswell, 2003:188 Page 


\section{APPENDIX 5.1 Questions explored in focus group sessions}

Q1 Why are you interested in helping with this research?

What do you want from helping out with the research?

Q2 Describe the training you've had and the training you're doing now:

where? (describe things about this)

who is teaching? (describe)

is it easy or hard? why?

Q3 What do/did you like most about your training?

What do/did you not like about your training?

Q4 Think about what you will do when you finish training:

a) Where would you like to work?

b) What would you like to do with your skills?

c) What skills do you need for this work?

Q5 You want to USE A COMPUTER

a) For what - why?

b) What do you need to know to get what you want/need?

c) What makes you think/believe this?

d) If you get training - what do you feel you need as a result: local certificates, international standards - why?

Q6 What skill have you gained in training that you didn't have before you were trained?

Q7 After they held employer interviews

How does their training fit the kinds of skills needed that were described by employers?

What does the training lack?

Q8 What kind of computer work is there in Vila?

What kind of skills do we need for these jobs?

How can our training be better to prepare us for these jobs?

Q9 What do you think could be done to improve training in Vila?

Focus on

Skills needs

Training objectives

Course Materials

Training Rooms

Teaching, language and methods

Other?

\section{Consider}

What kind of work is done using computers in Vila?

What kind of skills are needed in Vila?

What other qualities do employers look for in employees?

What do you think is important?

things like work experience, other essential skills (management skills, personal and professional) 


\section{APPENDIX 5.2 Powerpoint slides from focus groups' presentation}

3 pages total. Slides read across $\mathrm{L}$ to $\mathrm{R}$
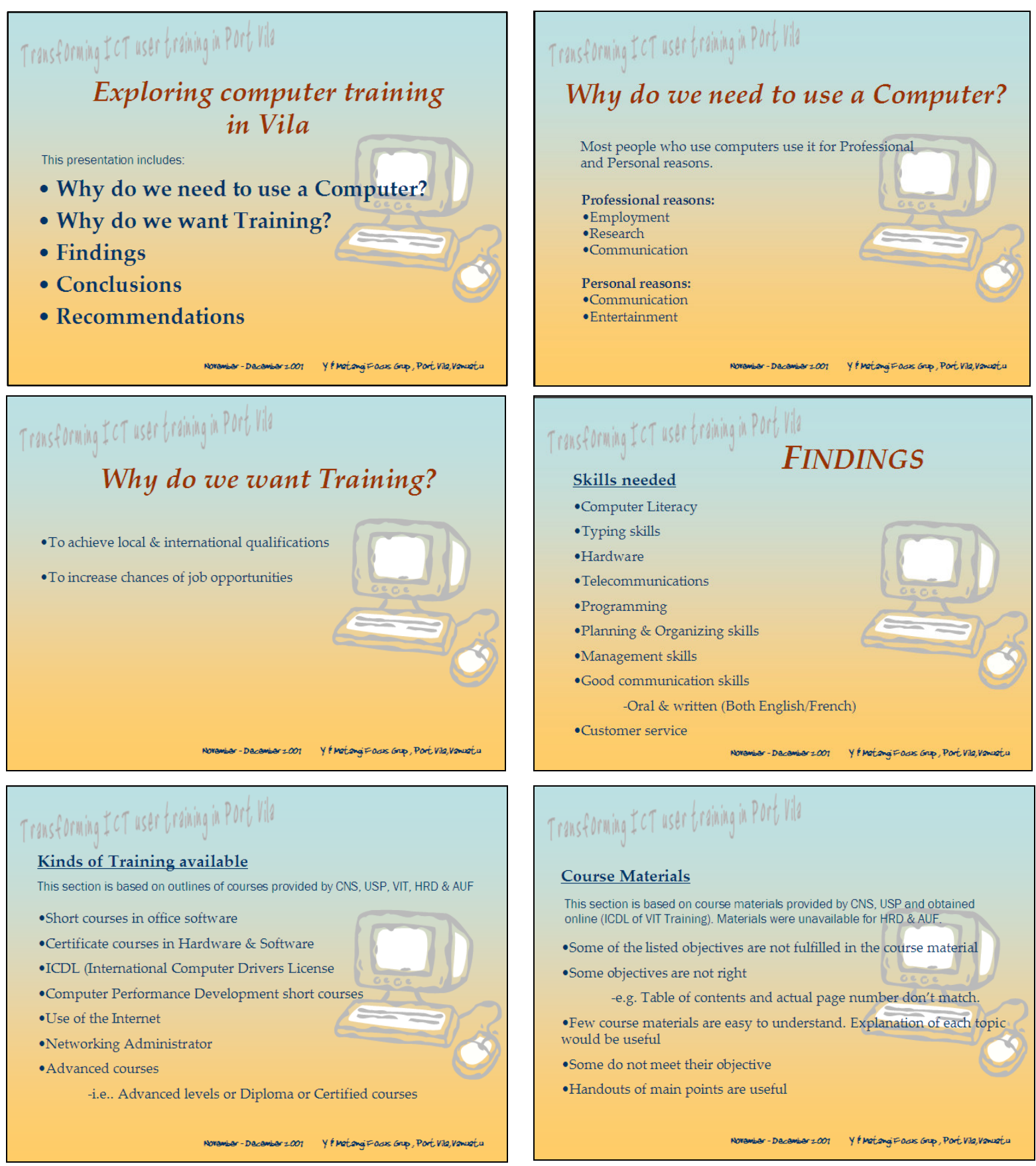

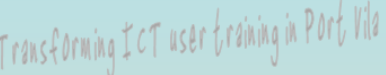

\section{Course Materials}

This section is based on course materials provided by CNS, USP and obtained online (ICDL of VIT Training). Materials were unavailable for HRD \& AUF.

-Some of the listed objectives are not fulfilled in the course material -Some objectives are not right

$$
\text { -e.g. Table of contents and actual page number don't match. }
$$

-Few course materials are easy to understand. Explanation of each topic would be useful

-Some do not meet their objective

-Handouts of main points are useful 

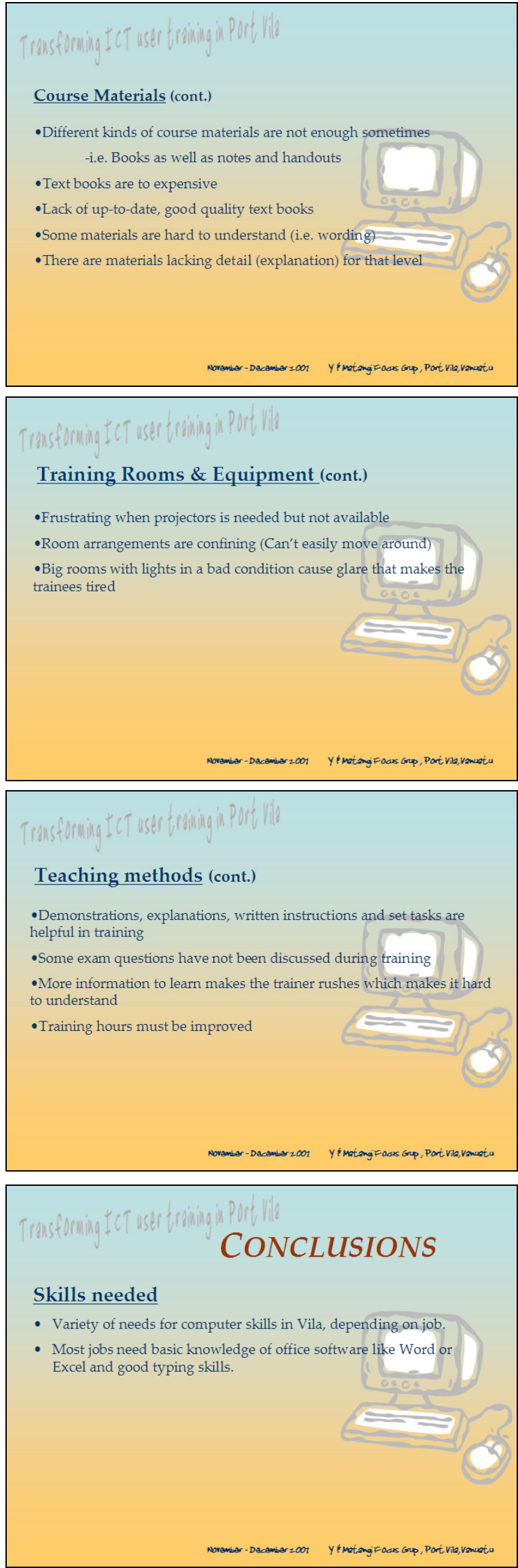
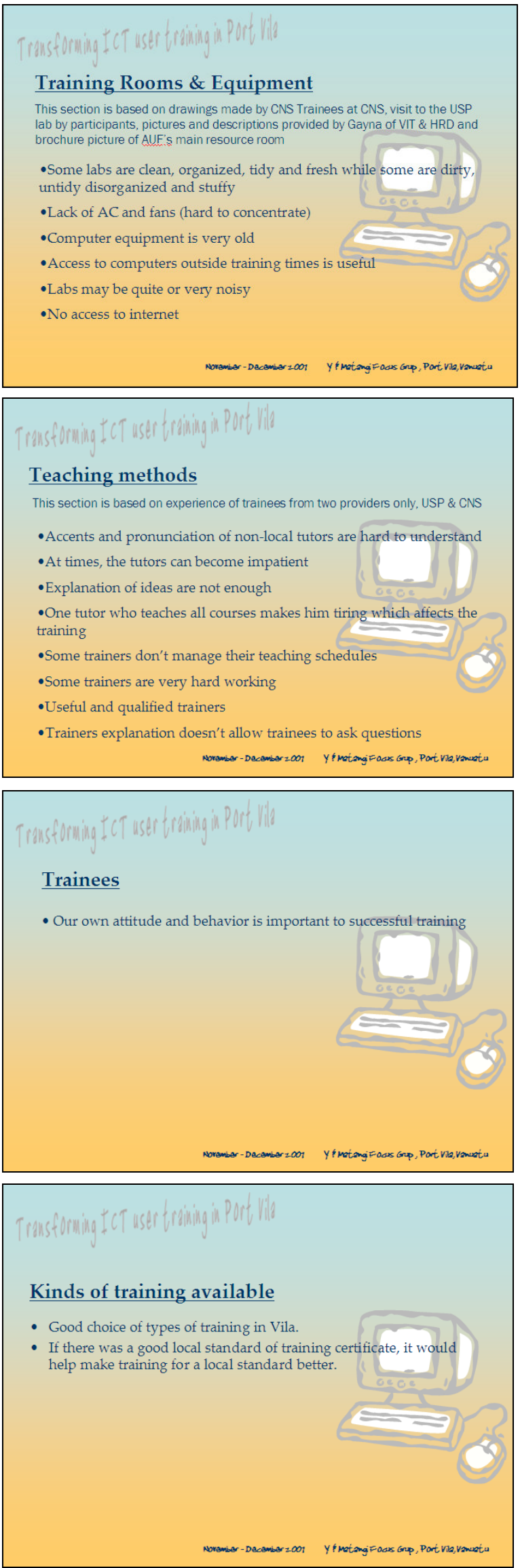

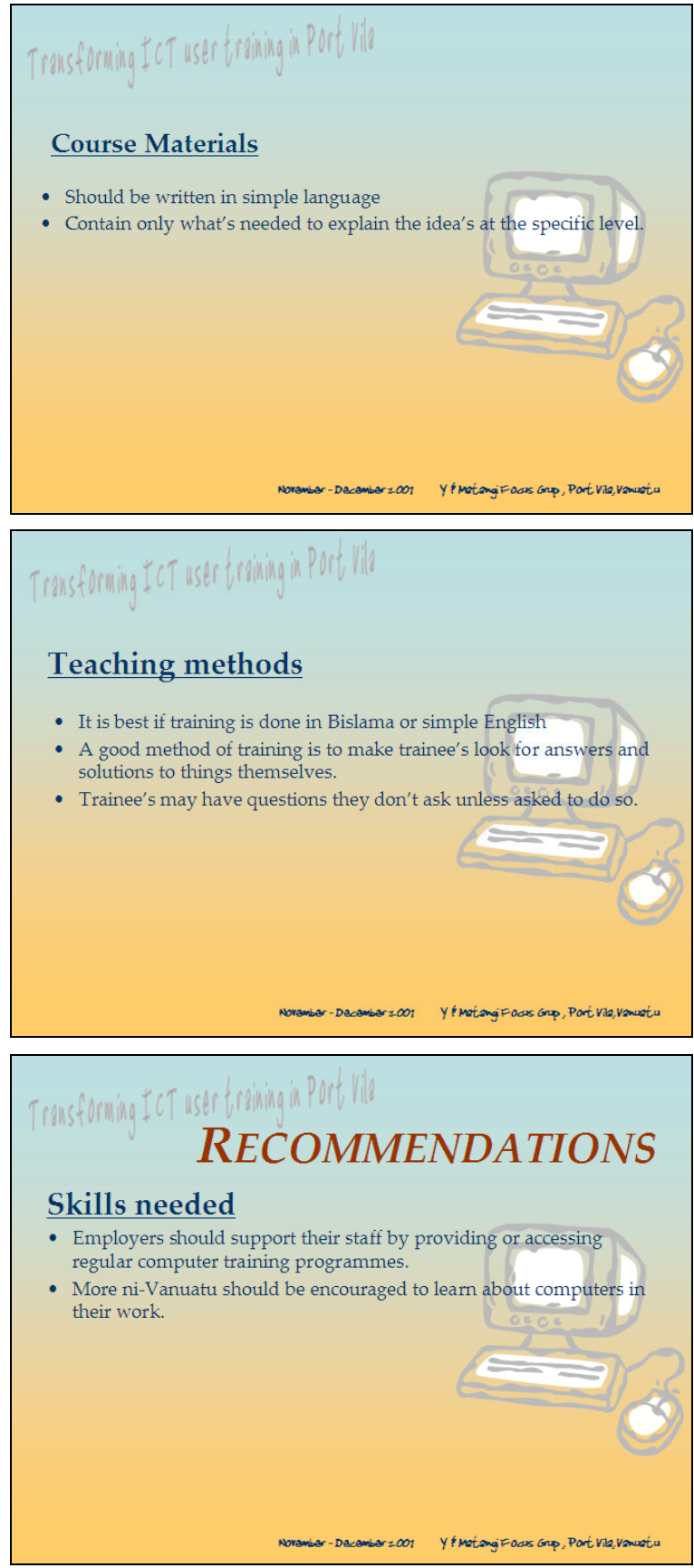

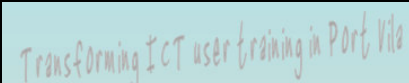

\section{Teaching Methods}

- If a trainer is speaking English as a second language, he or she should remember to speak slowly and clearly and to clarify what i being said.

- It is most helpful if trainers learn to use Bislama.

- A mixture of step-by-step instruction, explanation, demonstration and practical work is useful.

- The trainer should remember to ask if there are questions several times in training.

- The trainer should not have such a busy schedule that they aren't available to talk to trainees outside of training.

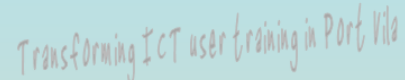 \\ Training rooms and equipment \\ Factor's supportive of a good training environment: \\ - Good maintenance of Lab equipment \\ - Neatly organized, clean, cool labs. Should have fans in the labs, if not air conditioning. \\ - Good ventilation (windows and/or fans) and up-to-date computers provide comfort for trainee's and help them concentrate. - \\ - Enough space for the number of students is preferred by trainee's \\ - Room arrangement \\ - Big enough space to move around the lab is very helpful \\ - Lighting should be just right \\ Y imotang Foas Grep, Part Via, Vemuata}

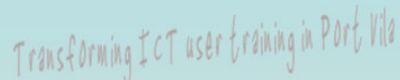

\section{Trainees}

- A good attitude toward learning and good attendance, our training is more successful.

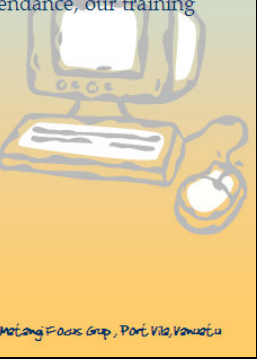

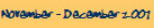

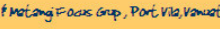

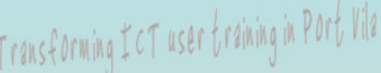

\section{Course Materials}

- Make/get lower cost, up-to-date resource materials for trainee Perhaps a library of computer books that is kept up-to-date.

- Perhaps the government could support online course material being available to anyone who has access to the internet.

- Course materials written locally with some Bislama and local examples would help learning.

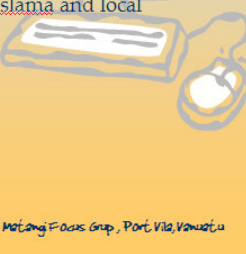

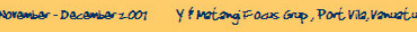

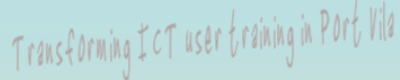

\section{Trainee}

- The trainee should understand his or her own good attitude and input into the courses is important to their success as well as the above aspects of training.

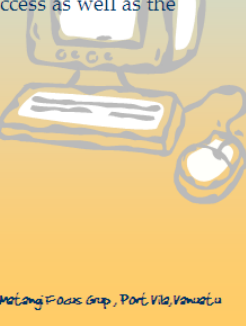




\section{APPENDIX 6.1 Planning matrix used by researcher}

Week

1

Sat

$17 / 11$

Wed

$21 / 11$

2

Sat 24/11

Wed

$28 / 11$
Administration: questionnaires, informed consent, photos,

Group building: setting standards for participation (arriving on time, breaks, cleaning up, materials)

Emphasise the importance of their part in the research.

Discussion: Why are you interested in helping with this research? Think about it...be honest... What do you want out of this?

Focus: Thinking about your training. How could it be better?

TASK: think about what you will do when you finish training: where would you like to work, what would you like to do with your skills? What skills do you need for this work?

payment of bus fare

Describe the training you've had, the training you're doing now - where? who is teaching? is it easy or herd? why?

Focus: What are you training for? Employment? What jobs are there in the industry that use computer skills?

What would you like to do?

Discuss and prepare: To talk to someone in the industry who employs people with computer skills. We need to create a list of questions to ask.

Get ideas from them of some of these places - come up with list of places they will visit. Suggest some. not technical skills as much as user skills - even training places.

TASK: interview 1 business that uses some computer equipment/needs staff with computer skills. Use the questionnaire, take notes and bring to next session. (Also, bring some course training materials that you've used - or describe details).

\section{Gayna to prepare}

Materials: research journals to

keep, pencils to use here

Chalk, pencil sharpener,

whiteboard markers, paper,

consent forms, questionnaires, munchies

Recorder

Camera

Bus fare \& signup sheet

\section{Recorder}

Camera

Bus fare \& signup sheet

Suggestions for employer

interviews - where they work

now. VFHA, Microtech,

UNELCO, TVL, etc.

Example interview questions.

Payment of bus fare 
3

Focus: Training - your trainers, facilities, materials, qualifications.

Does this fit your needs - what you've found out from last week?

Sat $1 / 12$

Discuss: issues about each of the above. Draw maps of their facilities, describe the equipment, think about the

\section{Wed} materials - books, notes, printed materials, what's drawn on the board. How are they useful? How could they be

$5 / 12$ improved - what else could there be?

TASK: Think about this more and write down what you think we would tell those who ask us how we would like our training to be done so it's better. How could our training be improved?

Focus: Tying all of this together - planning, writing what we'll present.

Discuss: How we feel about our training. What kind of jobs are there - what kind of skills do we need for these jobs? How can our training be better to prepare us for these jobs?

Sat

Do you want to work in Vanuatu or do you want to work overseas?

Wed TASK: prepare for and presentation.

$12 / 12$

Plan our presentation date/time.

Preparation - when we can. arrange to get together (starting in weekend before)

Present

findings

1 meeting to present our findings/recommendations to stakeholders.

Our formal finish

\section{Recorder}

Camera

Bus fare \& signup sheet

Get from trainers - lists of their equipment, course materials where possible, how they test, etc.

\section{Recorder}

Camera

Bus fare \& signup sheet

Computer with projector, arrange with Russell.

Organise room

Projector

Refreshments 


\section{APPENDIX 6.2 Research overview and contact 'card'}

\section{Research proposal Gayna Vetter}

Origin While working as a computer skills instructor in Vanuatu (1997-2001) and Tanzania (20032005), I came to appreciate the need for a more sustainable local system of training and for there to be standards based on local needs rather than on Western-based models of technology use. This led to my interest in how ICT training in developing countries might be made more suitable to local people. It is my viewpoint that industry needs, methods, pedagogy, materials and course design for a particular locality are important considerations for providing relevance to training.

: Rationale The need for ICT training begins in industry. There is a growing demand for these technologies in local government, private industry and Non-governmental Organisations (NGOs) in the Pacific region. With this demand there is increased pressure for locals to receive training that suits their needs. The University of the South Pacific (USP) Laucala campus' Pacific eLearning Observatory notes that there is a lack of skills at a level to make the best use out of the technologies by locals in the Pacific region and more opportunities for training provision and ICT skill development are needed.

An aspect of integration of ICT into Pacific education is that it is done in a way that preserves local and regional control of content and teaches relevant topics in a relevant way. A step in this direction would be assessment of the way training can be made locally sustainable in a specific context and to possibly create a means of training resource creation by local people. Vanuatu has an active technological infrastructure that supports these localised needs and is a familiar setting to the researcher.

Key questions The key question that is a framework for exploration in this research is: 'What methodologies for training Information and Communications Technology (ICT) users in developing countries are relevant to their needs?'. The research aims are to discover how ICT training is now being done in Port Vila, Vanuatu, and to consider what factors work and which are missing or inappropriate. Ideas for improvement will be explored and recommendations based on the findings will be made to suit the local context.

Purpose As a result of exploration, the recommendations made will possibly suggest changes to training methodologies. It is hoped this could inform policy pertaining to ICT being introduced into education in Vanuatu and for there to be a growing practice of local participation in developing programmes, preparing their delivery methods and producing context-relevant materials.

The researcher's purpose is to document the participatory process for her Masters thesis.

Proposed methodology: Process The study will be conducted by forming focus groups that will conduct research in a collaborative process using Participatory Action Research (PAR). There will be two focus groups with 5-10 members. Participants will be engaged in all parts of research from posing questions and gathering data to interpretation, identifying findings, preparing and reporting recommendations. Questions the focus groups will pursue will be how users are being trained, what the user-based needs of the local industry are, what users' training needs are and factors for improvement of training. Focus groups will interview participants from local industry to gain an understanding of local ICT user skill needs in Port Vila. Documents relating to ICT training will be analysed; these will include course materials used at training centres, available texts, course outlines, student work, email discussions, software used and job descriptions from the industry contributors. ICT user training facilities in Port Vila will also be analysed for suitability. 
Participants The focus groups' participants will be chosen based on 1) having received, or are currently receiving, user training and 2) including teacher trainers who have had ICT user training. A mixture of island of origin and ethnic groups representative of local population will be sought to gain a realistic cultural mix.

The choice of industry interviewees will include as wide a selection as possible from local industry. The requirement for their participation is the use of ICT in their workplace.

Stakeholders Those with a stake in this research include but are not limited to: the researcher, focus group participants, industry contributors, computer users, ICT training institutions in Port Vila, the Vanuatu Ministry of Education, Vanuatu Cultural Council, USP's Pacific eLearning Observatory in Suva, and Victoria University of Wellington.

Port Vila, Vanuatu, October - December 2007

Researcher's contact card given to each focus group member.

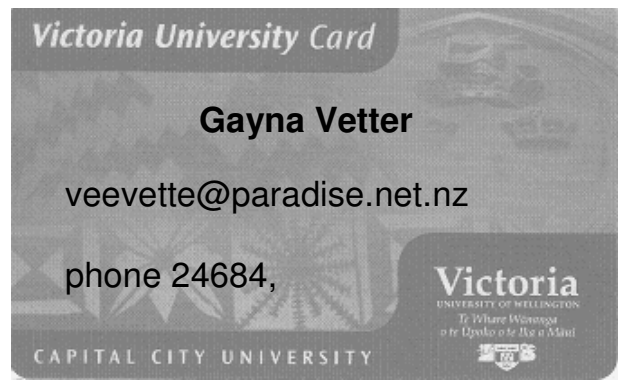


APPENDIX 6.3 Calendar of the weekly plan posted for focus group use

\section{Calendar for Risej Focus Groups - VAnuatu 2007}

\begin{tabular}{|c|c|}
\hline Novemba & Decemba \\
\hline $\begin{array}{l}\text { SAT 17 } \\
\text { FOCUS: Tingting long saed blong trening. } \\
\text { Hao nao i stap? } \\
\text { Sipos oli save mekem i moa gud? } \\
\text { QUESTION: From wanem yu interest blong givhan long mekem risej } \\
\text { ia? }\end{array}$ & $\begin{array}{l}\text { SAT 1 WED 5 } \\
\text { FOCUS: Yumi focus long saed blong trening. Yumi lukluk ol kos material } \\
\text { (buk, outline, notes) mo ples blong trenem (komputa rum, ol komputa) } \\
\text { QUESTION: Trening long evri ples, i wok gud i go long wanem ol } \\
\text { employer oli wantem? }\end{array}$ \\
\hline $\begin{array}{l}\text { SAT } 24 \text { WED } 28 \\
\text { FOCUS: From wanem yu wantem usum komputa? } \\
\text { From wanem yu wantem mekem trening? eg. wok, blong yu nomo... } \\
\text { QUESTION: Wanem kin skil ol employer i stap lukaotem long saed } \\
\text { blong komputa? } \\
\text { TASK: Long taem bitwin session ia, bae yu go mekem toktok wetem } \\
\text { wan employer we oli usum man we i save mekem wok blong komputa. }\end{array}$ & \begin{tabular}{l} 
SAT 8 \\
\multicolumn{1}{c}{ WED 12} \\
FOCUS: Wanem yu ting se nao yu bin lukaotem ol samting long saed \\
blong trening? Yu ting se i stret blong mekem i moa gud long wok blong \\
yu - o long findem wok? \\
QUESTION: Wanem yumi bin lanem long ples ia? Wanem yu ting se bae \\
i improvem trening programme long Vila?
\end{tabular} \\
\hline & $\begin{array}{l}\text { WAN TAEM LONG WIK LONG } 17 \text { KASEM 21: } \\
\text { FOCUS: Presentem information long ol we i gat interest }\end{array}$ \\
\hline
\end{tabular}


APPENDIX 6.4 List of employing organisations interviewed by focus group members

Le Lagon Resort

Computer Network Services (CNS)

Telecom Vanuatu Limited (TVL)

Vanuatu Institute of Technology (VIT)

Save the Children Australia

Public Service Commission

Department of Customs and Inland Revenue

Agence universitaire de la Francophonie (AUF)

Vanuatu Family Health Association (VFHA)

Site Acquisition Services (SAS)

Civil Status Department 


\section{APPENDIX 6.5 Second questionnaire given to focus group members in session three (in Bislama) \\ Sam samting long yu nomo}

Translation follows the questionnaire

Hao mas yia yu bin kasem?

Yu Francophone or Anglophone?

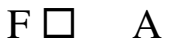

Wea ples yu bin go long primary school?

Yu bin yusum kompiuta long primary school?

$\mathrm{Y} \square \quad \mathrm{N}$

Wea ples yu bin go long secondary school?

Yu bin yusum kompiuta long secondary school? $\quad \mathrm{Y} \square \quad \mathrm{N}$

Wanem ol yia yu bin atendem...

...primary skul?

...secondary skul?

Taem wea yu bin atendem, skul blong yu i bin gat kompiuta long Admin ofis?

$$
\text { primary } \quad \mathrm{Y} \square \quad \mathrm{N} \square \quad \mathrm{N} \square
$$

Wanem yu ting se long saed blong evri studen sud gat access long kompiuta taem we it stadi long skul?

Wanem age long studen yu ting se i gud blong stat blong lanem kompiuta skil?

Wanem kaen skil long komputa yu ting se it gud blong lanem taem we it stap long skul?

Afta trening, yu plan blong stap wea ples? 


\section{Translation of second questionnaire:}

1. What is your age?

2. Are you a French or English speaker?

3. Where did you go to primary school?

4. Did you use a computer when in primary school?

5. Where did you go to secondary school?

6. Did you use a computer when in secondary school?

7. What years did you attend primary and secondary school?

8. When you attended school, did your school have a computer in their Administration office? (primary and secondary)

9. What do you think about students having access to computers when they are at school?

10. What age do you think students should start to learn computing skills?

11. What kind of computing skills do you think it is good for students to learn in school?

12. After you finish training, where do you hope /plan to live? 
APPENDIX 6.6 Interview focus grid

what kind of work is done

electronically - with computers?

What computer skill training do they like/want employees to have had for their work?

What skills other than computing

skills do they want in an employee? 


\section{APPENDIX 6.7 Course outlines and materials, facilities, and training costs analysis grids (actuals)}

There were three course materials grids prepared, two facilities and one cost. These are the actual grids used for analysis (six pages total).

Course materials analysis grid

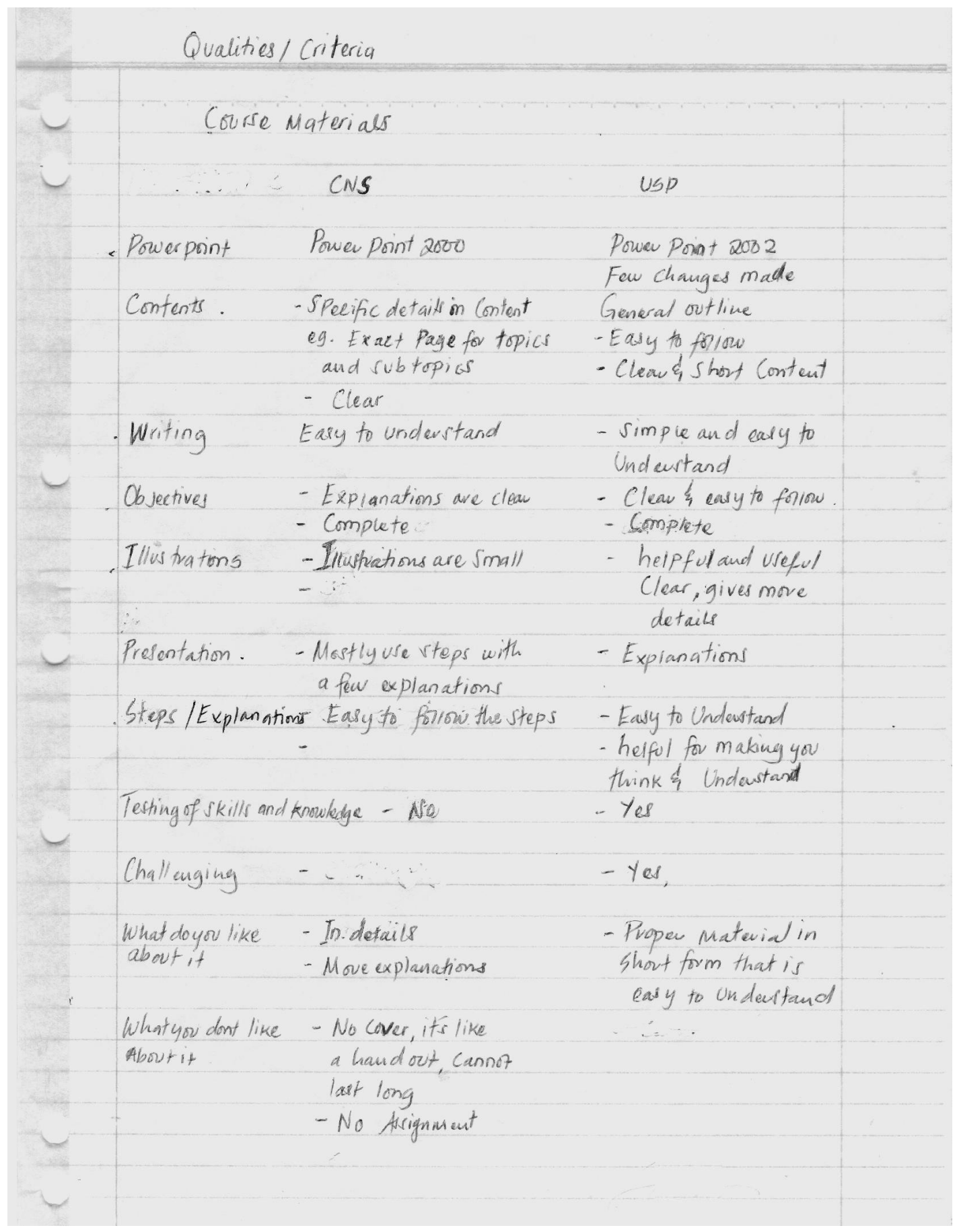




\section{Course materials analysis grid}

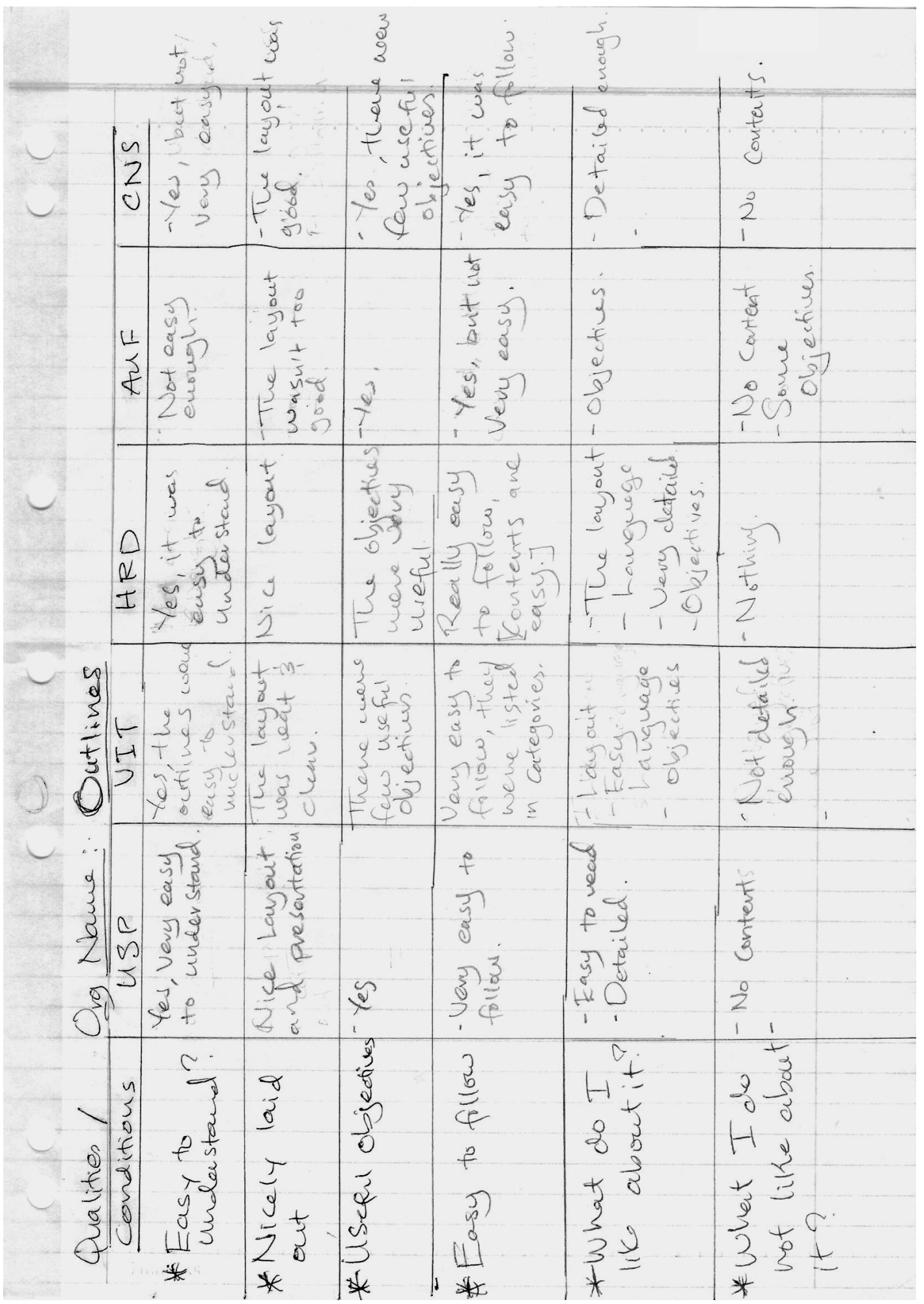




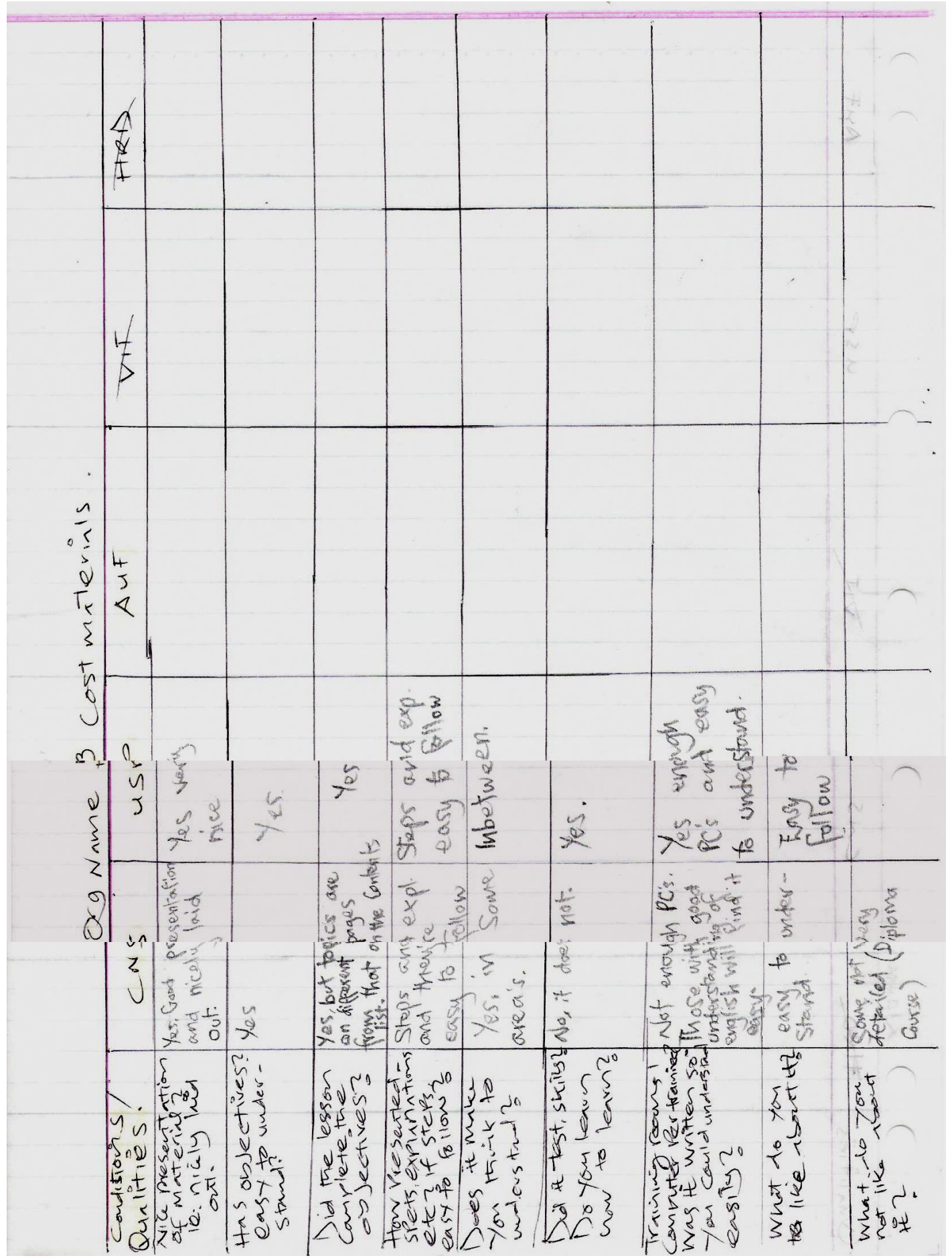


Facilities analysis grid

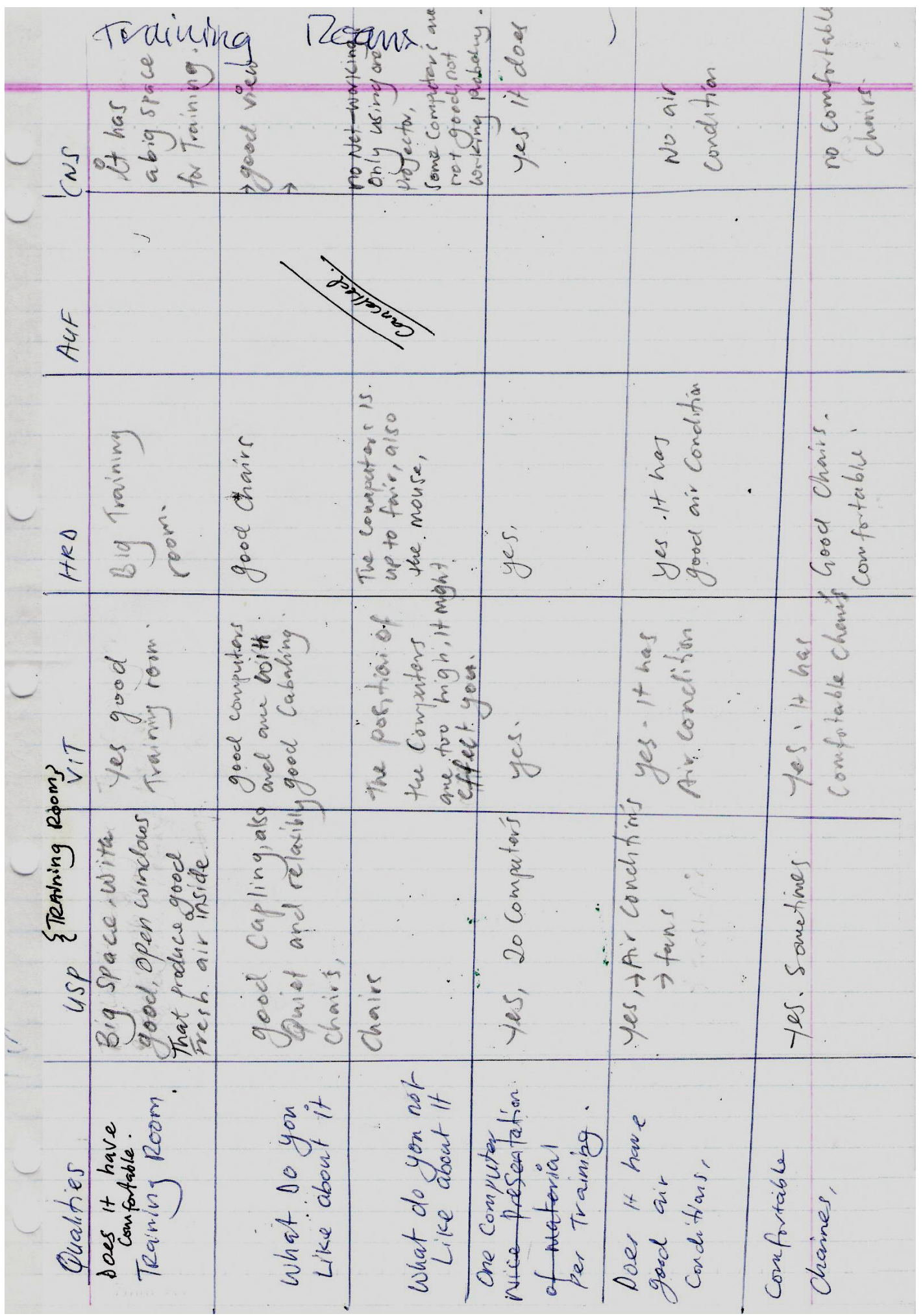


Facilities analysis grid

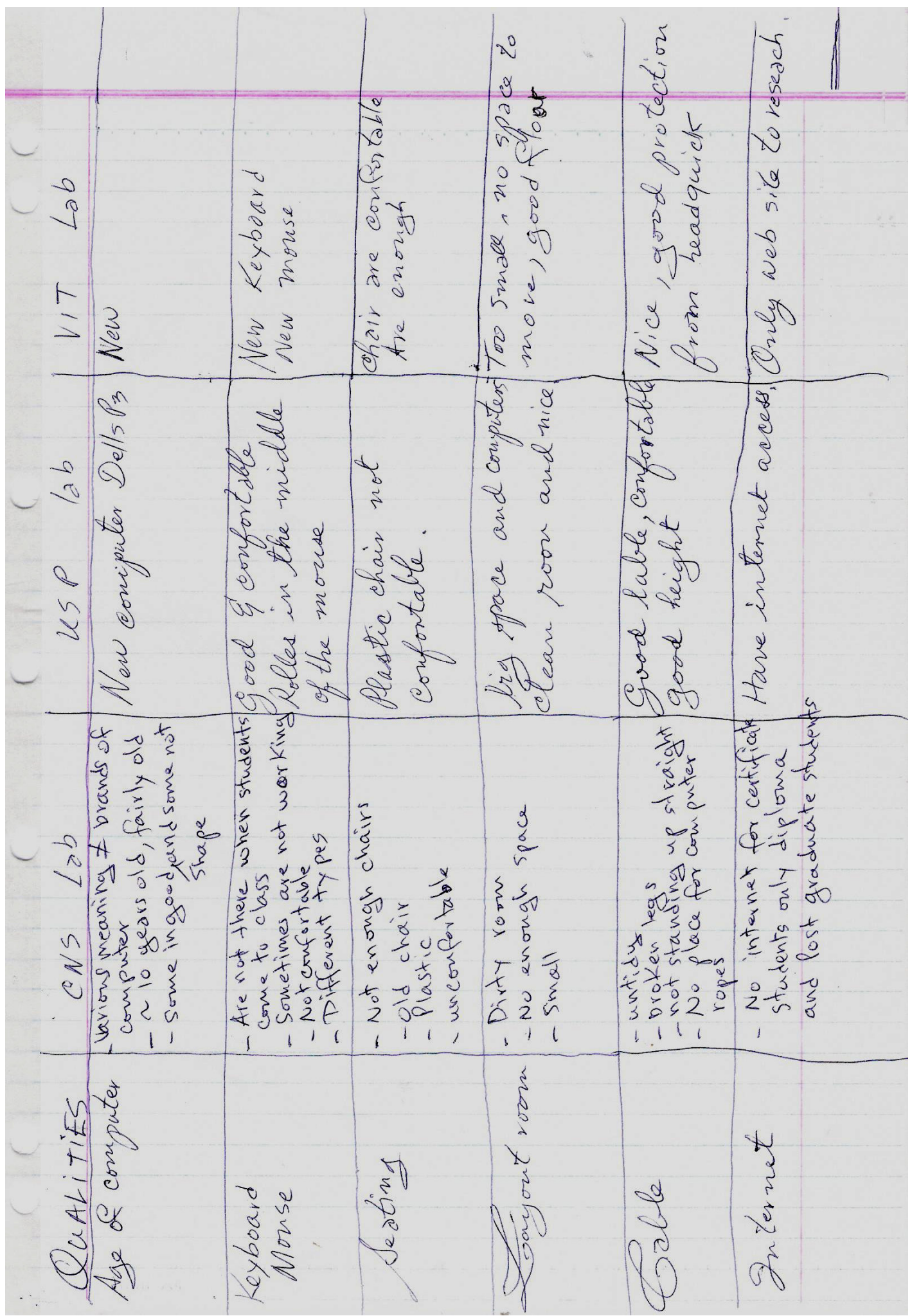


Costs analysis grid

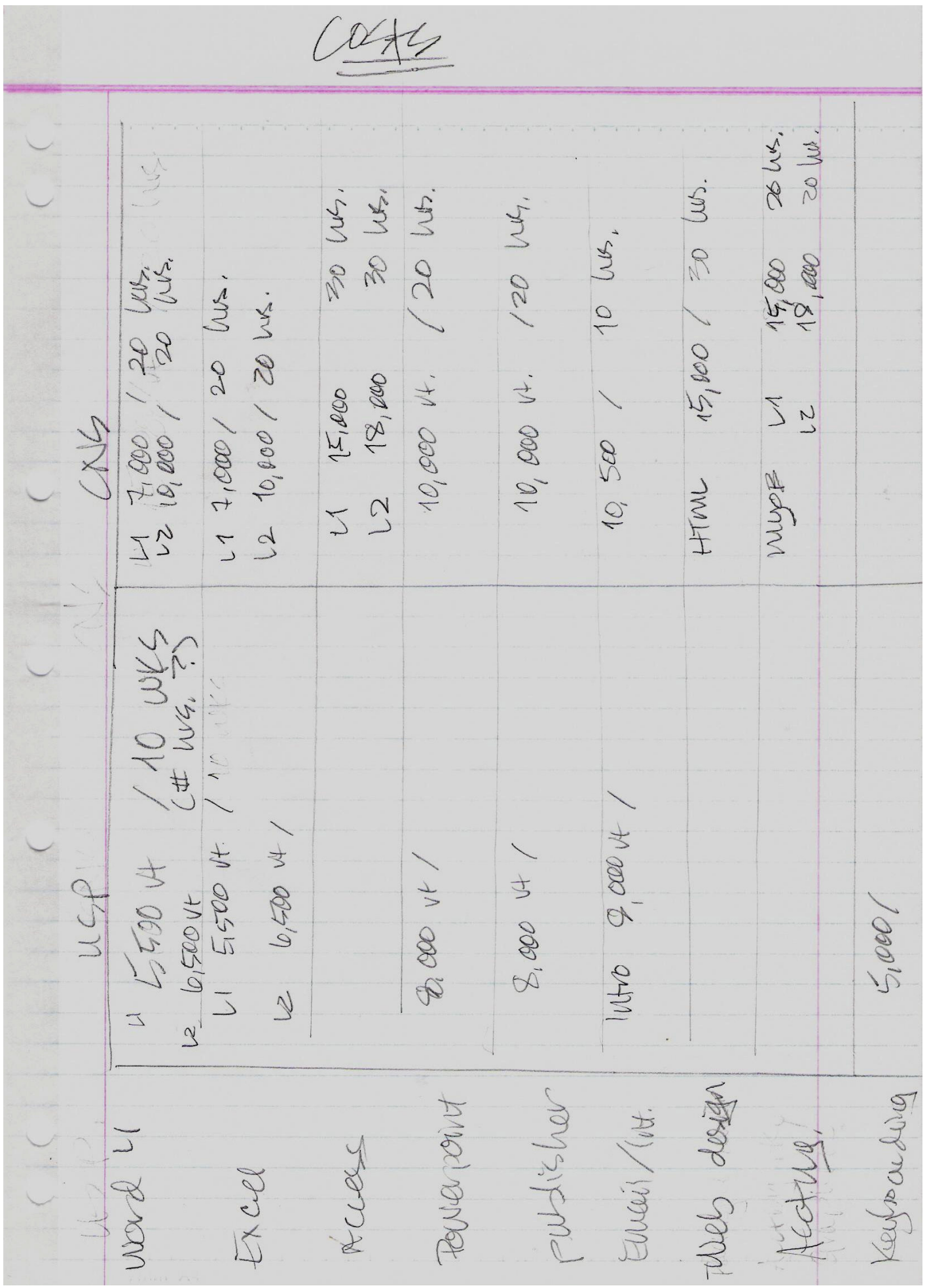




\section{APPENDIX 7.1 Example of evaluations used by training institutions}

This is an actual form in use. Identifying information has been removed from the original.

\section{Evaluation of Computer Course}

Your evaluation of this course in terms of course objectives and constructive suggestions will be very valuable for planning future programs.

Please circle your rating from 1 to 10 and make comments where appropriate.

\begin{tabular}{|c|c|c|}
\hline & Rating & Comments \\
\hline $\begin{array}{c}\text { 1. Was the course } \\
\text { relevant to your work? }\end{array}$ & $\begin{array}{c}12345678910 \\
1 \text { Not at all relevant to } \\
10 \text { Very relevant }\end{array}$ & \\
\hline $\begin{array}{c}\text { 2. If handouts were given, } \\
\text { were they useful to } \\
\text { you? }\end{array}$ & $\begin{array}{c}12345678910 \\
10 \text { Very useful }\end{array}$ & \\
\hline $\begin{array}{c}\text { 3. Were given exercises } \\
\text { useful to you? }\end{array}$ & $\begin{array}{c}1 \text { Not at all useful to } \\
10 \text { Very useful }\end{array}$ & \\
\hline & & \\
\hline
\end{tabular}

Page 1 of 4 
4. Did you find the duration of the course appropriate? Please tick

$\square$ Too Long $\square$ Too Short $\square$ Just Right

5. Do you think you achieved the learning outcomes?

6. What was not useful in the workshop?

7. What do you think the trainer did that helped you?

8. Did you find the pace of training appropriate? Please tick

$\square$ Too fast $\quad \square$ Too slow $\square$ Well paced

Page 2 of 4 
9. What did you learn which will really help you in your work?

10. What topics were of little value to you? Why?

11. How often do you anticipate that you will refer back to the handouts/materials in your workplace? Please tick

$\square$ Never $\quad \square$ Occasionally $\square$ Frequently

12. Will you do anything differently at work now that you have done this workshop? If so, what?

Page 3 of 4 
13. Overall, on a scale 1 to 10 how would you rate the course/workshop/seminar? Please circle

12345678910

1 No good to 10 Excellent

14. General Comments about the course:

18. Are there other areas in which you have specific training needs:

(a) related to this course

(b) not related to this course

Thank you for your contribution

Page 4 of 4 